Portland State University

PDXScholar

1996

\title{
An Empirical Study on the Jump-diffusion Two-beta Asset Pricing Model
}

Hongqing Chen

Portland State University

Follow this and additional works at: https://pdxscholar.library.pdx.edu/open_access_etds Let us know how access to this document benefits you.

Recommended Citation

Chen, Hongqing, "An Empirical Study on the Jump-diffusion Two-beta Asset Pricing Model" (1996). Dissertations and Theses. Paper 1325.

https://doi.org/10.15760/etd.1324

This Dissertation is brought to you for free and open access. It has been accepted for inclusion in Dissertations and Theses by an authorized administrator of PDXScholar. Please contact us if we can make this document more accessible: pdxscholar@pdx.edu. 


\title{
AN EMPIRICAL STUDY ON
}

\section{THE JUMP-DIFFUSION TWO-BETA ASSET PRICING MODEL}

\author{
by \\ HONGQING CHEN
}

\begin{abstract}
A dissertation submitted in partial fulfillment of the requirements for the degree of
\end{abstract}

DOCTOR OF PHILOSOPHY

in

SYSTEMS SCIENCE: BUSINESS ADMINISTRATION

Portland State University

1996 


\section{DISSERTATION APPROVAL}

The abstract and dissertation of Hongqing Chen for the Doctor of Philosophy in

Systems Science: Business Administration were presented on February 19, 1996 and accepted by the dissertation committee and the doctoral program.

COMMITTEE APPROVALS: Jolumpiryir Chair

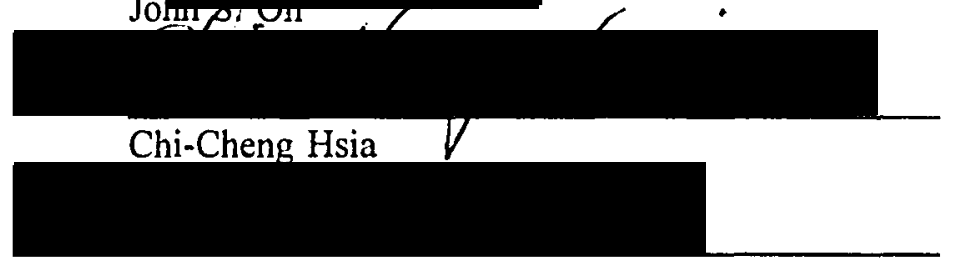

Kuan-Pin Lin

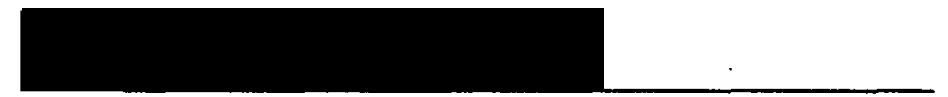

Martin Zwick

Thomas P. Potiowsky

Representative of the Office of Graduate Studies

DOCTORAL PROGRAM APPROVAL:

Beatrice Oshika, Director

Systems Science Ph.D. Program 


\begin{abstract}
An abstract of the dissertation of Hongqing Chen for the Doctor of Philosophy in Systems Science: Business Administration presented February 19, 1996
\end{abstract}

Title: An Empirical Study on the Jump-diffusion Two-beta Asset Pricing Model

This dissertation focuses on testing and exploring the usige of the jump-diffusion two-beta asset pricing model. Daily and monthly security returns from both NYSE and AMEX are employed to form various samples for the empirical study. The maximum likelihood estimation is employed to estimate parameters of the jump-diffusion processes. A thorough study on the existence of jump-diffusion processes is carried out with the likelihood ratio test. The probability of existence of the jump process is introduced as an indicator of "switching" between the diffusion process and the jump process. This new empirical method marks a contribution to future studies on the jump-diffusion process. It also makes the jump-diffusion two-beta asset pricing model operational for financial analyses.

Hypothesis tests focus on the specifications of the new model as well ats the distinction between it and the conventional capital asset pricing model. Both parametric and non-parametric tests are carried out in this study.

Comparing with previous models on the risk-return relationship, such as the 
capital asset pricing model, the arbitrage pricing theory and various multi-factor models, the jump-diffusion two-beta asset pricing model is simple and intuitive. It possesses more explanatory power when the jump process is dominant. This characteristic makes it a better model in explaining the January effect. Extra effort is put in the study of the January Effect due to the importance of the phenomenon. Empirical findings from this study agree with the model in that the systematic risk of an asset is the weighted average of both jump and diffusion betas. It is also found that the systematic risk of the conventional CAPM does not equal the weighted average of jump and diffusion betas. 


\section{PLEASE NOTE}

Page(s) missing in number only; text follows.

Filmod as recoived. 


\section{ACKNOWLEDGMENT}

I consider myself very lucky to be born in a family of book-lovers. In the beginning of the Cultural Revolution, my father sold loads of his book collections at the price of waste piper because of the fear for Red Guards. Yet there were still two bookcases full of books in our one-room home after we were sent to the countryside when I was five. How I wanted to read all books in the world when I finished reading my first novel. I paid a dear price with a heavy prescription for my glasses for my ambition becaluse our room in the village was al ways dark without electricity. It wats then when I set my goal to be a scholar one day.

My parents have always supported me, sometimes even pushed me to achieve higher goals. I remember once my academic goal wals merely to graduate from college. That was 1978 when the college admission test was just reinstated alter the ten-year Cultural Revolution in China. When the opportunity of receiving higher education catme, I simply followed it. It was 1987 when I came to Portland State University for the degree of Ph.D. I met and married my husband Danicl during studying at PSU. He has supported and pushed me to finish my dissertation from the beginning of our relationship. In other words, he joined my parents to be the physical driving force behind my study. I almost quit when my daughter came into my life two years ago. "No. Never," shouted my parents and husband. So I continued. I am grateful to them now because I do not have to call myself a "quitter." I hope one day my daughter ean be proud of her mother 
for being a full-time mother, writing a dissertation, and working on a job that brings home some income at the same time. Although it took me longer time than I expected to finish my degree because of my baby, I would not do it any other way.

The process of this dissertation research has been a wonderful learning experience for me. With the help of committee members, especially Professor Chi-Cheng Hsia and Professor Kuan-Pin Lin, I have been able to overcome many technical difficulties to reach the conclusion of this empirical study. They also supported me mentally and physically when I encountered problems in daily life. They make me understand that a good professor not only teaches his students about one subject but also becomes his guide on the path of life.

My husband, Dr. Daniel Miles Amos deserves lots of credit for the completion of this dissertation. Without his help around the house and the baby, I would not be able to get the research and writing done. The same gratitude to my mother who came from Chinat to take care of my daughter for almost one year. Daniel was also most helpful in editing the fext although he was frustrated sometimes by the strange terminology in my dissertation. In conclusion, this dissertation is a collective work of many people. I would also like to use this space to thank Professor Wang Ji-Yu and his friend Prolessor Cai from Wuhan University in China for helpful suggestions. Many thanks to Wes Brenner and his colleagues in the Academic Computing Service at the computing center of PSU. Their talents and many hours of input were essential to the success of my reseatreh. 


\section{TABLE OF CONTENTS}

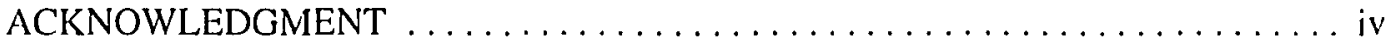

INTRODUCTION $\ldots \ldots \ldots \ldots \ldots \ldots \ldots \ldots \ldots \ldots \ldots \ldots \ldots \ldots \ldots \ldots$

CHAPTER ONE

A REVIEW OF ASSET PRICING MODELS $\ldots \ldots \ldots \ldots \ldots \ldots \ldots \ldots$

I.1 CAPITAL ASSET PRICING MODEL $\ldots \ldots \ldots \ldots \ldots \ldots \ldots \ldots \ldots 4$

1.1.1 Derivation of Capital Asset Pricing Model ............4

1.1.2 Modifications of CAPM ..................

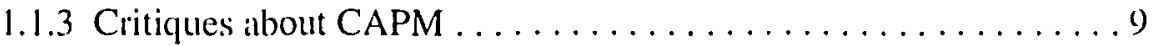

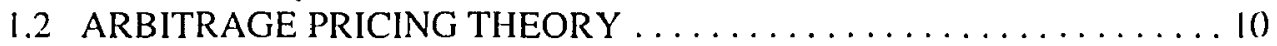

1.3 OPTION PRICING THEORY $\ldots \ldots \ldots \ldots \ldots \ldots \ldots \ldots \ldots \ldots \ldots \ldots$

1.4 JUMP AND DIFFUSION STUDIES $\ldots \ldots \ldots \ldots \ldots \ldots \ldots \ldots \ldots \ldots$

CHAPTER TWO

JUMP-DIFFUSION TWO-BETA ASSET PRICING MODEL $\ldots \ldots \ldots \ldots 20$

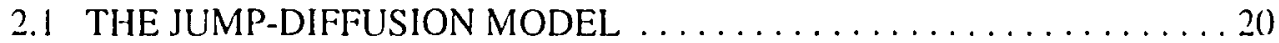

2.2 PROPERTIES OF THE JUMP-DIFFUSION MODEL . . . . . . . . . . . 22

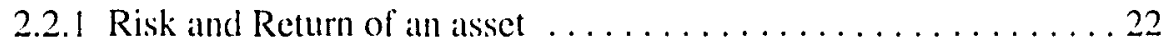

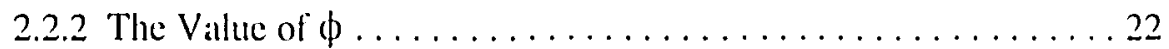

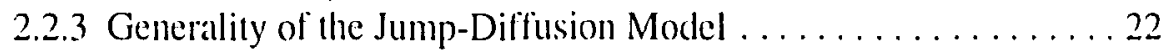

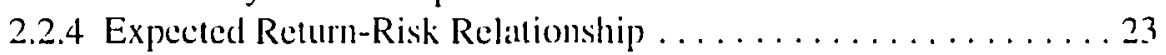

2.3 TESTABILITY OF THE JUMP-DIFFUSION MODEL . . . . . . . . . 24

CHAPTER THREE

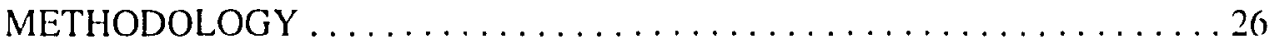

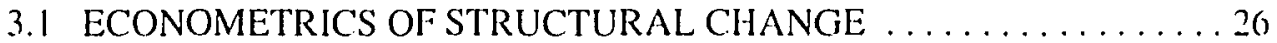

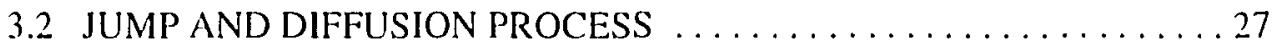

3.3 MAXIMUM LIKELIHOOD ESTIMATION EQUATION . . . . . . . . . . 29

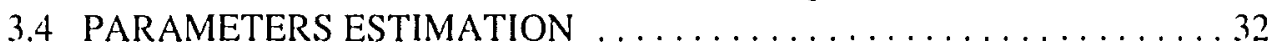

3.5 IDENTIFYING JUMPS AND ESTIMATING PARAMETERS $\ldots \ldots \ldots 33$

3.6 ISSUES OF AUTOCORRELATION AND HETEROSCEDASTICITY . . 36

3.7 PROCESS OF THIS RESEARCH $\ldots \ldots \ldots \ldots \ldots \ldots \ldots \ldots \ldots \ldots$

CHAPTER FOUR

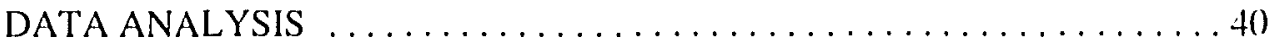

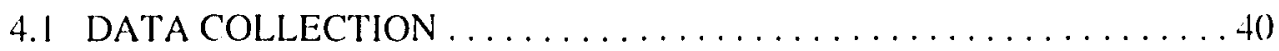




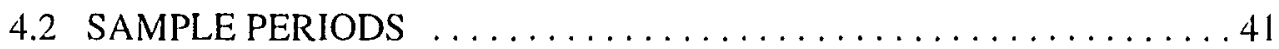

4.3 BEHAVIOR OF MARKET RETURNS $\ldots \ldots \ldots \ldots \ldots \ldots \ldots \ldots \ldots$

4.4 ESTIMATION OF PARAMETERS $\ldots \ldots \ldots \ldots \ldots \ldots \ldots \ldots \ldots \ldots \ldots$

4.4.1 Market Parameters . . . . . . . . . . . . . . . . . 47

4.4 .2 Portfolio Estimates . . . . . . . . . . . . . . . . . 48

4.5 HYPOTHESIS TESTING AND TEST RESULTS $\ldots \ldots \ldots \ldots \ldots \ldots . \ldots 49$

4.5.1 Testing Specifications of the Jump-Diffusion Model . . . . . . . 49

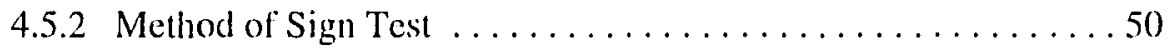

4.5.3 Hypothesis Testing on CAPM ................. 54

4.5.4 Distinction between the Jump-Diffusion Model and the CAPM .55

CHAPTER FIVE

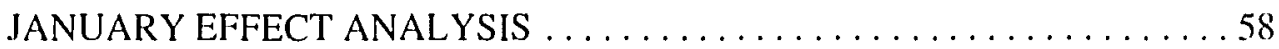

5.1 REVIEW OF PREVIOUS STUDIES $\ldots \ldots \ldots \ldots \ldots \ldots \ldots \ldots$

5.2 SAMPLE COLLECTION AND ANALYSIS $\ldots \ldots \ldots \ldots \ldots \ldots \ldots . \ldots 9$

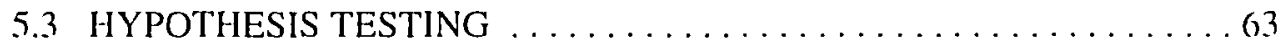

5.4 COMPARISON BETWEEN THE JUMP-DIFFUSION MODEL

AND THE FAMA AND FRENCH'S FIVE FACTOR MODEL . . . . . .66

CHAPTER SIX

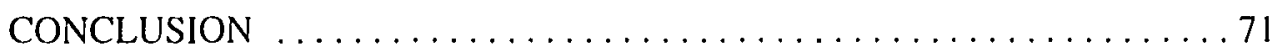

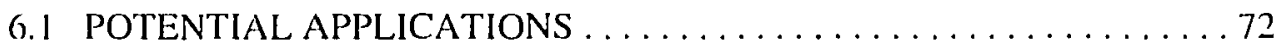

6.2 REMARKS ON FOLLOW-UP STUDIES $\ldots \ldots \ldots \ldots \ldots \ldots \ldots$

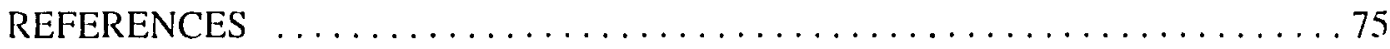

APPENDIX A:

DERIVATION OF THE MEAN-VARIANCE EFFICIENT FRONTIER ... Al

APPENDIX B:

DERIVATION OF THE JUMP-DIFFUSION TWO-BETA ASSET PRICING

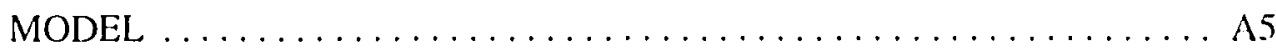

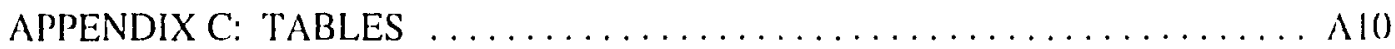

APPENDIX D: GAUSS® PROGRAM AND SAMPLE OUTPUTS $\ldots \ldots \ldots \ldots \ldots$ A2() 


\section{INTRODUC'TION}

It has been proven empirically that the conventional capital asset pricing model (CAPM) is not working. As early as in 1977, Roll pointed out the impossibility of obtaining a true market portfolio for the use of the model. He also argues the untestablity of the hypothesis of the mean-valuiance efficiency of the matket portfolio. After repeated empirical studies on the CAPM, Fama and French $(1992,1993)$ and Roll and Ross (1992) concluded that beta has very weak explanatory power.

One of the reasons that may account for the weak explanatory power of the beta is that the CAPM assumes security returns are generated by a normal process, while in fact the empirical observation of the security returns indicates that this assumption is not supported. Studies on stochastic behavior of the security market generally agree that security returns are generated by a mixed process witl continuous diffusion and discontinuous jumps. In this sense, the CAPM beta may only capture a part of the mixedprocess, the diffusion process. Therefore, the beta of the CAPM is not an alcurate risk measure when the process is mixed with jumps. Hsiats (1992) jump-diffusion two-beta asset pricing model provides an alternative to the CAPM. It prices both jump and diffusion risks. Empirical tests of this dissertation show that it is a better assed pricing model than the CAPM, especially for the period when jumps atre more intensive and frequent.

Following this introduction, Chapter One presents a review of previous studies on 
the asset pricing models. Summaries of the CAPM model, its extensions, and criticues are presented in this chapter, together with reviews of arbitrage pricing theory and option pricing theory. Theoretical and empirical works on the mixed jump and diffusion processes are also reviewed in this chapter.

Chapter 2 presents a brief description of the jump-diffusion model, a discussion on its properties, and the testability of the jump-diffusion model.

Chapter 3 reports the methodologies employed in this research. How to identify at jump has been the focus of empirical studies on the jump-diffusion processes. Starting with a summary of econometrics of structural change, it presents a review of techniques used in previous studies. Benefiting from previous researches, this dissertation employs a maximum likelihood method to estimate the patrameters needed to separate the jump process from the diffusion process. The concept of "switching" becomes reality by calculating the probability of the existence of the jump process. Thus the jump process is identified and is physically separated from the diffusion process. The suceess of this procedure is one of the contributions of this dissertation.

Chapter 4 presents the datat analysis of this research. It includes data collection. sampling method and sample statistics, frequency distribution of market returns, estimation of parameters, hypotheses testing and test results.

Chapter 5 presents how the jump-diffusion two beta asset pricing model explains the January effect, a well-documented financial market anomaly. Besides testing the new model with a sample of the turn-of-the-year daily returns, a comparison with the most recent Famal and French's five-factor model is carried out with the exact sample of 
monthly returns. At the end of the extensive analysis, the conclusion of the dissertation research is made and is included in this chapter. So are some thoughts for future researches. 


\section{CHAPTER ONE}

\section{A REVIEW OF ASSET PRICING MODELS}

Modeling is a tool to simplify and thus to analyze the real world. Models have been used in mathematics and physics, and to study environmental problems, economic problems, and social problems. In the fields of social sciences, however, results of modeling should always be carefully interpreted due to the complexity of problems with human factors. In the world of finance, modeling processes began with asset pricing models. Factors contributing to the change of asset values have been the focus of finance studies. Asset pricing models, as reviewed in this chapter, have proven their usefulness in analyzing the financial market.

\section{I CAPITAL ASSET PRICING MODEL}

\subsubsection{Derivation of Canital Asset Pricing Model}

Assume all investors are risk-averse. Investors make their decisions based on maximizing their expected utilities under uncertainty when forming a portfolio. According to Markowitz (1959), investors' preferences in selecting portfolios are defined over the mean and variance of the probability distribution of portholio returns. This 
concept leads to a revolution in the theory of finance and lays the foundation for modern capital market theory (Jensen 1972). The CAPM is developed by Sharpe (1964) and Lintner (1965) following Markowitz's work on portfolio selection. The mathematical derivation is illustrated in Appendix A. Figure 1 graphically illustrates the derivation process:

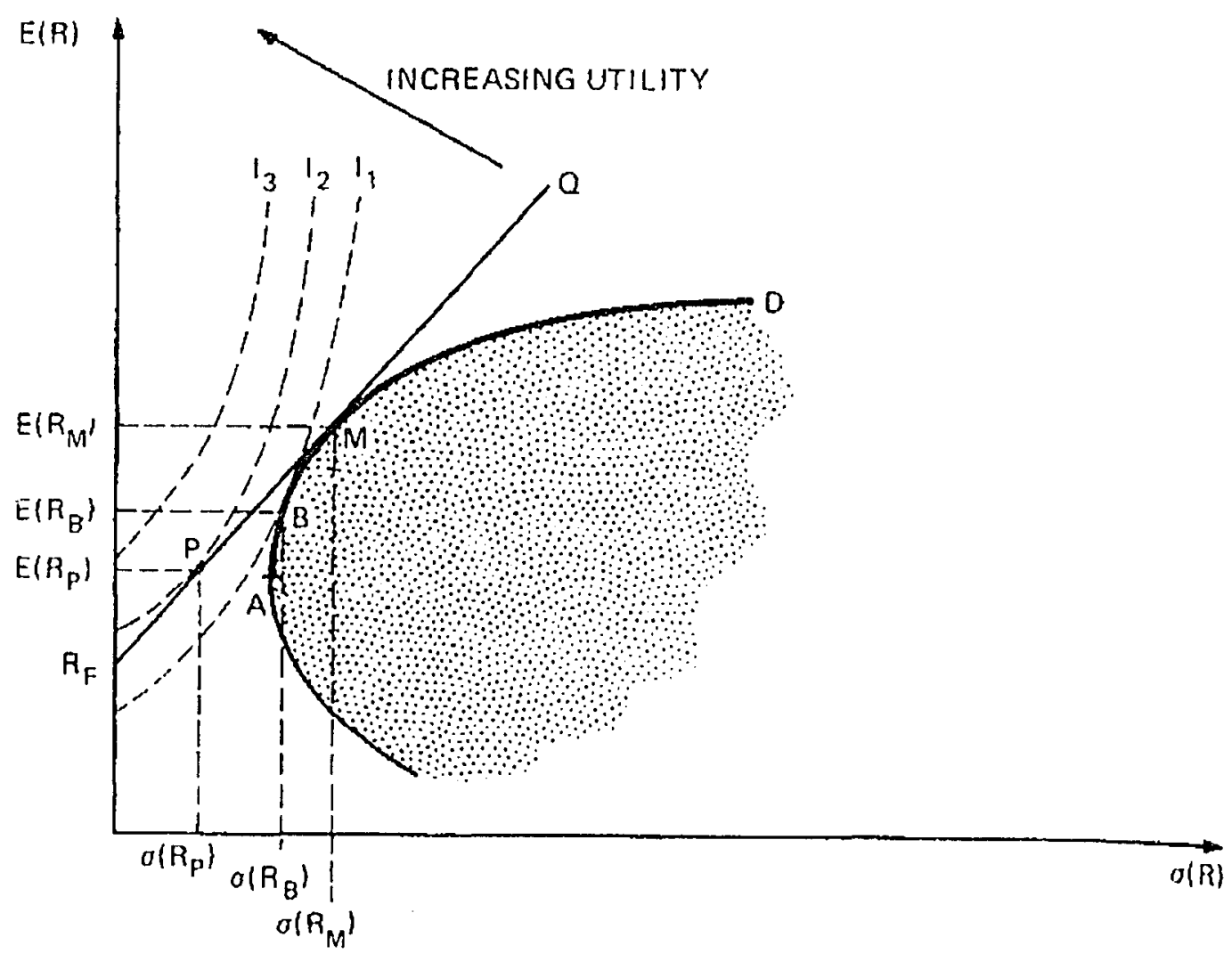

Figure 1: $\quad$ The Maximization of Investor's Utility Given the Existence of A Riskless Asset

Based on investors' utility function, we draw indifference curves on the scale of "expected return" (mean of retum) and "standard deviation" (equivalent alternative of variance) for every security. Since utility function is concave (Fama and Miller 1972), 
investors who want to maximize the expected utility would select securities that place them on the highest indifference curve (represented by $\mathrm{I}_{1}, \mathrm{I}_{2}$, and $\mathrm{I}_{3}$ ). The shaded area in Figure I represents all possible combinations of risk and return available from investments in risky securities. It is the opportunity set of risky assets available to investors. The upper boundary ABMD of the opportunity set is called the efficient frontier, which consists of all portfolios with the highest expected returns for a given level of standard deviations. The efficient frontier is also called the minimum variance opportunity set.

An investor limited only to investments in risky assets would choose to invest in portfolio $B$, which has expected return, $E\left(R_{13}\right)$, and standard deviation of return, $\sigma\left(R_{13}\right)$, to maximize his expected utility $I_{1}$. Now assume there is a riskless asset $F$ with a certilin return $\mathrm{R}_{\mathrm{f}}$. An investor has the possibility to invest in such a riskless asset as well as in al risky asset (or a portfolio). The $\mathrm{R}_{1} \mathrm{MQ}$ line is the so-called capital market line. The tangent point $\mathrm{M}$ is the market portfolio. The investor can then construct a combined portfolio which allows him to reach any combination of the risk and return lying along the line. Thus he may distribute his funds between portfolio $M$ and riskless asset $F$ such that his combined pottfolio, $P$, yields him $E\left(R_{1}\right)$ and $\sigma\left(R_{p}\right)$, and maximum utility of $I_{2}>I$ 1. The CAPM wals derived by Sharpe (1964) and Lintner (1965) with the global meanvariance efficiency (i.e., efficient portfolios lie on the frontier of the minimum variance opportunity set) under the following six assumptions:

1. Investors are risk-averse individuals who maximize the expected utility of their end-of-period wealth.

2.Investors have homogeneous expectations about asset returns that have a joint 
normal distribution.

3.There is a risk-free asset such that investors may borrow or lend unlimited amounts at the risk-free rate.

4.The quantities of assets are fixed. All assets are marketable and perfectly divisible.

5.Asset markets are frictionless; information is costless and simultaneously available to all investors.

6.There are no market imperfections such as taxes, regulations, or restrictions on short selling. (Copeland, 194)

Given these assumptions, the equilibrium expected return is

$$
\bar{R}_{j}=R_{E}+\left(\bar{R}_{m}-R_{f}\right) \beta_{j}
$$

where

$$
\begin{aligned}
\bar{R}_{j}= & \begin{array}{r}
\text { Expected Rate of Return } \\
\text { of Security (Portfolio) } j
\end{array} \\
R_{f}= & \text { Risk-free Rate } \\
\bar{R}_{m}= & \text { Expected Rate of Return } \\
\quad \text { of Mean-Variance Efficient Market Portfolio } & \\
\beta_{j}= & \frac{\operatorname{Cov}\left(R_{j}, R_{m}\right)}{\sigma^{2}\left(R_{m}\right)}
\end{aligned}
$$

According to the CAPM, the equilibrium expected return on all risky assets are at function of their covariance with the market portfolio. It implies that the appropriate measure of the risk of any individual asset is its covariance with the market portfolio, $\operatorname{cov}\left(R_{i}, R_{m}\right)$ and not its variance $\sigma^{2}\left(R_{i}\right)$ (Jensen 1972). This is because that the diversification can eliminate the effects of an alsset's own variance on the variance (or the standard deviation) 
of a portfolio but cannot eliminate the effects of an asset's covariance with all other assets in the portfolio. In other words, an asset's own variance (or the standard deviation) is the nonsystematic risk that can be hedged to zero by forming a portfolio with a number of selected securities. Its covariance with the market is the systematic risk, $\beta_{\mathrm{i}}$ that cannot be diversified away. Therefore as CAPM states, it is the only risk that investors will pay a premium $\left(\bar{R}_{m}-R_{f}\right)$ to avoid. This important property of the CAPM, that is, to quantify the risk of investment, makes its unrealistic assumptions tolerable. In fact, it has dominated the financial literatures since its invention. Its simple and intuitive structure makes it popular with the practical financial world (Modigliani, Franco and Pogue 1974, Rosenberg 1981, Mullins 1982). The risk measure, beta ( $\beta$ ), is published by major investment publications, such as Standard \& Poor and Moody's Investors Guide, for every listed security as well as for evaluated industrics.

\subsubsection{Modifications of CAPM}

Since its invention, the CAPM has been tested empirically by many reseatrehers. Conclusions are generally unsatisfactory either statistically or instrumentally. Not only do the test results of the CAPM depend on the length of period', but also the explanatory power of beta is so weak that the CAPM cannot accurately predict the required rates of return of assets (Black, Jensen and Scholes 1972, Blume and Friend 1973). Mally reseanches note unexplainable market anomalies when using the CAPM (Banz 1981.

1. As stated by Copland, "over long periods of time the rate of return on the market portfolio is greater than the risk-free rate (215)." 
Keim 1986, Keim and Stambaugh 1986, Roll 1983). The common speculation is that the unrealistic assumptions based on which the CAPM is derived cause those problems. Therefore, in the past several decades much effort had been concentrated on exploring the extensions of the CAPM by relaxing some of its assumptions.

A zero-beta CAPM was developed by Black (1972) by assuming there is no riskless asset for investors to borrow or to lend; instead there exists a zero-beta portfolio. This means a portfolio orthogonal to the market portfolio, which maly be created by short selling or hedging. The CAPM with the existence of a non-marketable asset was developed by Mayers (1972). When allowing differential taxes on capital gains and dividends, Brennan (1970) found that a higher dividend yield requires a higher rate of return. This effect is later studied by Litzenberger and Ramaswamy (1979). Friend, Landskroner, and Losq (1976) looked at CAPM under uncertain inflation. Works on relaxing the assumption of normality are reviewed later in this chapter.

\section{1 .3 Critiques about CAPM}

Modifications on the CAPM are usually related with the criticisms about the model. Friend and Blume (1970) raised questions about its usefulness in explaining market behavior. Later in 1973, they argued for the rejection of the CAPM. Despite these, the CAPM has been considered to be a great model until Roll's critique was published in 1977. Two fatal points pointed out by Roll are 1) the only testable hypothesis about CAPM is the mean-variance efficiency of the market portfolio, but the true market portfolio is unobservable and 2) the market portfolio which should include all 
assets of the market is unobtainable (Roll 1977). Upon this ground, Roll concluded that the CAPM is untestable although it is still valid in theory. In 1980 Roll again pointed out that benchmark errors exist when using the CAPM to evaluate portfolio performance. He stated that: "CAPM benchmalk error is present whenever the market index is not 'optimized', i.e., whenever the index is not an ex ante mean/variance efficient portfolio. $(12)^{\prime \prime}$

After almost fifteen years of Roll's critique, the validity of CAPM was brought up again by several financial economists and later broadcasted by Fama and French (1992) in their article which questioned the usefulness of beta. Following a series of empirical research on the correlation between an expected rate of return of an asset and its beta, Fama and French reported their research in which they found beta is the least important factor in estimating the expected rate of return. Roll and Ross (1992) then theoretically proved the little relevance of beta in estimating the expected rate of return by showing that it is almost impossible to find an accurate market index which representing minimum variance opportunity set only through which can sensible/relevant beta be obtained. Needless to say, their opinions shocked the financial world which has adopted beta as the most important factor in pricing financial assets.

\subsection{ARBITRAGE PRICING THEORY}

Before the irrelevance of beta was pointed out, its weak performance in predicting the expected rate of return urged academicians to find an alternative asset pricing model. 
Ross (1976) suggested the arbitrage pricing theory (hereon APT). Naturally this model is embraced by CAPM's critiques because it is not restricted to an all-included market portfolio.

APT is developed based on the notion that security prices adjust as investors form portfolios in search of arbitrage profits. When such profit opportunities have been exhausted, security prices are in equilibrium. In this context a definition of market efficiency is the absence of arbitrage opportunities, having been eliminated by arbitragers. It is an asset pricing model in which the expected return on any risky asset is viewed as a linear combination of various common factors that affect asset returns. The actual return of a security, $\mathrm{Rj}$, is

$$
R_{j}=\bar{R}_{j}+b_{1 j} F_{1}+b_{2 j} F_{2}+\ldots+b_{n j} F_{n}+e_{j}
$$

where

$$
\begin{aligned}
\bar{R}_{j}= & a_{0}+a_{1} b_{1 j}+a_{2} b_{2 j}+\ldots+a_{n 1} b_{n j} \\
\bar{R}_{j}= & \text { the expected equilibrium } \\
& \text { return of security } j \\
F_{i}= & \text { factor } i \\
b_{i j}= & \text { sensitivity coefficients } \\
& \text { associated with factor } i \\
a_{i}= & \text { risk premiums for } \\
& \text { the risk associated with factor } i
\end{aligned}
$$

According to APT, which assumes that investors agree on what the relevant factors are and on the coefficient b's in equation (1.2), two securities with the same array of b's must 
provide the same expected return. Otherwise investors would rush to buy the security with the higher expected return and sell the other. Such arbitrage action would cause price adjustments in both securities until their expected returns are the stme. Thus the elimination of arbitrage profits with respect to the relevant factors results in equilibrium pricing of all securities.

The difficulty of selecting influential factors has been a problem of implementing the APT since its invention. Roll and Ross (1980) suggested four factors to be systematic sources of security portfolio risks: (1) unanticipated changes in inflation, (2) unanticipated changes in industrial production, (3) unanticipated changes in the yield differential between low- and high-grade bonds (the default-risk premium), and (4) unanticipated changes in the yield differential between long-term and short-term bonds (the term structure of interest rates) (Roll and Ross 1980). According to this model, investors are characterized as having risk preferences along four dimensions. Each investor would formulate a portfolio of securities depending on his or her desired risk exposure to each of the factors. Different investors will have different risk attitudes. For instance, some maly want little inflation risk but be willing to tolerate considerable productivity risk and default risk.

When Dybvig and Ross (1985) proved the APT is testable, the superiority of the APT over the CAPM is clear. As proved by Hsial (1981), APT is a more general asset pricing model than the CAPM. The CAPM is a special calse of APT: While APT allows more than one factor to explain the expected return on a risky asset, the CAPM only allows one (the mean-variance efficient market portfolio). A number of empirical tests 
on the APT show that there are indeed more than one factor, i.e., a market portfolio, found to influence security returns (Van Horne 1989, p83). Among them, Trzcinka (1986) concluded his study on the number of factors by stating there is "at least one (factor)" affecting the returns. Famal and French (1992) found that the CAPM beta is the least influential on the stock return among five factors. In an effort of searching more influential factors, Fama and French (1993) identified five common risk factors in returns of stock and bonds. They are thrce stock-market factors: a size risk factor, book-tomarket equity risk factor, and market factor; and two bond-market factors: unexpected changes in the term structure of interest rates, and default risk. According to Fama and French, "the five factors seem to explain average returns in stocks and bonds" except for January Effect $^{2}$ (43). Nor could Roll (1983) explain the January Effect with his fourfactor APT.

Empirical studies on the comparison between the CAPM and the APT draw mixed conclusions. Chen (1983) found that empirical tests on the APT are favorable. Bower, Bower and Logue (1984) found that APT works better than the CAPM in policymaking because it includes sensitive factors. However it is not clear whether APT possesses higher explanatory power than the CAPM. Even Roll (1988) himself wats disappointed after comparing the APT with the CAPM. He found little improvement of the APT over the CAPM on its explanatory power in terms of $\mathrm{R}^{2}$. The failure of APT in capturing the January Effect also shows its weakness in the explanatory power.

2. January Effect is explained in detail in Chapter Five. 


\subsection{OPTION PRICING THEORY}

From a different angle, Black and Scholes (1974) developed the option pricing theory (Hereon OPT). A term of physics, diffusion was then introduced to the finance world.

An option is the right to buy (a call option) or to sell (al put option) a share of stock at a specified price (the exercise price) for a specified period of time (the expiration date). The value of the option at the expiration date is the value of the stock minus the exercise price, or it may be zero. It cannot be a negative value. With a stock and an option on the stock, it is possible to establish a riskless hedged position by buying the stock and writing options or selling them short, or by buying options and selling the stock short. In efficient financial markets, the rate of return on a perfectly hedged position would be the risk-free rate. As a result, the option price will bear a precise relationship to the stock price. And the value of the option can be determined at the beginning of the period.

Based on a notion that investors are able to maintain reasonably hedged positions over time and that arbitrage will drive the return on such positions to the risk-free rate, the OPT provides an exact formula for determining the value of an option based on the volatility of the common stock, the price of the common stock, the exercise price of the option, the time to expiration of the option, and the short-term interest rate. One can also derive the price of the stock if given the value of its option and other four factors.

The assumptions based on which the model is derived are as following: 
1. Only European options are considered, that is, options that can be exercised only at maturity.

2. There are no transaction costs. Options and stocks are infinitely divisible, and information is available to all without cost.

3. No imperfections exist in writing an option or selling a stock short.

4. The short-term interest rate is known and constant throughout the duration of the option contract. Market participants can both borrow and lend at this rate.

5. The stock pays no dividend.

6. Stock prices behave in a manner consistent with a random walk in continuous time.

7. The probability distribution of stock returns over an instant of time is normal.

8. The variance of the return is constant over the life of the option contract and is known to market participants. (Van Horne 1989, pl02)

The equilibrium value of an option is

$$
V_{o}=S N\left(d_{1}\right)-\frac{K}{e^{r t}} N\left(d_{2}\right)
$$

where

$$
\begin{aligned}
& S= \begin{array}{c}
\text { current price of the common stock } \\
\text { based on which the option is written }
\end{array} \\
& K= \begin{array}{r}
\text { the exercise price } \\
\text { of the option }
\end{array} \\
& r= \begin{array}{l}
\text { the short-term interest rate } \\
\text { continuously compounded }
\end{array} \\
& t= \begin{array}{c}
\text { the length of time (years) } \\
\text { till the expiration of the option }
\end{array} \\
& N(d)=\begin{array}{c}
\text { the value of the cumulative } \\
\text { normal density function }
\end{array} \\
& d_{1}=\frac{\ln \left(\frac{S}{K}\right)+\left(r+\frac{1}{2} \sigma^{2}\right) t}{\sigma \sqrt{t}} \\
& d_{2}=\frac{\ln \left(\frac{S}{K}\right)+\left(r-\frac{1}{2} \sigma^{2}\right) t}{\sigma \sqrt{t}}
\end{aligned}
$$




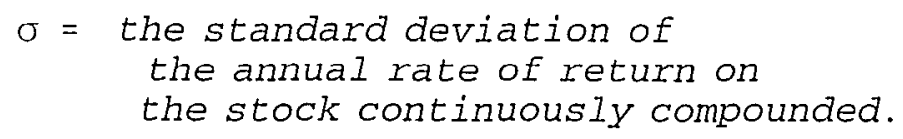

The OPT leads a new path for modern financial studies. Not only has OPT been proven to be useful in estimating option prices as well as asset prices, but also it is coherent with CAPM and APT (Hsia 1981). Most important, its introduction of "diffusion process" becomes the base for studies on stochastic processes in the stock market. The early studies of jump and diffusion processes, in fact, are mostly within the context of option pricing theory.

\subsection{JUMP AND DIFFUSION STUDIES}

When Fama (1965) discovered that the empirical distribution of daily returns on New York Stock Exchange securities are not normally distributed but have "fat tails." the normality assumption of financial theories, including CAPM, APT. and OPT, is questioned. Studies on the stochastic processes start. Merton (1976) concluded the early explanations and laid the foundation for current jump-diffusion studies. He extended the OPT to include the diffusion process and the jump process. Studies on the stochastic processes since Merton is summarized by Bates (1991) who classifies into three major classes (1015):

(1) constant elasticity of variance processes, special cases of which include arithmetic and geometric Brownian motion, such as in Cox and Ross (1976); 
(2) stochastic volatility processes, the benchmark models being those for which volatility evolves independently of the asset price, such as in Wiggens (1987) and in Melino and Turnbull (1990);

(3) jump-diffusion processes, the benchmark model being Merton's (1976) and Ball and Torous'(1983) specification of log-symmetric jumps with zero mean. Let us focus on the jump-diffusion process studies. The introduction of the notion of jump is certainly based on empirical observations. Press (1967), Merton (1976), Ball and Torous (1983) state that the behavior of the (log) returns can be divided into two independent components:

(1) the continuous part which is responsible for the usual (or "normal") day-to-day price movement. The changes in stock prices may be due to variation in capitalization rates, a temporary imbalance between supply and demand, or the receipt of any information which only marginally affects stock prices. It is described by the traditional Brownian motion and modeled as a lognomal diffusion process:

(2) a discontinuous part which is due to the receipt of any important information that caluses a more than marginal change (or "abnormal" change) in the price of stock. The arrival of this kind of information is random. The number of information items is assumed to be distributed according to a Poisson process. Thus, this part is modeled as al Poisson jump process.

This description is intuitive. In fact it may be the answer to market anomalies such ats the size effect (small firms' stocks carn higher returns), the January effect or the weekend 
effect, holiday effect, and so on. After all, the term "anomaly" means abnormal changes in prices in the financial context (Bhardwaj and Brooks 1992, Keim 1983 and 1989, Keim and Stambaugh 1986, Lakonishok 19, and Roll 1983).

Merton (1976), Cox and Ross (1976), and Ball and Torous (1983) extend the OPT to include the jump process. Their models assume risk-neutral and imply that the distribution is symmetric and slightly positively skewed, as stated by Fama (1965). They assume that jumps in the prices of the underlying asset are uncorrelated with the changes in the price of the market portfolio, so that the jump risk is not priced in equilibrium. While Neither Merton (1976) nor Cox and Ross (1976) conducted any empirical work with their suggested models, Ball and Torous did and found that $78 \%$ stocks examined in their study indicate jumps presence.

When important news like wars arrive, however, the market jumps, too. Most recent examples are the crashes of 1987 and the volatile markets during the Persian Gulf War. Naik and Lee (1990) derived an equilibrium model, which includes premiums for both jump and diffusion risks, to price the option on the market portfolio. Their work moves the jump-diffusion studies from focusing on individual assets to the market portfolio. When commenting on Merton's (1976) model, they point out that a "feature of the Merton model is the assumption that the jumps in security prices ate uncorrelated with the return on the market portfolio. Clearly, this assumption is violated if the security under consideration is the market portfolio itself (495)." Another merit of their model is its recognition of the jump risk as systematic risks, which is left out by Merton as well as Cox and Ross (1976). 
If the return of stocks should be divided into jump part and diffusion part, certainly the risk associated with return of securities should be decomposed into two parts, too. The CAPM states that beta, a diffusion risk, is systematic and nondiversifiable. So is the jump risk when taking both diffusion process and jump process into account. Bates (1991) deve!op a general equilibrium jump and diffusion option pricing model which has an asymmetric distribution. He also prices both jump and diffusion risks. Based on his contribution, Hsia (1992) obtained a jump-diffusion two-beta asset pricing model. The derivation of the jump-diffusion two-beta asset pricing model is illustrated in Appendix B. 


\section{CHAPTER TWO}

\section{JUMP-DIFFUSION TWO-BETA ASSET PRICING MODEL}

\subsection{THE JUMP-DIFFUSION MODEL}

Under the same assumptions of the CAPM, except the normality of asset returns, the jump-diffusion model takes two different types of beta into account when pricing the underlying asset. One is the diffusion beta, which measures the systematic risk when no jump occurs. The other is the jump beta, which measures the systematic risk when jumps take place. In a similar form as that of the CAPM, the jump diffusion two-beta asset pricing model is as follows:

$$
\begin{aligned}
\bar{R}_{j}= & R_{f}+\left(\bar{R}_{w}-R_{t}\right)\left[(1-\phi) \beta_{j}+\phi \beta_{\Lambda j}\right] \\
\bar{R}_{j}= & \begin{array}{l}
\text { Expected Return } \\
\quad \text { of Security } j
\end{array} \\
\bar{R}_{\omega}= & \begin{array}{l}
\text { Expected Return of } \\
\text { an Optimally Invested wealth }
\end{array} \\
R_{f}= & \text { Risk-free Rate } \\
\beta_{j}= & \text { Diffusion } \beta \text { of } \\
& \text { Security } j
\end{aligned}
$$

where 


$$
\begin{gathered}
\beta_{j}=\frac{\operatorname{Cov}\left(R_{j}, R_{w}\right)}{\sigma^{2}\left(R_{w}\right)} \\
R_{j}=\begin{array}{l}
\text { Random Return of Security } j \\
\text { Generated by a Diffusion Process }
\end{array} \\
R_{w}=\begin{array}{l}
\text { Random Return of an Optimally Invested } \\
\text { Wealth Generated by a Diffusion Process }
\end{array}
\end{gathered}
$$

$\operatorname{Cov}\left(R_{j}, R_{w}\right)=$ Instantaneous Covariance of $R_{j}, R_{w}$

$$
\begin{aligned}
& \sigma^{2}\left(R_{w}\right)=\text { Variance of } R_{w} \\
& \beta_{\Delta j}=\text { Jump } \beta \text { of Security } j \\
& \beta_{\Lambda j}=\frac{\operatorname{Cov}\left(R_{\Lambda j}, R_{\Lambda W}\right)}{\sigma^{2}\left(R_{\Lambda W}\right)} \\
& R_{\Lambda j}=\text { Random Return of Security } j \\
& \text { Generated by a Jump Process } \\
& R_{\Lambda \omega}=\text { Random Return of an Optimally Invested } \\
& \text { Weal th Generated by a Jump Process }
\end{aligned}
$$

$$
\begin{aligned}
& \operatorname{Cov}\left(R_{\Lambda j}, R_{\Lambda W}\right)=\text { Covariance of } R_{\Lambda j}, R_{\Lambda \omega} \\
& \sigma^{2}\left(R_{\Lambda \omega}\right)= \text { Variance of } R_{\Lambda \omega} \\
& \phi= \text { Weight Parameter } \\
& \phi=\frac{\lambda \sigma^{2}\left(R_{\Lambda W}\right)}{\sigma^{2}\left(R_{w}\right)+\lambda \sigma^{2}\left(R_{\Lambda W}\right)} \\
& \lambda=\text { Mean Rate of Jumps }
\end{aligned}
$$




\subsection{PROPERTIES OF THE JUMP-DIFFUSION MODEL}

\subsubsection{Risk and Retumn of an asset}

The jump-diffusion two-beta asset pricing model shows that the expected return of a security consists of three components: (i) the risk-free rate, $\mathrm{R}_{t}$, for compensating the time value of investing, (ii) the premium for taking diffusion risk $\left[\overline{R_{w}}-R_{f}\right](1-\phi) \beta_{j}$, and (iii) the premium for taking jump risk $\left[\overline{R_{w}}-R_{t}\right] \phi \beta_{\wedge j}$. It clearly shows that jump risk is a systematic risk and it is priced with premiums.

\subsubsection{The Value of $\phi$}

The weight parameter $\phi$ is a function of $\lambda, \sigma^{2}\left(R_{w}\right)$, and $\sigma^{2}\left(R_{\Delta w}\right)$. Since all three parameters are non-negative, the value of $\phi$ is bounded between 0 and 1 , that is,

$$
0 \leq \phi \leq 1
$$

which is ideal for $\phi$ to serve as a weight parameter of the jump-diffusion two-beta asset pricing model.

\subsubsection{Generality of the Jump-Diffusion Model}

Equation (2.1) is a more general asset pricing model that takes both the pure diffusion and pure jump CAPM as two special cases. If there is no jump in the market, $\lambda$ $=0$ which implies $\phi=0$, equation (2.1) reduces to the conventional CAPM,

$$
\bar{R}_{j}=R_{f}+\left(\bar{R}_{g}-R_{E}\right) \beta_{j} .
$$

The equation (2.2) differs from equation (1.1) in that it does not use $\mathrm{R}_{\mathrm{m}}$, the mallket 
portfolio, but $\mathrm{R}_{\mathrm{w}}$.

If the intensity of Poisson jumps increases indefinitely (i.e., $\lambda \rightarrow \infty$ ), Poisson

distribution converges to Normal and the jump beta converges to the diffusion beta.

Consequently, equation (2.1) again reduces to the conventional CAPM, equation (2.2).

On the other hand, if security returns are generated by a pure jump process, $\sigma^{2}\left(R_{w}\right)$ $=0$ which implies $\phi=1$, then equation (2.1) reduces to a pure jump CAPM,

$$
\bar{R}_{j}=R_{f}+\left(\bar{R}_{w}-R_{f}\right) \beta_{\Lambda j}
$$

Equation (2.2), the pure diffusion CAPM, and equation (2.3), the pure jump CAPM are the two special cases of equation (2.1), the jump-diffusion two-beta asset pricing model.

\subsubsection{Expected Return-Risk Relationship}

The conventional CAPM implies that securities have same expected returns if they have same betas. The expected-risk relationship of the jump-diffusion model is different. The jump-diffusion model has two different types of beta. It is twodimensional instead of one. One measures the systematic risk when no jump occurs, and the other measures the systematic risk when jumps occur. These two types of beta are independent by definition. Different securities may have different diffusion and jump risks. As a result, securities will have different expected returns even if they have the same diffusion betas.

The conventional CAPM implies two-fund separation which claims that all investors hold the same two portfolios, a market portfolio and a riskless asset. This is no longer true in the Jump-Diffusion model because investors may have different 
preferences to diffusion and jump risks. It is difficult, if not impossible, to find a portfolio that is optimally invested wealth which requires the same premium on both the diffusion and jump risks that are carried by different securities.

\subsection{TESTABILITY OF THE JUMP-DIFFUSION MODEL}

Roll (1977) shows that the conventional CAPM is untestable because the only testable hypothesis is mean-variance efficiency of the market portfolio, but the market portfolio is unobservable and cannot be used in the tests. Then the question is: Is the jump-diffusion two-beta asset pricing model testable? The following reasons suggest its testability.

First, the concept of mean-variance efficiency is relevant only to equation (2.2), a special case of the jump-diffusion model. In general, the mean-variance elficiency is not at testable hypothesis of the new model.

Second, the mean-variance efficiency is equivalent to the two-fund separation. The mean-variance efficiency is a testable hypothesis of the conventional CAPM, if and only if the two-fund separation holds, i.e., all investors hold the same two portfolios. As explained above, the two-fund separation no longer holds in the context of the new

model. Consequently, the mean-variance efficiency of the market portfolio is no longer a testable hypothesis of the new model.

Third, the concept of an all-inclusive market portfolio is not relevant to the new model either. The parameter that is closest to the concept of a market portfolio in the new 
model is W which is defined as optimally invested wealth. Bates (1991) tested his option pricing model on the futures of the S\&P 500 index. From the point of view of component securities, the S\&P 500 is optimally invested wealth. The expected return-risk relationship between the component securities and the S\&P 500 is described by equation (2), the jump-diffusion two-beta asset pricing model. Thus, the new model is testable and can be tested by a subset of assets against an optimally invested market-wide portfolio. 


\section{CHAPTER THREE}

\section{METHODOLOGY}

\subsection{ECONOMETRICS OF STRUCTURAL CHANGE}

There have been decades of studies on the structural change in the field of econometrics. The classic example is the structural change between the supply and demand model in economics. Given a sample of time series economic data. Due to changes in policies and other factors, the data may be on the supply curve or on the demand curve during different periods (disequilibrium). If when the change takes place is known, the Chow test is used to identify it (Greene, p218-p224). If it is uncertain when the change takes place, alternative tests are CUSUM (cumulated sum of residuals) or CUSUM-Squared tests (Greene, p224-p227). The null hypothesis used in CUSUM and CUSUM-Squared tests is that the coefficients of the model are the same for all periods. With the CUSUM or CUSUM-Squared method, one can test whether they are the same or not, yet without knowing what they are. The random coefficients model can actually predict them with the assumption that "the parameter heterogeneity . . . as due to stochastic variation (Greene, p476)." As summarized in Greene (p476-p479), the application of this method is with cross-sectional rather than time-series datil. For studies 
with time series data in disequilibrium, however, a method called switching regression is most effective to estimate different coefficients. Goldfeld and Quandt (1974) summarized various usage of the switching regression with detailed explanations. Since this technique is applied to solve problems with mixed structure where "switching" from one structure to the other takes place, it can be applied to stochastic problems like the mixed jump-diffusion process.

\subsection{IUMP AND DIFFUSION PROCESS}

Since the study of the mixed process of financial markets started in the 1970s, how to separate jump process from diffusion process has always been a challenge. Early studies focused on estimating descriptive statistics, and mean and variances of the jump and diffusion processes without actually separating them. The review of published works reveals progress of both knowledge and computing technology. Press (1967) limited the sample size to only ten NYSE listed common stocks over the period 1926 through 1960 in his pioneer study. In order to describe the jump-diffusion process, Press constrains the instantaneous expected rate of return on the security to be zero. Employing the method of cumulants, he obtains many negative estimates of the variance parameters for both diffusion and jump processes. In an effort to modify the procedures of Press, Beckers (1981) sets the mean jump size to zero. Beckers admits the superiority of the maximum likelihood method because "the parameter estimates are elficient and the asymptotic distribution of the estimates is known, the first order condition is highly nonlinear and 
contains an infinite sum (Idid: 129)." However, he found it "computationally impractical . . because the occurrence of a jump cannot be identified easily (Idid: 129)." Therefore, Beckers employs the method of cumulants again and obtains many negative estimates of both diffusion and jump's variance parameters.

Frustration over the difficulty of empirical implementation and verification of the mixed jump and diffusion processes was overcome when Ball and Torous (1983) reported their studies. They put forward an implementable model to ascertain the presence of a jump and employed the maximum likelihood method with their Bernoulli jump process model:

$$
\ln L=\sum_{i=1}^{n} \ln \left[(1-\lambda) \psi\left(\alpha, \sigma^{2}\right)+\lambda \psi\left(\alpha, \sigma^{2}+\delta^{2}\right)\right]
$$

where

$$
\psi\left(\alpha, \sigma^{2}\right)=\frac{1}{\sqrt{2 \pi \sigma^{2}}} \exp \left(\frac{-\left(x_{i}-\alpha\right)^{2}}{2 \sigma^{2}}\right) .
$$

The $\lambda$ in equation (3.1) is not the same as that in equation (2.1), the JumpDiffusion model. It is only an indicator that is 0 if no jump taking place. By testing whether $\lambda=0$ with a form of likelihood ratio test, Ball and Torous found that "over $78 \%$ of stocks indicate presence of jumps at the 1 percent significance level (p60)." They obtained no negative estimates of variance with this method (p.59). While the presence of jumps is detected, however, the actual jump process is not separated from the diffusion process.

Jorion (1989) proposes a practical model to identify the jump process in both the foreign exchange market and stock market. It is implementable and in the form of 
maximum likelihood function. The derivation of the equation is illustrated in next section. Although he notes that "discontinuities are harder to identify in the stock market index (Idid: 442)," Jorion's model provides a method to empirically study the stock market. Johnson and Schneeweis (1994) carried out a jump-diffusion study on the impact of the macroeconomic news based on Jorion's mixed process model. This research is also based on his method.

Naik and Lee (1990) priced both jump risk and diffusion risk in an extension of the OPT model. Bates (1991) also prices the jump risk as a systematic risk, but his notion of the jump risk is not beyond the context of the OPT.

A common feature of the previous discussed works is the complexity of pricing the jump risk. They estimate jump and diffusion parameters implicitly with the option price. In contrast, this paper presents an intuitive and effective way to explicitly identify jump and diffusion processes. This method is not limited by the OPT and can be applied to all assets.

\section{$\underline{3.3 \text { MAXIMUM LIKELIHOOD ESTIMATION EQUATION }}$}

In his derivation of the maximum likelihood function of the mixed process, Jorion (1989) illustrates the following. If prices follow a diffusion process with constant drift parameter $\mathrm{E}(\Delta \mathrm{P} / \mathrm{P})=\alpha$ and constant variance $\mathrm{V}(\Delta \mathrm{P} / \mathrm{P})=\sigma^{2}$, then

$$
d P_{1} / P_{1}=\alpha d t+\sigma d z_{1}
$$

where $P_{1}$ is the daily price of stock matret index and $z$ is a standard Gauss-Wiener 
process (Merton 1976, p128). Let $X_{1}$ be the logarithm of price relatives, i.e. $X_{1}=$ $\ln \left(P_{1} / P_{1-1}\right)$. The assumption that prices follow the diffusion process implies that $X_{1} \sim N(\mu$, $\sigma^{2}$ ), normally distributed with mean $\mu=\alpha-\sigma^{2} / 2$ and variance $\sigma^{2}$. As shown in Oldfield et al (1977, p391-392), the result of solving the differential equation (3.2) is

$$
X_{t}=\ln \left(P_{t} / P_{t-1}\right)=\mu+\sigma z
$$

in discrete time. The density function of $X_{1}$ is a standard Gaussian density:

$$
\begin{aligned}
f\left(x_{t}\right) & =\psi\left(\mu, \sigma^{2}\right) \\
& =\frac{1}{\sqrt{2 \pi \sigma^{2}}} \exp \left(\frac{-\left(x_{t}-\mu\right)^{2}}{2 \sigma^{2}}\right)
\end{aligned}
$$

Now, add the factor of the jump process to equation (3.2), we shall have the mixed jump-diffusion process as modeled by the following differential equation

$$
\mathrm{dP}_{1} / \mathrm{P}_{1}=\alpha \mathrm{dt}+\sigma \mathrm{d} \mathrm{z}_{\mathrm{t}}+\mathrm{dq} \mathrm{q}_{\mathrm{t}}
$$

where $q$ is the Poisson process with $\lambda$ as the mean rate of jumps occurring per unit time. The jump size $Y$ has a posited distribution $\ln Y \sim N\left(\theta, \delta^{2}\right)$, normally distributed with mean $\theta$ and variance $\delta^{2}$. q is assumed independent of $z$. Now $X_{1}$ can be expressed by the following equation:

$$
\begin{aligned}
x_{t} & =\ln \left(P_{t} / P_{t-1}\right) \\
& =\mu+\sigma z+\sum_{i=1}^{N_{i}} \ln Y_{i}
\end{aligned}
$$

where $\mathrm{N}_{\mathrm{j}}$ is the number of jumps during the interval (detailed derivation can be found in Oldfield et al). As derived by Beckers (1981) and reconfirmed by Ball and Torous (1983), in the form of a Poisson mixture of Gaussian densities, the density function of $\mathrm{X}_{\mathrm{t}}$ 
is:

$$
f\left(x_{t}\right)=\sum_{i=0}^{\infty} \frac{e^{-\lambda} \lambda^{i}}{i !} \psi\left(\mu+\theta i, \sigma^{2}+\delta^{2} i\right)
$$

that is,

$$
f\left(x_{t}\right)=\sum_{i=0}^{n} \frac{e^{-\lambda} \lambda^{i}}{i !} \frac{1}{\sqrt{2 \pi\left(\sigma^{2}+\delta^{2} i\right)}} \exp \left(\frac{-\left(x_{t}-\mu-\theta i\right)^{2}}{2\left(\sigma^{2}+\delta^{2} i\right)}\right)
$$

where $i$ is a random number. It is easy to see that when $\lambda=0$ and $i=0$, equation (3.7) reduces to equation (3.4).

With $\mathrm{T}$ independent observations, the likelihood function is

$$
L\left(\psi ; x_{t}\right)=\prod_{t=1}^{T}\left[\sum_{i=0}^{\infty} \frac{e^{-\lambda} \lambda^{i}}{i !} \frac{1}{\sqrt{2 \Pi\left(\sigma^{2}+\delta^{2} i\right)}} \exp \left(\frac{-\left(x_{t}-\mu-\theta i\right)^{2}}{2\left(\sigma^{2}+\delta^{2} i\right)}\right)\right]
$$

the logarithm of the likelihood function $\mathrm{L}(\psi ; \mathrm{x})$ can then be written as

$$
\begin{aligned}
F(\boldsymbol{b}) & =\ln L\left(\psi ; x_{t}\right) \\
& =\sum_{t=1}^{T} \ln \left[\sum_{i=0}^{\infty} \frac{e^{\lambda} \lambda^{i}}{i !} \frac{1}{\sqrt{2 \Pi\left(\sigma^{2}+\delta^{2} i\right)}} \exp \left(\frac{-\left(x_{t}-\mu-\theta i\right)^{2}}{2\left(\sigma^{2}+\delta^{2} i\right)}\right)\right]
\end{aligned}
$$

where $\mathbf{b}$ is the vector of parameters, that is

$$
\mathbf{b}^{\prime}=(\lambda, \mu, \sigma, \theta, \delta)
$$

as shown in Jorion (p443). Again, $\lambda$ is the mean rate of jumps, $\mu$ mean of diffusion process, $\sigma$ the standard deviation of the diffusion process, $\theta$ mean of lognormal jump size, $\delta$ the standard deviation of the lognormal jump size. If there is a pure diffusion process, the logarithm of the likelihood function should be

$$
\ln L_{\text {diEt }}=\sum_{t=1}^{T} \ln \left[\frac{1}{\sqrt{2 \mathrm{II} \sigma^{2}}} \exp \left(\frac{-\left(x_{t}-\mu\right)^{2}}{2 \sigma^{2}}\right)\right]
$$


where $\mathrm{L}_{\text {diff }}$ differentiates from $\mathrm{L}(\psi ; \mathrm{x})$ in equation (3.9). Rename $\mathrm{L}(\psi ; \mathrm{x})$ as $\mathrm{Lmix}$. The equation (3.10) is used to obtain the likelihood ratio:

$$
\Lambda=\frac{L_{\text {diff }}}{L_{\text {mix }}} .
$$

The existence of the jump-diffusion process can then be tested by the chi-square statistics:

$$
\chi^{2}=-2 \ln \Lambda=-2\left[\ln \mathrm{L}_{\text {liff }}-\ln \mathrm{L}_{\text {mixix }}\right]
$$

with degrees of freedom equal to the number of parameters between the two models (d.f. $=3$ in this case)

\subsection{PARAMETERS ESTIMATION}

Using Quadratic Hill-Climbing method to numerically maximize the likelihood function, given data $X_{1}$, five parameters $(\lambda, \mu, \sigma, \theta$, and $\delta)$ are obtained. The principle is explained in many textbooks. Summarized by Fomby et al. (1984), it can be briefly described as follow.

If $F(b)$ expressed in the equation (3.9) is continuous and has continuous first and second order partial derivatives, the necessary and sufficient conditions for a local maximum are

$$
\left.\frac{\partial F}{\partial b}\right|_{b \cdot b}=0
$$

and at the point $\mathbf{b}^{*}$ defined by (3.12) that the Hessian matrix

$$
\left.\frac{\partial^{2} F}{\partial b \partial b^{\prime}}\right|_{b b^{\prime}}=H^{\prime}
$$


is negative definite. Hence $F(b)$ is maximized by finding all the solutions to (3.12) such that the Hessian is negative definite and then choosing as the solution the point corresponding to the global maximum (Idid: 604).

In practice, $F(\mathbf{b})$ is maximized numerically because it is extremely difficult to solve (3.12) analytically. The numerical maximization methods are iterative, trial-anderror methods. The quadratic hill climbing method is one of the numerical methods applied to solve maximization problems, suggested by Goldfeld et. cll. (1966). Jorion (1989) also estimates these parameters with equation (3.9). This dissertation goes one step further, a critical step to this empirical research: to identify the jump process.

\subsection{IDENTIFYING JUMPS AND ESTIMATING PARAMETERS}

A concept is borrowed from the switching regression in identifying the jump process. Ball and Torous (1981) employs an indicator $(\lambda)$ in their Bernoulli mixture of Gaussian densities model, equation (3.1). It identifies whether any relevant information arrival occurs to affect the stock prices. The null hypothesis $(\lambda=0)$ is tested with this model. This coincides with one technique of switching regression, that is, testing the hypothesis that no switch took place (Goldfeld and Quandt, 4). With the hypothesis testing result, Ball and Torous successfully proved the existence of jumps in the stock market.

As stated in section 3.2, the existence of jumps is tested with likelihood ratio obtained by equation (3.11). However, we have to go one step further than Ball and 
Torous, i.e., to identify jumps from diffusion. Therefore, a simple test on the occurrence of jumps is not sufficient although it is important. Let $p_{t}$ denote the probability of occurrence of a jump on day t. It is calculated as

$$
P_{t}=1-\frac{\left.f\left(X_{t}\right)\right|_{(3.4)}}{\left.f\left(X_{t}\right)\right|_{(3.7)}} \text {. }
$$

As a quantitative method to identify the "switch," probability p presents a state of adjustment from one "structure" (one "process" in this case) to the other. In the calse of this jump-diffusion study, a higher $p_{1}$ value indicates the strong presence of a jump while a lower $p$, value shows the dominant diffusion process.

As pointed out previously, equation $(3.7)\left(\left.f\left(X_{t}\right)\right|_{(3.7)}\right)$ reduces to a pure diffusion density function, equation (3.4) $\left(\left.\mathrm{f}\left(\mathrm{X}_{1}\right)\right|_{(3.4)}\right)$ when jump is absent. Therefore, when $\lambda=0$ and $\mathrm{i}=0, \mathrm{p}_{1}=0$. On the other hand, when there is no diffusion, equation (3.4) equals to zero. Thus, $p_{t}=1$. The Jump-Diffusion model implies that the daily stock prices are results of the mixed processes. Thus the value of $p_{1}$ should be within the range $[0,1]$. In the mixed processes, when the diffusion process is dominant, $p_{1} \cdot 0$. When jumps ate more frequent, however, $p_{1}-1$. Since $0 \leq p_{1} \leq 1$, it represents the probability of jump occurrence. This has been proved to be true with our calculation of equation (3.14). --For the benefit of future research, the computer program and some outputs are included in the Appendix D.

The jump process is identified with the estimated value of parameter $\lambda$. By its definition, $\lambda$ is the ratio of the number of jumps and the number of total observations, 
i.e.,

$$
\lambda=\# \text { jumps / \# observation }
$$

We use the $\lambda$ obtained from the maximum likelihood estimation equation (3.9) as the standard. As stated before, the equation (3.14) implies that the higher the value of $p_{1}$ the closer it is to belong to the jump process. Sort the sample first with $\mathrm{p}_{1}$. Select any number of observations with the highest $p_{t}$ values. Then divide the number of selected observations by the size of the sample. Compare the solution with $\lambda$. If it is higher than $\lambda$, select a smaller number of observations with higher pt values. Otherwise select a larger number. Repeat this process until the solution of equation (3.15) equals to the estimated value of $\lambda$. Then the final group of selected observations belongs to the jump process and the remaining group belongs to the diffusion process.

The assumption that the jump process is independent from the diffusion process makes it feasible to estimate the rest parameters. The value of the weight parameter is simply calculated by equation

$$
\Phi=\frac{\lambda \sigma^{2}\left(R_{\Lambda W}\right)}{\sigma^{2}\left(R_{w}\right)+\lambda \sigma^{2}\left(R_{\Lambda W}\right)}
$$

where $\sigma^{2}\left(R_{w}\right)$, the diffusion variance, and $\sigma^{2}\left(R_{\Delta w}\right)$, the jump variance, are calculated from the separated diffusion and jump samples, $\mathbf{R}_{w}$ and $\mathbf{R}_{\Delta w}$ respectively. The value of $\sigma^{2}\left(R_{w}\right)$ is not necessarily the same as the output of maximum likelihood estimation, $\sigma^{2}$, due to the nature of nonlinear estimates. The same is true for the estimated $\alpha$ via (3.9) and the mean return of $R_{w}$. $\theta$ and $\delta^{2}$ are not comparable with the mean and valliance estimates of the 
jump process because they are the mean and variance of the lognormal jump size rather than the process itself.

The jump beta, $\beta_{\Delta \mathrm{j}}$ and diffusion beta, $\beta_{\mathrm{j}}$ are the ordinary least square estimators. First divide portfolio returns into two separate samples, $\mathbf{R}_{\Delta \mathrm{j}}$ and $\mathbf{R}_{\mathrm{j}}$, according to $\mathbf{R}_{\Delta \mathrm{w}}$ and $\mathbf{R}_{w}$, respectively. $\mathbf{R}_{\Delta \mathrm{w}}$ and $\mathbf{R}_{\mathrm{w}}$ as well as $\mathbf{R}_{\Delta \mathrm{i}}$ and $\mathbf{R}_{\mathrm{j}}$ are vectors of daily returns.

$$
\begin{aligned}
& \mathbf{R}_{\Delta w}=\left(R_{\Delta w 1}, R_{\Delta w 2}, \ldots R_{\Delta w n \Delta}\right)^{\prime} \\
& \mathbf{R}_{w}=\left(R_{w 1}, R_{w 2}, \ldots R_{w T}\right)^{\prime} \\
& \mathbf{R}_{\Delta j}=\left(R_{\Delta j 1}, R_{\Delta, 22}, \ldots R_{\Delta j n \Delta}\right)^{\prime} \\
& \mathbf{R}_{j}=\left(R_{j 1}, R_{j 2}, \ldots R_{j T}\right)^{\prime}
\end{aligned}
$$

where $\mathrm{n} \Delta$ and $\mathrm{T}$ are number of observations in jump sample and diffusion sample respectively, and $\mathrm{j}$ indicates $\mathrm{jth}$ portfolio. $\beta_{\Delta \mathrm{j}}$ and $\beta_{\mathrm{i}}$ are then obtained by

$$
\begin{aligned}
& \beta_{\Delta \mathrm{j}}=\left(\mathbf{R}_{\Delta w} \mathbf{R}_{\Delta w}\right)^{-1} \mathbf{R}_{\Delta \mathrm{w}} \cdot \mathbf{R}_{\Delta \mathrm{j}} \\
& \beta_{\mathrm{j}}=\left(\mathbf{R}_{\mathrm{w}} \mathbf{R}_{\mathrm{w}}\right)^{-1} \mathbf{R}_{\mathrm{w}} \mathbf{R}_{\mathrm{j}} .
\end{aligned}
$$

\subsection{ISSUES OF AUTOCORRELATION AND HETEROSCEDASTICITY}

Working with time-series data of mixed processes with implied structural changes, issues of autocorrelation and heteroscedasticity should be concerned. Jorion (1989) employed ARCH (AutoRegressive Conditionally Heteroscedastic) model as an additional measure to investigate the stochastic processes in his research. He found that the power of ARCH model for the jump-diffusion process is higher than that without it. Jolmson and Schneeweis (1994) point out that a large number of observations are needed 
to increase the power of the model (p316). They did not adopt the ARCH model. It is tempting to adopt the $\mathrm{ARCH}$ model in this empirical research. However trials are not successful. The loglikelihood value does not improve even after 5,000 iterations. Reviewing Jorion's work, arguments made by Johnson and Schneeweis, it may be explained that samples used in this study are not fit for ARCH modeling. Unlike Jorion's sample of 10-year daily data, samples used in this study are jump/event intensified. The discontinuity of the time-series data disqualifies the assumption of autocorrelation. The heteroscedasticity is taken care of by the definition of jump variance and diffusion variance. Thus, adoption of the ARCH model is going to duplicate the effort of adjusting for heteroscedasticity. That is why the trials in this study with the ARCH model failed to improve the value of the log likelihood.

\subsection{PROCESS OF THIS RESEARCH}

The primary goal of this empirical research is to test the specifications of the jump-diffusion model. Daily security returns and a market index from the CRSP' magnetic tape are employed in this study. The data collection is done by generating 30 portfolios after downloading security returns from the tape. The jump-diffusion processes are identified through the maximum likelihood estimation. The existence of the mixed process is confirmed by conducting the likelihood ratio test against the pure diffusion process. The portfolio jump betas and diffusion betas are obtained for every

3. CRSP --- Center of Research for Stock Prices, University of Chicago. 
sample. As a preliminary test on the specifications of the jump-diffusion model, the mean-test is conducted. It tests whether the observed mean returns equal to the expected mean returns calculated by the jump-diffusion model with jump betas and diffusion betas of 30 portfolios. Due to the assumption of a non-normal distribution for the jumpdiffusion model, a non-parametric test, the sign test, is employed to check and/or to reinforce results of the mean-test.

Secondly, the comparison between the jump-diffusion model and the conventional CAPM is carried out as follow. CAPM betas for each portfolio are obtained first with the original, mixed or non-separated sample. Then a cross sectional regression is run in the form of the CAPM. The coefficients of the cross sectional regression are tested against the specifications of CAPM. Another cross sectional regression is also run, but in the form created by a hypothesis that the CAPM beta is equivalent to the weighted average of jump beta and diffusion beta. The hypothesis test is carried out on its coefficients.

The well-documented January Effect has now almost become a benchmark test for any new asset pricing model. As mentioned in Chapter One, various models developed so far cannot explain the January Effect or abnormal returns during the turn of the year. After testing the specifications of the Jump-Diffusion model, the new model is applied to the turn of year sample. Since the time span is long, a conventional testing method is employed. A cross sectional regression is run after estimating mean returns, jump betas, and diffusion betas of thirty portfolios. The coefficients of the cross sectional regression are tested against the specifications of the model.

Due to the great influence of Fama and French's five-factor model (1993), the 
January Effect study is extended to use another sample of data. In order to make a true comparison with Fama and French's findings, the exact sample of CRSP monthly data is used. Thus Monthly security returns and a market index from the CRSP magnetic tape are used. The data collection is done by generating 20 portfolios after downloading security returns from the tape. Similar procedure as employed by Fama and French is followed in this study. 


\section{CHAPTER FOUR}

\section{DATA ANALYSIS}

\subsection{DATA COLLECTION}

Three groups of data are required by the jump-diffusion two-beta asset pricing model: returns of optimally invested wealth, returns of individual securities (portfolios), and a risk-free rate. The two sets of data are available on the CRSP tape. Value weighted market index (VW) is employed to represent the daily return of the optimal invested wealth, $R_{w}$. Returns on thirty portfolios, cross-classified by market value of firm's equity and stock price are obtained each year by the following procedure as $R_{i}$ :

1. Each year all NYSE and AMEX ${ }^{4}$ stocks with the previous yearr's ending price and shares outstanding information available from CRSP are included in the sample.

2. The firm size proxied by equity market value is determined as the share price multiplied by the number of shares outstanding. The stocks are ranked in ascending order based on the firm size and then divided equally into thirty size groups from low to high.

\footnotetext{
4. NYSE --- New York Stock Exchange AMEX --- American Exchange
} 
3. Daily returns on stocks within each size group are used to obtain the average return on 30 size-related portfolios.

4. Repeating steps 1 through 3 for each year in the 30 -year period, yields $R_{\mathrm{j}}$, the average daily returns of 30 portfolios for 30 years.

The risk free rate, $R_{f}$, is the daily rate of a treasury bill.

\subsection{SAMPLE PERIODS}

For the empirical verification of the Jump-Diffusion model, the period around the Persian Gulf Crisis is selected as the sample period. Since August 2, 1990, when Iraqi invaded Kuwait, stock prices dropped (negative jump) precipitously whenever expectations of the war were heightened, and jumped sharply up whenever peace appeared hopeful. More important, the jumps are not just associated with any particular firm, or any particular industry. The jumps are associated with the market as a whole. Thus, the period around the Persian Gulf Crisis is ideal for testing the jump-diffusion two-beta asset pricing model.

The whole sample period is 1990 and 1991, 506 trading days in total. The whole period is divided into three sub-periods. The first period (pre-invasion) is from the beginning of 1990 to the week prior to the Iraqi invasion, i.e., the end of July 1990. The second period (invalsion) is from July 30, 1990 to the end of February, about one week after the cease fire agreement was signed (February 18, 1991). The third period (postinvasion) is from then to the end of 1991 . Therefore, there are two periods of peace and 
one of war.

The results of step 1 through 4 in the section of Data Collection are partially reported in a set of tables which are presented in Appendix $C$ due to large volume of data. Table 1: $\quad$ Average sizes of thirty portfolios during five years;

Table 2: $\quad$ Statistics of average daily returns of the value weighted market index and thirty portfolios during the whole sample period;

Table 3: A covariance/variance matrix of the average daily returns of thirty portfolios and the value weighted market index.

The full report is available upon request. The size of the largest portfolio is almost a thousand times the size of the smallest portfolio. The average daily return of the smallest portfolio is almost ten times that of the market index, which is almost the same as the largest portfolio. On the other hand, the standard deviation of the smallest portfolio is almost twice as large as that of the largest portfolio. Again, the standard deviation of the market index is almost identical as that of the largest portfolio. These facts are also confirmed by the covariance/variance matrix. It shows that the larger the portfolio is, the bigger the covariance with the market index becomes. That is, the largest portfolio moves almost identically with the market because it is strongly correlated with the market. This is significant because the systematic risk, betal of the portfolio is calculated as dividing the covariance between itself and the market index by the valriance of the market index. Therefore the larger the portfolio, the closer to I the betil of the portfolio. 


\subsection{BEHAVIOR OF MARKET RETURNS}

Since the jump-diffusion asset pricing model is built on the assumption that the underlying probability distribution is a mixture of Normal and Poisson, for testing the model, it is important to examine the frequency distribution of the market returns to see whether the assumption is approximated or not.

In Figure 2, a group of four graphs, heavy black vertical bars are the actual frequency distributions of VW market returns during four sampling period. A theoretical normal curve is superimposed as a line on top of the frequency distribution for ease of comparison. The frequency distribution of the market returns for the whole sample period shows relatively good fit between the actual histogram and the standard normal distribution. However, the following set of four figures, each representing one sampling period, has indeed shown the characteristics of fat tails and leptokurtosis, a phenomenon well documented in the finance literature. As one would suspect, the fat tails and leptokurtosis are more serious in the sampling period of the invalsion (figure 2c), when jumps are more frequent than the other two sub-sampling periods of peace (figure $2 \mathrm{~b}$ and 2d). 


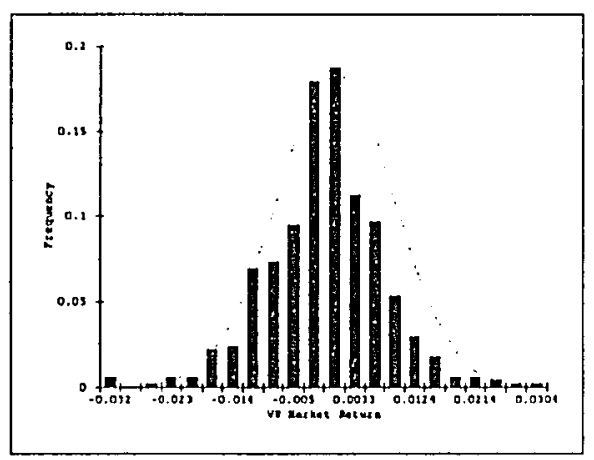

2a: Whole Period

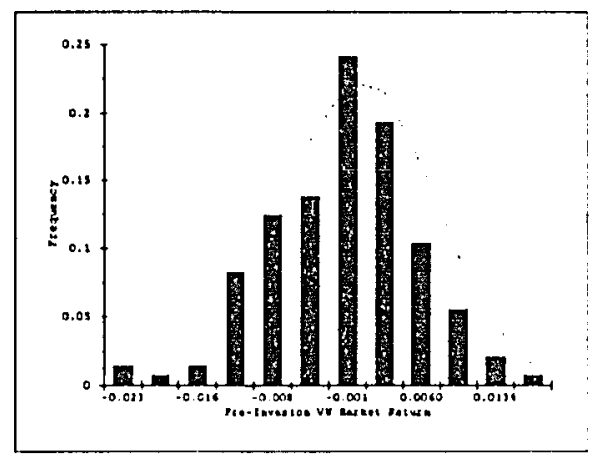

2b: Pre-Invasion Period

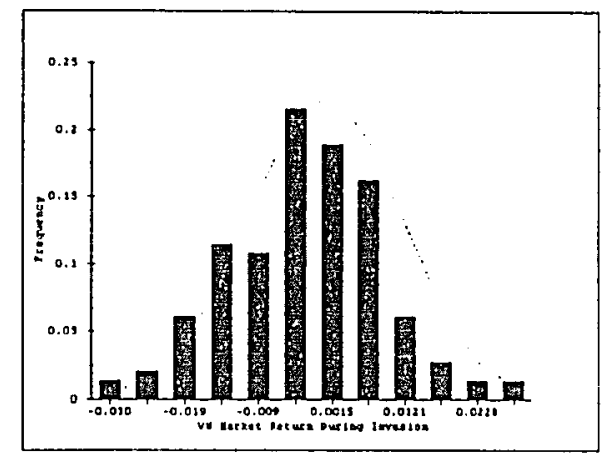

2c: Invasion/War Period

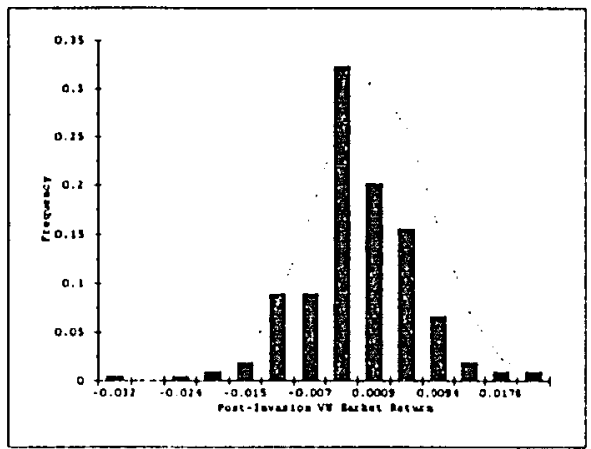

2d: Post-Invasion Period

Figure 2: $\quad$ Frequency Distribution of Value Weighted Market Index During the Gulf War Sampling Periods 


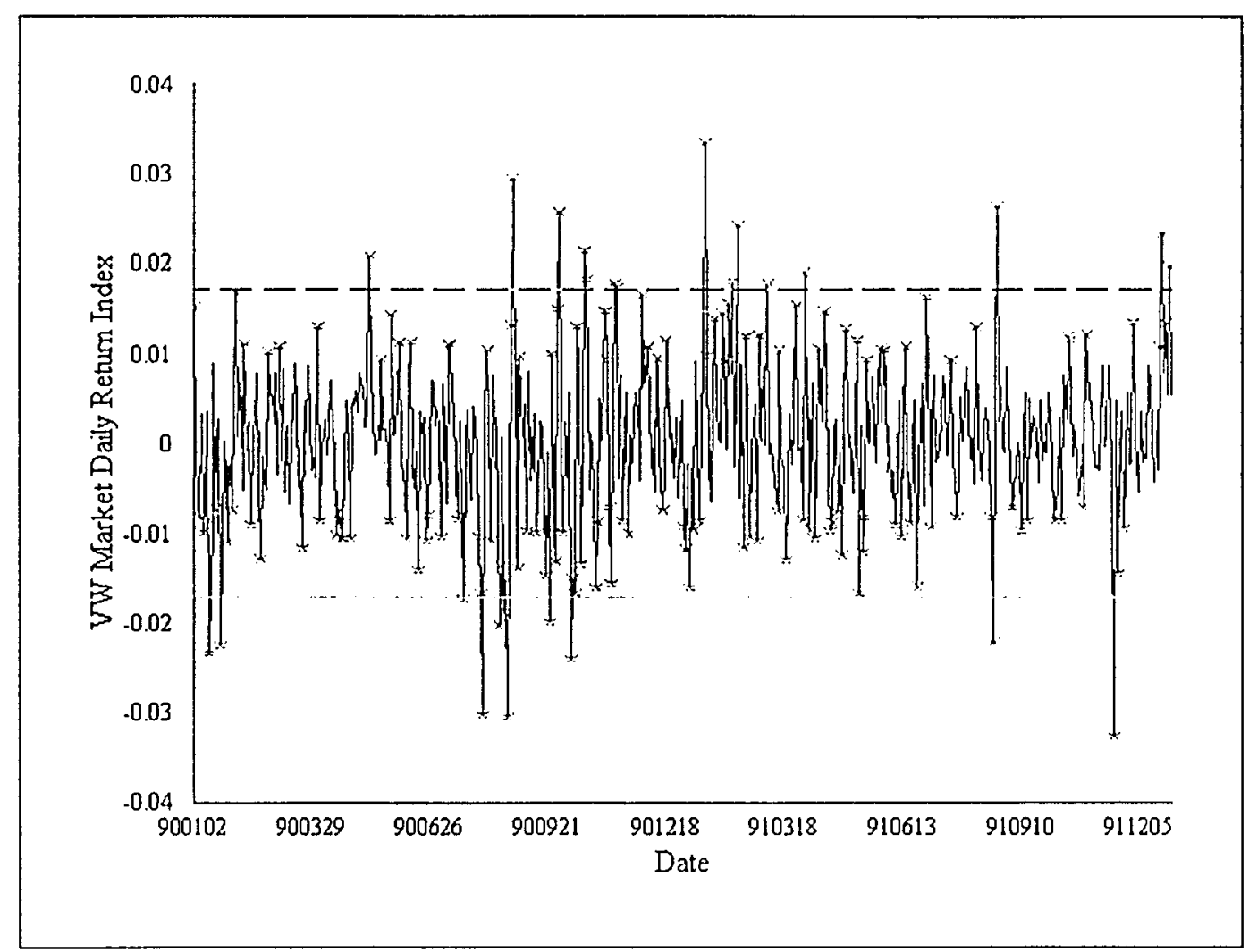

Figure 3: Characteristics of the Daily Value Weighted Market Index During the Gulf War Period, 1990 - 1991

The characteristics of the market returns during the Gulf War period are presented in Figure 3. The existence of jump process is clear from this graphic demonstration.

Cross marks are indicators of jumps which are identified via the maximum likelihood estimation. This result is convincing and proves that the identification method is better than any ad hoc method, such as using $\pm 2 \sigma$ as a range for diffusion and picking observations beyond that range as jumps. The $+2 \sigma$ line and $-2 \sigma$ line in Figure 3 clearly shows that such a method would miss a number of jumps. In fact, it captures about only 
$16.56 \%$ of total jumps with this sample.

Table 4 reports the result of the maximum likelihood estimation and the likelihood ratio test against the pure diffusion model.

\section{Table 4}

\section{Parameter Estimation Results of Maximum Likelihood Estimation}

with the Gulf War Period Sample

\begin{tabular}{|c|c|c|c|c|c|c|c|}
\hline Process & $\mu\left(\times 10^{-4}\right)$ & $\sigma^{2}\left(\times 10^{-5}\right)$ & $\lambda$ & $\theta\left(\times 10^{-4}\right)$ & $\delta^{2}\left(\times 10^{-4}\right)$ & $\begin{array}{c}\text { Log } \\
\text { Likelihood }\end{array}$ & Chi-Square \\
\hline Diffusion & $\begin{array}{c}4.3074 \\
(1.1315)\end{array}$ & $\begin{array}{c}7.3353 \\
(15.873)\end{array}$ & & & & 1690.6 & \\
\hline Jump-Diffusion & $\begin{array}{c}6.7252 \\
(0.4628)\end{array}$ & $\begin{array}{c}4.0916 \\
(9.145)\end{array}$ & $\begin{array}{c}0.31 \\
(5.3173)\end{array}$ & $\begin{array}{c}-7.6966 \\
(-0.544)\end{array}$ & $\begin{array}{c}1.0528 \\
(4.8707)\end{array}$ & 1703.9 & $26.6^{*}$ \\
\hline
\end{tabular}

Note: Asymptotic t-statistics in parentheses. Pure diffusion process is modeled by $\mathrm{N}(\mu$, $\sigma^{2}$ ). The jump-diffusion process is the combined Poisson and Normal distribution, with a mean rate of jump as $\lambda$ and size of jumps modeled by $\mathrm{N}\left(\theta, \delta^{2}\right)$. The chi-square statistics (d.f. $=3$ ) tests the hypothesis of a pure diffusion process against a jump-diffusion process. "indicates significant at $1 \%$ level.

The null hypothesis of the likelihood ratio test is that the jump-diffusion process is no different from the pure diffusion process. The significance of the chi-square statistics shows that the jump-diffusion process describes the price movement of the stock market better. In other words, jump does exist and the jump-diffusion model should be chosen over the pure diffusion model.

Table 4 also shows that the estimation of $\mu$ and $\theta$ are weak. Several steps are taken to increase the power of the estimation. Then the attempt is given up becaltse it is not the focus of the research. 


\subsection{ESTIMATION OF PARAMETERS}

\subsubsection{Market Parameters}

Table 5 lists descriptive statistics of value-weighted market daily returns for different sampling periods as well as for different samples.

\section{Table 5}

Descriptive Statistics of Market during the Gulf War Period

\begin{tabular}{|c|c|c|c|c|}
\hline & Whole Period & Pre-Invasion & Invasion & Post-Invasion \\
\hline \multicolumn{5}{|c|}{ Mixed Sample } \\
\hline$N$ & 506 & 145 & 150 & 211 \\
\hline $\operatorname{ABS}\left(R_{w}\right)$ & 0.0063925 & 0.0057199 & 0.0083559 & 0.0054730 \\
\hline \multirow[t]{2}{*}{$\mathrm{R}_{w}$} & 0.000467521 & 0.00007168 & 0.0004889 & 0.0000760690 \\
\hline & $(0.0085727)$ & $(0.0073111)$ & $(0.0108724)$ & $(0.0074862)$ \\
\hline \multicolumn{5}{|c|}{ Jump Sample } \\
\hline $\mathrm{N}_{\mathrm{i}}$ & 157 & 39 & 65 & 53 \\
\hline$A B S\left(R_{\Delta W}\right)$ & 0.0130597 & 0.01155794 & 0.01450626 & 0.012 .39066 \\
\hline \multirow[t]{2}{*}{$\mathrm{R}_{\mathrm{JW}}$} & -0.0010284 & -0.003049559 & -0.00081614 & 0.00019857 \\
\hline & $(0.01411287)$ & $(0.01196162)$ & $(0.01576419)$ & $(0.013507 .3)$ \\
\hline \multicolumn{5}{|c|}{ Diffusion Sample } \\
\hline$N_{11}$ & 349 & 106 & 85 & 158 \\
\hline$A B S\left(R_{d w}\right)$ & 0.003339322 & 0.003571872 & 0.00365268 & 0.003113378 \\
\hline \multirow[t]{2}{*}{$R_{\mathrm{dw}}$} & 0.00114047 & 0.001220057 & 0.0014860 & 0.000000070 .3 \\
\hline & $(0.003998721)$ & $(0.00407123)$ & $(0.0(1) 42441)$ & $(0.003793292)$ \\
\hline
\end{tabular}

The "Mixed Sample" means a sample without the separation of jump process from 
diffusion process. $\mathrm{N}$ denotes number of observations within a sample. $R_{w}$ is the mean of $\mathbf{R}_{w}$, which is the vector containing daily returns of the value-weighted market index. $R_{\Delta w}$ is the mean of $\mathbf{R}_{\Delta w}$, the jump sample of $\mathbf{R}_{w}$. $\mathbf{R}_{d w}$ is the mean of $\mathbf{R}_{d w}$, the diffusion sample. Data within parentheses is standard deviation of the estimated mean. ABS is the mean of the absolute values.

The absolute values of $R_{\Delta w}$ reveals the magnitude of jump size. It is at least twice as large as the diffusion size, $A B S\left(R_{d w}\right)$. The standard deviations of $R_{d w}$ and $R_{\Delta w}$ confirm this finding. The negative values of $\mathrm{R}_{\Delta w}$ show that most of jumps are downwards. With these statistics, we obtain estimation of $\phi$, which are listed in Table 6, together with estimations of $\lambda$ and $R_{f}$, the risk-free rate. $R_{f}$ is the mean of a daily treasury bill rate. $\lambda$ is estimated with equation (3.16) for each sampling period, while $\phi$ is obtained with equation (3.17).

\section{Table 6}

\section{Estimates of Jump-Diffusion Model Parameters}

with the Gulf War Period Samples

\begin{tabular}{|c|c|c|c|c|}
\hline Palameter & Whole & Pre-Invasion & Invasion & Post-Invasion \\
\hline$\lambda$ & 0.31 & 0.27 & 0.43 & 0.25 \\
\hline$\phi$ & 0.795386 & 0.698957 & 0.856704 & 0.761048 \\
\hline$R_{i}$ & 0.00017943 & 0.0002152 & 0.00019103 & 0.00014628 \\
\hline
\end{tabular}

\subsubsection{Portfolio Estimates}


The portfolio estimates include portfolio return $R_{i}$, jump betal $\beta_{\Delta j}$, diffusion beta $\beta_{j}$, and the CAPM betal $\beta_{\mathrm{j}}^{\prime}$. For easy comparison, these estimated values are listed together in Table 7 which is presented in Appendix $\mathrm{C}$ due to the large volume. There are four panels, panel A, B, C, and D in Table 4 for the four sampling periods respectively. While estimating betas, results of the Durbin-Watson test and $\rho$ are included in the output. They show little evidence of autocorrelation.

\subsection{HYPOTHESIS TESTING AND TEST RESULTS}

\subsubsection{Testing Specifications of the Jump-Diffusion Model}

The assumption of the jump-diffusion two-beta asset pricing model is the mixed distribution of normal and Poisson. Therefore, one cannot use the ordinary method to test the model specifications. As a start, a mean test is conducted to find out how well the model performs with four samples. T-ratios are computed as follow:

$$
t=\frac{E\left(\bar{R}_{j}\right)-E\left(R_{j}\right)}{\sqrt{\frac{\sigma^{2}\left(\bar{R}_{j}\right)+\sigma^{2}\left(R_{j}\right)}{(n-1)}}}
$$

where $\bar{R}_{j}=R_{f}+\left(R_{w}-R_{f}\right)\left[(1-\phi) \beta_{j}+\phi \beta_{\Lambda j}\right]$,

and

$$
E\left(\bar{R}_{j}\right)=\frac{1}{30} \sum_{j=1}^{30} \bar{R}_{j}
$$


because the hypothesis is that

$$
\mathrm{H}_{10}: \quad \bar{R}_{j}=R_{j} \quad j=1, \ldots, 30 .
$$

The results are reported in Table 8 .

Table 8

\section{Results of Mean-'Test}

$($ d.f. $=29)$

\begin{tabular}{|c|c|c|c|c|}
\hline & Whole & Pre-Invasion & Invasion & Post-Invasion \\
\hline t-ratio & -1.3009 & 1.0794 & -1.2293 & $-2.4026^{*}$ \\
\hline
\end{tabular}

Note: * indicates the ratio is significant at 0.05 level.

The test results show that the jump-diffusion model lunctions well. That is, the hypothesis that model estimated portfolio retum equals to the observed portfolio return is not rejected in all sample periods except the post-invasion period. Understanding the underlying probability distribution being a mixture of Poisson and normal, however, a strict non-parametric test is conducted to enhance the hypothesis test. The sign test (Hoel, Port, and Stone 1971, p172-174) is chosen because it can be applied to any density function $f(x)$, to test the specification of the jump-diffusion model.

\subsubsection{Method of Sign Test}

Define the median of $f(x)$ ats 


$$
\int_{-\infty}^{\xi} f(x) d x=\int_{\xi}^{\infty} f(x) d x=\frac{1}{2}
$$

Let the random sample be denoted by $X_{1}, \ldots, X_{n}$ which possesses the density function $f(x)$ and is used to test the hypothesis

$$
\mathrm{H}_{0}: \xi=\xi_{01} \quad \text { against } \quad \mathrm{H}_{1}: \xi>\xi_{0} .
$$

Since $P\left(X>\xi_{0} \mid H_{0}\right)=1 / 2$, then

$$
P\left(X_{i}-\xi_{0}>0 \mid H_{0}\right)=1 / 2 . i=1, \ldots, n
$$

Let

$$
Z_{i}=\mid \begin{array}{ll}
0, x_{i}-\xi_{0} \leq 0 & (4.4 a) \\
1, x_{i}-\xi_{0}>0 & (4.4 b)
\end{array}
$$

The $Z$ 's are independent, identically distributed random variables. When $H_{0}$ is true, $E\left(Z_{i}\right)$ $=1 / 2$; therefore when $\mathrm{H}_{0}$ is true, the $\mathrm{Z}$ 's represent a random sample of size $n$ of a Bernoulli variable with $p=1 / 2$. When $H_{1}$ is true, $E\left(Z_{i}\right)>1 / 2$ becaluse the frequency of positive values of $X_{1}-\xi_{1)}$ will increase if the true median is larger than $\xi_{10}$. Hence, we can choose the binomial variable

$$
z=\sum_{i=1}^{n} z_{i}
$$

as statistic for constructing the test and use right tail of the distribution of $Z$ ats critical region. Here

$$
E(Z)=n p=n / 2
$$

and

$$
\operatorname{Var}(Z)=n p q=n / 4
$$

If $n$ is sufficiently large to justify using the normal approximation to the binomial 
distribution, then the test should choose as critical region the region $\tau>\tau_{0}$, where $P(\tau>$ $\left.\tau_{0}\right)=\epsilon$ and $w h e r e$

$$
\tau=\frac{z-\left(\frac{n}{2}\right)}{\sqrt{\frac{n}{4}}}
$$

In this case, $n=30$ and $X_{i}$ is denoted by $e_{j}$ which is the error term of the expected return of stock $\mathrm{j}$ from the realized return of stock $\mathrm{j}$, i.e.,

$$
e_{j}=\bar{R}_{j}-R_{j} \quad j=1, \ldots, 30
$$

where

$$
\bar{R}_{j}=R_{f}+\left(R_{w}-R_{f}\right)\left[(1-\phi) \beta_{j}+\phi \beta_{\Lambda j}\right]
$$

which is the jump-diffusion two-betal asset pricing model itself, and $R_{j}$ is estimated mean return of stock $\mathrm{j}$ in Table $4 . \xi_{0)}$ is 0 because our hypothesis should be that the expected returns estimated with the jump-diffusion model equal to the real returns. Referring to the text above,

and

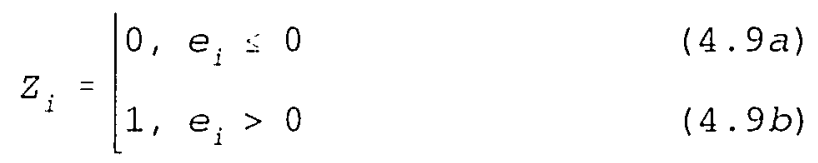

$$
z=\sum_{i=1}^{n} z_{i}
$$

The test statistic is

$$
\tau=\frac{z-\mu}{\sqrt{\frac{n}{4}}}=\frac{z-15}{\sqrt{\frac{30}{4}}}
$$

At the $5 \%$ significance level, the hypothesis is rejected if $\tau \geq|1.64|$. Employing datal 
from table 5 to table 7 , the test results for each sampling periods are reported in Table 9.

Table 9

Results of Sign Test

\begin{tabular}{|c|c|c|c|c|}
\hline & Whole & Pre-Invasion & - Invasion & Post-Invasion \\
\hline Z-ratio & 1.4606 & $3.6515^{*}$ & 1.4606 & $-3.6515^{*}$ \\
\hline
\end{tabular}

Note: * indicates the ratio is significant at 0.05 level.

The hypothesis that the expected return of a valued asset by the jump-diffusion model is not significantly different from the average realized return of the asset camnot be rejected for either the whole period or the invasion period. This conclusion agrees with the results of the parametric t-test for all periods except the pre-invasion period. One could argue that the sign test is more strict for the mixed distribution assumption. At least we can conclude that the jump-diffusion model is useful to periods within which jumps are more frequent despite the disagreement between the t-test and the sign test . That the hypothesis is rejected in the post-invasion period, in addition to the pre-invasion period, shows that the jump-diffusion model is not general enough to predict the expected returns during non-eventful time. Logically, one would ask how the conventional CAPM performs with the same sets of data? 


\subsubsection{Hypothesis Testing on CAPM}

The conventional CAPM is based on the assumption of normality. Therefore, we should conduct the parametric t-test on its specifications. Let

$$
Y_{j}=\left(R_{j}-R_{f}\right) /\left(R_{w}-R_{f}\right)
$$

The CAPM is then rewritten as

$$
Y_{j}=\beta j
$$

The regression equation on which the hypothesis testing is based is

$$
Y_{j}=b_{0}+b_{1} \beta_{j}^{\prime}+\epsilon_{j}
$$

The hypotheses are:

$$
\begin{aligned}
\mathrm{H}_{0}: & \mathrm{b}_{0}=0 \\
\mathrm{~b}_{1} & =1 .
\end{aligned}
$$

Table 10

\section{Results of t-Test on the CAPM}

\begin{tabular}{||c|c|c|c|c|c||}
\hline Sample Period & $\mathrm{b}_{0}$ & $\mathrm{~b}_{1}$ & $\mathrm{R}^{2}$ & $\mathrm{I}\left(\mathrm{b}_{11}=0\right)$ & $\mathrm{l}\left(\mathrm{b}_{1}=1\right)$ \\
\hline Whole & $\begin{array}{c}6.4658 \\
(2.0421)\end{array}$ & $\begin{array}{c}-7.3417 \\
(2.8704)\end{array}$ & 0.1894 & $3.1663^{*}$ & $-2.906 \mathrm{I}^{*}$ \\
\hline Pre-Invasion & $\begin{array}{c}0.0472 \\
(2.8819)\end{array}$ & $\begin{array}{c}2.4561 \\
(4.5128)\end{array}$ & 0.0105 & 0.0164 & 0.3227 \\
\hline Invasion & $\begin{array}{c}10.931 \\
(2.6186)\end{array}$ & $\begin{array}{c}-12.397 \\
(3.3951)\end{array}$ & 0.3226 & $4.1743^{*}$ & -.3 .946()$^{*}$ \\
\hline Past-Invatsion & $\begin{array}{c}3.2026 \\
(0.8307)\end{array}$ & $\begin{array}{c}-2.9877 \\
(1.2301)\end{array}$ & 0.1740 & $3.8552^{*}$ & $-3.2419^{*}$ \\
\hline
\end{tabular}

Note: 1. Standard errors of estimations are listed with parentheses.

2. * indicates ratios atre significant at 0.05 level. 
Table 10 shows that the CAPM is not rejected with only one sample period. It failed with all other three sets of data. During the pre-invasion period when the hypotheses are not rejected, however, $\mathrm{R}^{2}$ of the cross regression is only 0.0105 . Such a small value of $\mathrm{R}^{2}$ indicates the insignificance of coefficient estimation. Therefore, the regression results generally show that the CAPM is a weaker model in explaining the return of assets.

\subsubsection{Distinction between the Jump-Diffusion Model and the CAPM}

How distinct is the jump-diffusion model from the conventional CAPM? Tests on model specifications are in favor of the jump-diffusion model. However, it is necessary to test whether the jump-diffusion model is related to the CAPM. Since the jump-diffusion model can be written as

$$
Y_{j}=(1-\phi) \beta_{j}+\phi \beta_{\Delta i}
$$

with equation (4.13), such a test should then be based on whether the beta in the conventional CAPM is the weighted average of the jump beta and diffusion beta in the Jump-Diffusion model. The hypothesis therefore is

$$
H_{0}: \quad \beta_{i}^{\prime}=(1-\phi) \beta_{j}+\phi \beta_{\Delta j} \quad j=1, \ldots, 30
$$

The hypothesis can be tested with the following regression model

$$
\beta_{\mathrm{j}}=c_{0}+c_{1} \beta_{\mathrm{i}}+c_{2} \beta_{\Delta i}+\mu_{i} . j=1, \ldots, 30
$$

The testable hypotheses are

$$
c_{6}=0 \text {, }
$$




$$
\begin{aligned}
& c_{1}+c_{2}=1, \\
& c_{2}=\phi .
\end{aligned}
$$

The results of testing are reported in Table 11 .

Note that the hypothesis $\mathrm{c}_{1}+\mathrm{c}_{2}=1$ and $\mathrm{c}_{2}=\phi$ are really joint hypotheses. The rejection of either one implies the rejection of the hypothesis that the systematic risk is a weighted average of diffusion and jump betas. Hypothesis $c_{2}=\phi$ is rejected by the t-test for all sample periods except the post-invasion samples. For the post-invasion period, the hypothesis testing results on the specifications of both jump-diffusion model and the CAPM suggest that there is no significant difference between specifications of the jumpdiffusion model and those of the CAPM. 
Table 11

Testing Results on Distinction

between Jump-Diffusion Model and the CAPM

\begin{tabular}{|c|c|c|c|c|c|c|c||}
\hline Sumple Period & $c_{i j}$ & $c_{1}$ & $c_{2}$ & $R^{2}$ & $t\left(c_{i 1}=0\right)$ & $t\left(c_{1}+c_{2}=1\right)$ & $t\left(c_{2}=\phi\right)$ \\
\hline Whole & $\begin{array}{c}0.0067 \\
(0.0056)\end{array}$ & $\begin{array}{c}0.1540 \\
(0.0095)\end{array}$ & $\begin{array}{c}0.8412 \\
(0.0146)\end{array}$ & 0.9996 & 1.1878 & -0.8119 & $3.1628^{*}$ \\
\hline Pre-Invasion & $\begin{array}{c}0.0035 \\
(0.0077)\end{array}$ & $\begin{array}{c}0.3460 \\
(0.0152)\end{array}$ & $\begin{array}{c}0.6553 \\
(0.0187)\end{array}$ & 0.9964 & 0.4563 & 0.1147 & $-2.3362^{*}$ \\
\hline Invasion & $\begin{array}{c}0.0087 \\
(0.0046)\end{array}$ & $\begin{array}{c}0.0836 \\
(0.0036)\end{array}$ & $\begin{array}{c}0.9079 \\
(0.0073)\end{array}$ & 0.9996 & 1.8826 & -1.7391 & $6.9977^{*}$ \\
\hline Post-Invasion & $\begin{array}{c}0.0110 \\
(0.0068)\end{array}$ & $\begin{array}{c}0.2057 \\
(0.0156)\end{array}$ & $\begin{array}{c}0.7791 \\
(0.0221)\end{array}$ & 0.9983 & 1.6146 & -1.5816 & 0.8392 \\
\hline
\end{tabular}

Note: 1. Standard errors of estimations are listed with parentheses.

2. * indicales, ratios are significant at 0.05 level. 


\section{CHAPTER FIVE}

\section{JANUARY EFFECT ANALYSIS}

\subsection{REVIEW OF PREVIOUS STUDIES}

The January effect has been well documented. In a series of works, Keim (1983, 1986, and 1989) documented the January effect in various perspectives. Lakonishok and Smidt found the existence of the January effect over ninety years of the stock market history. Roll (1983) found that the January effect is size-related, i.e. small firm stocks tend to be more volatile at the turn of the year. Keim and Stambaugh (1986) further explored size effect/January effect relationship and concluded the same. Bhardwaj and Brooks (1992) argue, however, that it would be more accurate to state that the January effect is "a low-price phenomenon rather than a small firm effect (p553)."

Finance academicians agree that the January effect exists, but disagree on the cause(s). Some well known hypotheses are tax selling to create capital loss in the end of the year, information shortage for small firms, etc. None of these hypotheses are confirmed. In fact, the January effect is such a classical problem (unexplainable so firr) that it has become a standiard application to test any new asset pricing models (Fama and French 1993, p43). The CAPM has been widely criticized for it (Banz 1981 and Keim 
1986). The APT cannot explain it either (Roll 1983). The most recent development by Fama and French (1993), a five-common-risk-factor model also failed to explain it because their risk factors do not contain January seasonals (p46). How would the jumpdiffusion model perform this task?

\subsection{SAMPLE COLLECTION AND ANALYSIS}

The complete recorded thirty years are selected. The last trading day of a year and the first three trading days of the following year, totaling 4 daily returns, are sampled for "the turn of the year," while the rest days are grouped together as another sample. Due to the limitation of the computing device, only the smaller size sample, i.e., the turn-of-theyear 4 trading days from 1962 to 1991 , is used for the jump-diffusion study. However, in order to get a close-to-reality data set to estimate jump process and diffusion process, the whole two months of the turn of the year, i.e., December and January data are used for maximum likelihood estimation. The distribution of the sample is shown in figure 6 ats an evidence of abnormality. The results of the maximum likelihood estimation are shown in figure 7 and table 12. 
Figure 6: Distribution of Value-Weighted Market Index During Turn-of-Year from $1962-1991$

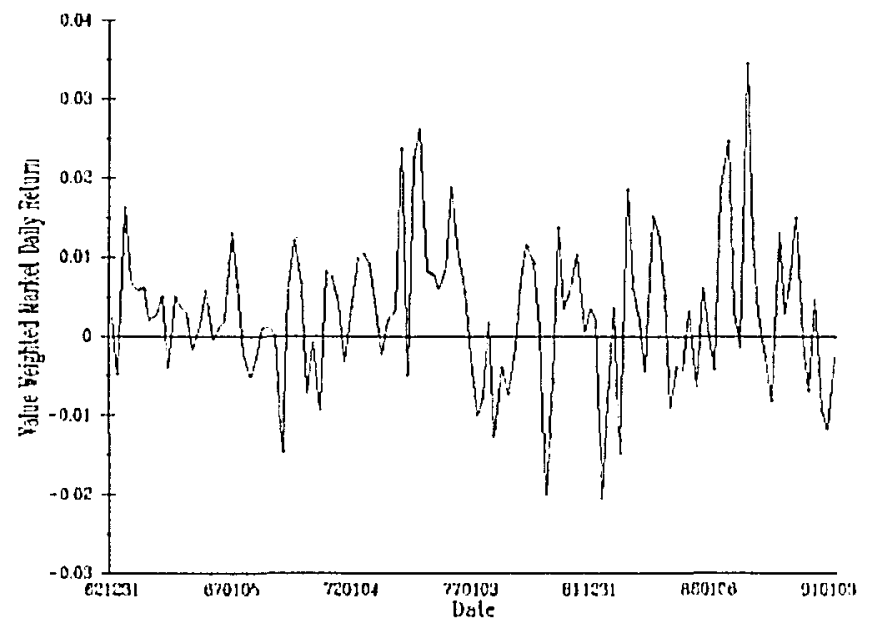

Figure 7: $\quad$ Characteristics of The Value Weighted Market Return at Turn of The Year from 1962 to 1991

As a reminder, note that table 12 reports estimation results based on two sampling months' data from 1962 to 1991, while figure 7 plots the estimation results with turn-of- 
year four trading days only which are based on Table 12 estimations. Again the cross marks indicate jumps. The skewness to the left and fat tails in figure 6 as well as the intensity of jumps in figure 7 are clear signs of "January Effect." An interesting point, which actually assures the process of identifying the jump-diffusion process viat the maximum likelihood estimation, is that the jumps identified independently with the Gulf War period sample are confirmed with the turn-of-the-year sample. However, due to different data sets and the nature of nonlinear estimation, not every jump matches in both samples. Detailed output of the estimation can be obtained upon request.

Table 12

\section{Results of Maximum Likelihood Estimation}

with Turn-of-the-Year Sample

\begin{tabular}{|c|c|c|c|c|c|c|c||}
\hline Process & $\mu\left(\times 10^{-1}\right)$ & $\sigma^{2}\left(\times 10^{-5}\right)$ & $\lambda$ & $\theta\left(\times 10^{-4}\right)$ & $\delta^{2}\left(\times 10^{-4}\right)$ & $\begin{array}{c}\text { L.oug } \\
\text { Likelihood }\end{array}$ & Chi-Squalre \\
\hline Diffusion & $\begin{array}{c}8.5153 \\
(3.6901)\end{array}$ & $\begin{array}{c}0.6524 \\
(24.674)\end{array}$ & & & & 4164.8 & \\
\hline Jump-Diffusion & $\begin{array}{c}8.2665 \\
(4.4549)\end{array}$ & $\begin{array}{c}1.9780 \\
(11.842)\end{array}$ & $\begin{array}{c}0.49558 \\
(8.1466)\end{array}$ & $\begin{array}{c}0.4998 \\
(0.1125)\end{array}$ & $\begin{array}{c}0.9048 \\
(10.966)\end{array}$ & 4257.5 & $185.4^{4}$ \\
\hline
\end{tabular}

Note: Asymptotic t-statistics in parentheses. Pure diffusion process is modeled by $N(\mu$, $\left.\sigma^{2}\right)$. The jump-diffusion process is the combined Poisson and Normal distribution, with mean rate of jump as $\lambda$ and size of jumps modeled by $N\left(\theta, \delta^{2}\right)$. The chi-square statistic $(\mathrm{d} . \mathrm{f} .=3)$ tests the hypothesis of a pure diffusion process against a jump-diffusion process. * indicates significant at $1 \%$ level.

The mean rate of jump, $\lambda$ in Table 12 is almost 50 percent --- for whole two months around the turn of the year, comparing with 31 percent during the Gulf War sampling 
period. In addition, the chi-square statistic resulted from the likelihood ratio test shows that the jump-diffusion process is far superior to the pure diffusion assumption.

Following the same procedure as described in the previous chapter, the whole sample is divided into a jump data set and al diffusion data set. Estimated market parameters are reported in Table 13.

Talble 13

Estimated Miarket Parameters with Turn-of-Year Sample

\begin{tabular}{|c|c|c|c|}
\hline & Whole Simple & Jump & Diffusion \\
\hline $\mathrm{N}$ & 116 & 73 & 43 \\
\hline $\mathrm{ABS}\left(\mathrm{R}_{\mathrm{w}}\right)$ & 0.0073783 & 0.010406 & 0.0022387 \\
\hline $\mathrm{R}_{w}$ & 0.002945 & $\mid 0.004056$ & 0.001059 \\
\hline & $(0.009267)$ & $\mid(0.011432)$ & $(0.002306)$ \\
\hline$\lambda$ & 0.6293 & & \\
\hline$\phi$ & 0.93927 & & \\
\hline$R_{f}$ & 0.00018563 & & \\
\hline
\end{tabular}

This $\lambda$ (almost 63 percent) is the mean rate of jump during the turn of year four trading days from 1962 to 1991 . It is logical that this $\lambda$ is much higher than the $\lambda$ in Table 12 because it represents at concentrated period of the turn of the year. Comparing with the statistics of market returns listed in Table $5, \mathrm{R}_{\mathrm{w}}$ is almost seven times higher 
during the turn of the year than during the whole sample period of 1991 and 1992. There are more positive jumps than negative jumps during the turn of the year, resulting in an even higher value of $R_{w}$ in the jump set. These statistics agree with empirical observations and documentation on the January effect.

Table 14 in Appendix $\mathrm{C}$ reports estimations on portfolio returns, jump betas, diffusion betas, and CAPM betas. It shows that the smaller the portfolio size, the higher the average returns. This is so-called January/size effect as Roll (1983) pointed out.

\subsection{HYPOTHESIS TESTING}

Due to the long time span (30 years) of the turn-of-year sample, the ordinary parametric testing methods are employed in this section. The specifications of the jumpdiffusion model are tested with the turn of the year sample as follow.

Rewrite the jump-diffusion model as

$$
Y_{j}=a_{0}+a_{1} \beta_{j}+a_{2} \beta_{\lambda j}+\epsilon_{j} \quad j=1, \ldots, 30 .
$$

where

$$
Y_{j}=\frac{\bar{R}_{j}-R_{f}}{R_{w}-R_{f}} .
$$

The hypotheses to be tested are then

$$
\begin{array}{ll}
H_{0}: & a_{0}=0 \\
& a_{1}+a_{2}=1 \\
& a_{2}=\phi .
\end{array}
$$


Other tests are the same as described in Chapter Four. The purpose is to find out how this model explains the January effect, compared with the conventional CAPM. 
Table 15

\section{Hypotheses Testing \& Regression Results}

with Turn-of-Year Sample

\begin{tabular}{|c|c|c|c|c|c|c|c|}
\hline Model & $a_{0}$ & $a_{1}$ & $a_{2}$ & $\mathrm{R}^{2}$ & $t\left(a_{0}=0\right)$ & $\mathrm{t}\left(\mathrm{a}_{1}+\mathrm{a}_{2}=1\right)$ & $\mathrm{t}\left(\mathrm{a}_{2}=\phi\right)$ \\
\hline Jump-Diffusion & $\begin{array}{c}-1.8684 \\
(4.1465)\end{array}$ & $\begin{array}{c}-2.7366 \\
(0.7293)\end{array}$ & $\begin{array}{c}7.1246 \\
(4.0296)\end{array}$ & 0.3645 & -0.4506 & 0.8515 & 1.5350 \\
\hline & $b_{0}$ & $b_{1}$ & & $\mathrm{R}^{2}$ & $\mathrm{t}\left(\mathrm{b}_{0}=0\right)$ & $t\left(b_{1}=1\right)$ & \\
\hline \multirow[t]{2}{*}{ CAPM } & $\begin{array}{c}-3.7008 \\
(4.8048)\end{array}$ & $\begin{array}{c}6.5020 \\
(4.5815)\end{array}$ & & 0.0671 & -0.7702 & 1.2009 & \\
\hline & $c_{0}$ & $c_{1}$ & $\mathrm{c}_{2}$ & $\mathrm{R}^{2}$ & $\mathrm{t}\left(\mathrm{c}_{0}=0\right)$ & $t\left(c_{1}+c_{2}=1\right)$ & $\mathrm{t}\left(\mathrm{c}_{2}=\phi\right)$ \\
\hline $\begin{array}{c}\beta_{1}=c_{0}+c_{1} \beta_{i}+ \\
c_{2} \beta_{\Delta j}+\mu_{j}\end{array}$ & $\begin{array}{c}-0.0163 \\
(0.0296) \\
\end{array}$ & $\begin{array}{r}0.0064 \\
(0.0052) \\
\end{array}$ & $\begin{array}{c}1.0163 \\
(0.0288) \\
\end{array}$ & 0.9796 & -0.5512 & 0.7966 & $2.6772 *$ \\
\hline
\end{tabular}

Note: 1. Standard errors of estimations are listed with parentheses.

2. * indicates ratios are significant at 0.05 level. 
The results of hypotheses test show that the jump-diffusion model is a better model in explaining the January or turn-of-year effect than the CAPM based on $\mathrm{R}^{2}$. The jump-diffusion model is significantly different from the CAPM in terms of the risk measure specifications.

\subsection{COMPARISON BETWEEN THE JUMP-DIFFUSION MODEL AND THE FAMA AND FRENCH'S FIVE FACTOR MODEL}

Due to the great influence of Fama and French's five-factor model (1993), this study is bound to compare it with the Jump-Diffusion model. In order to do so, an exact sample (CRSP monthly data from July 1963 to December 1991) of 342 observations is used. Instead of forming 30 portfolios, only 20 portfolios are formed with the monthly sample. The monthly value-weighted market return index is used as $R_{w}$.

Fama and French use the following model to examine the January Effect:

$$
R(t)=a+b * J A N(t)+c
$$

where $\operatorname{JAN}(t)$ is a dummy variable that is 1 if month $t$ is January and 0 otherwise and $R(t)$ is the explanatory return of month $\mathrm{t}$ given by each of five factors. For easy comparison, table 16 is built based on Famal and French's result of the five risk factors model applying on the January effect. One can hardly conclude that the reported results by Famal and French are satisfactory. 
Table 16

Results of Fama and French's Five-Factor Model

\begin{tabular}{|c|c|c|c|c|}
\hline \multicolumn{5}{|c|}{ Fama and French's "Five-Factor Explanatory Returns" s } \\
\hline$R^{2}(\mathrm{RM}-\mathrm{RF})$ & $\mathrm{R}^{2}(\mathrm{SMB})$ & $\mathrm{R}^{2}(\mathrm{HML})$ & $\mathrm{R}^{2}(\mathrm{TERM})$ & $\mathrm{R}^{2}(\mathrm{DEF})$ \\
\hline 0.00 & 0.06 & 0.06 & -0.00 & 0.03 \\
\hline
\end{tabular}

where

RM = Value-weighted monthly stock market return

$\mathrm{RF} \quad=$ one-month Treasury bill rate

$\mathrm{SMB}=$ returns on the mimicking portfolios for the size factor in stock returns

$\mathrm{HML}=$ returns on the mimicking portfolios for the book-to-market factor in stock returns

TERM = LTG - RF where LTG is the long-term govermment bond return

$\mathrm{DEF}=\mathrm{CB}-\mathrm{LTG}$ where $\mathrm{CB}$ is the return on a proxy for the market portfolio of corporate bonds

In order to examine the January Effect with the Jump-Diffusion model with monthly data, a complete process of the estimation is run again. Results are summarized in Table 17 and Table 18. Since the goal of this part of research is to compare the JumpDiffusion model with the Fama and French's model, details of estimation are not reported.

5. Source: Famal and French, "Common Stock Fatctors in the Returns on Stocks and Bonds," Journal of Financial Economics, 1993, Table 10, p44. 
Table 17

\section{Results of Maximum Likelihood Estimation}

with Monthly Data

\begin{tabular}{|c|c|c|c|c|c|c|c|}
\hline Process & $\mu\left(\times 10^{-2}\right)$ & $\sigma^{2}\left(\times 10^{-3}\right)$ & $\lambda$ & $\theta\left(\times 10^{-2}\right)$ & $\delta^{2}\left(\times 10^{-3}\right)$ & $\begin{array}{c}\text { Log } \\
\text { Likclilood }\end{array}$ & Cli-Square \\
\hline Diflusion & $\begin{array}{c}0.8525 \\
(3.5127)\end{array}$ & $\begin{array}{c}2.0223 \\
(13.145)\end{array}$ & & & & 575.53 & \\
\hline Jump-Diffusion & $\begin{array}{c}1.2737 \\
(3.6866)\end{array}$ & $\begin{array}{c}1.0601 \\
(3.6851)\end{array}$ & $\begin{array}{c}0.3506 \\
(1.2476)\end{array}$ & $\begin{array}{c}-1.2010 \\
(-1.2856)\end{array}$ & $\begin{array}{c}2.5075 \\
(1.7145)\end{array}$ & 588.53 & $26^{*}$ \\
\hline
\end{tabular}

Note: Asymptotic t-statistics in parentheses. Pure diffusion process is modeled by $\mathrm{N}(\mu$, $\left.\sigma^{2}\right)$. The jump-diffusion process is the combined Poisson and Normal distribution, with mean rate of jump as $\lambda$ and size of jumps modeled by $N\left(\theta, \delta^{2}\right)$. The chi-square statistic (d.f. $=3$ ) tests the hypothesis of a pure diffusion process against a jump-diffusion process. * indicates significant at $1 \%$ level.

Table 18

Estimated Market Parameters

with Monthly Data Sample

\begin{tabular}{|c|c|c|c|}
\hline & Whole Sample & Jump & Diffusion \\
\hline $\mathrm{N}$ & 342 & 120 & 222 \\
\hline $\mathrm{ABS}\left(\mathrm{R}_{\mathrm{w}}\right)$ & 0.0349278 & 0.0592705 & 0.0217696 \\
\hline $\mathrm{R}_{w}$ & 0.0095734 & -0.004698 & 0.0172876 \\
\hline & $(0.0449385)$ & $(0.0682296)$ & $(0.0209512)$ \\
\hline$\lambda$ & 0.35 & & \\
\hline$\phi$ & 0.7882 & & \\
\hline $\mathrm{R}_{\mathrm{i}}$ & 0.00018563 & & \\
\hline
\end{tabular}


Once betas are estimated, run the following regression:

$$
R_{j}(t)=a+b * \bar{R}_{j}(t)+c * \operatorname{JAN}(t)+e_{j} \quad j=1, \ldots, 30
$$

where $\mathrm{R}_{\mathrm{j}}(\mathrm{t})$ is monthly portfolio return. $\vec{R}_{j}(t)$ is monthly estimated portfolio return using the Jump-Diffusion model. JAN $(t)$ is a dummy variable as defined by Fama and French. Comparing with the following model:

$$
R_{j}^{\prime}(t)=a^{\prime}+b^{\prime} * \bar{R}_{j}(t)+\epsilon_{j}^{\prime} \quad j=1, \ldots, 30 .
$$

where the dummy variable JAN(t) is added to capture the January Effect. $R(j(t)$ in equation (5.5) is also the monthly portfolio return. In their study on the jump-diffusion processes in the foreign exchange markets and the release of macrocconomic news, Johnson and Schneeweis (1994) incorporated such a variable to examine the impact of the release of macroeconomic news (p312). If January Effect does exist, equation (5.4) would have better fit than equation (5.5).

The regression results of equation (5.4) and (5.5) are reported in Table 19. The higher value of $\mathrm{R}^{2}$ and better estimates of parameters show that taking account of the January Effect certainly improves fitness of the regression model. Therefore, we conclude that the January Effect does exist.

Comparing values of $\mathrm{R}^{2}$ in Table 19 with those in Table 16, the results of Famal and French, it is not difficult to conclude that the Jump Diffusion model is a better model to explain the January Effect. 


\section{Table 19}

Regression Results of Monthly Sample

342 Months: from July 1963 to December 1991

\begin{tabular}{|c|c|c|c|c|c|c|c|}
\hline & al & $\underline{b}$ & $\underline{\mathbf{c}}$ & $\underline{\mathrm{R}^{2}}$ & $\underline{i l}^{+}$ & $\underline{b^{\prime}}$ & $\underline{\mathrm{R}^{\prime 2}}$ \\
\hline \multirow[t]{2}{*}{ P 1} & 0.001 & 0.962 & 0.105 & 0.490 & 0.009 & 1.012 & 0.3847 \\
\hline & $(0.289)$ & $(15.232)$ & $(8.653)$ & & $(2.42 .3)$ & $(14.579)$ & \\
\hline \multirow[t]{2}{*}{$P 2$} & -0.004 & 0.972 & 0.091 & 0.586 & 0.00 .3 & 1.015 & $0.4 \pi+1$ \\
\hline & $(-1.481)$ & $(19.005)$ & $(9.153)$ & & $(0.874)$ & $(17.86 .3)$ & \\
\hline \multirow[t]{2}{*}{ P 3} & $-0.0(0) 4$ & 0.981 & 0.081 & 0.618 & 0.002 & 1.019 & 0.5290 \\
\hline & $(-1.59)$ & $(20.757)$ & $(8.858)$ & & $(0.705 .5)$ & $(19.54)$ & \\
\hline \multirow[t]{2}{*}{ P 4} & -0.004 & 0.979 & 0.069 & 0.657 & 0.008 & 1.011 & 0.5873 \\
\hline & $(-1.862)$ & $(23.238)$ & $(8.299)$ & & $(0.316)$ & (21.997) & \\
\hline \multirow[t]{2}{*}{ P 5} & -0.004 & 0.976 & 0.065 & 0.679 & 0.0006 & 1.005 & 0.6143 \\
\hline & $(-1.917)$ & $(24.607)$ & $(8.245)$ & & $(0.25)$ & $(23.273)$ & \\
\hline \multirow[t]{2}{*}{ P 6} & -0.002 & 0.986 & 0.058 & 0.699 & 0.002 & 1.013 & 0.6435 \\
\hline & $(-0.951)$ & $(20.104)$ & $(7.937)$ & & $(1.045)$ & $(24.773)$ & \\
\hline \multirow[t]{2}{*}{ P 7} & -0.003 & 0.986 & 0.048 & 0.722 & 0.0004 & 1.0000 & 0.6808 \\
\hline & $(-1.688)$ & $(28.042)$ & $(7.065)$ & & $(0.175)$ & $(26.931)$ & \\
\hline \multirow[t]{2}{*}{ P 8} & -0.03 & 0.987 & 0.044 & 0.731 & 0.0004 & 1.008 & $0 .\left(b^{4}\right)\left(3^{4}\right)$ \\
\hline & $(-1.545)$ & $(28.9(02)$ & $(6.521)$ & & $(0.176)$ & $(27,96)$ & \\
\hline \multirow[t]{2}{*}{ PQ } & $-(0.003$ & 0.970 & 0.043 & 0.75 .5 & 0.0002 & 1.01 & 0.7216 \\
\hline & $(-1.713)$ & $(30.851)$ & $(6.804)$ & & $(0.085 .5)$ & $(29.686)$ & \\
\hline \multirow[t]{2}{*}{ PIO } & -0.002 & 0.985 & 0.038 & 0.801 & 0.0005 & 1.002 & 0.7789 \\
\hline & $(-1.50 .3)$ & $(30.07 .3)$ & $(6.813)$ & & $(0.292)$ & $(34.606)$ & \\
\hline \multirow[t]{2}{*}{ P 11} & $-(0.002$ & 0.987 & 0.031 & 0.810 & 0.0004 & 1.002 & 0.7899 \\
\hline & $(-1.289)$ & $(.36 .795)$ & $(5.908)$ & & $(0.27)$ & $(35.748)$ & \\
\hline \multirow[t]{2}{*}{ P12 } & -0.0016 & 0.9998 & 0.024 & 0.826 & 0.00002 & 1.011 & 0.81 .35 \\
\hline & $(-1.15)$ & $(39.169)$ & $(4.869)$ & & $(0.139)$ & $(38.511)$ & \\
\hline \multirow[t]{2}{*}{$P 1.3$} & -0.0003 & 0.906 & 0.023 & 0.84 .3 & 0.001 & 1.0007 & $0.53(3)$ \\
\hline & $(-0.252)$ & $(41.098)$ & $(5.067)$ & & $(1.09)$ & $(.40 .877)$ & \\
\hline \multirow[t]{2}{*}{ P 14} & $-(0.00 \mid 7$ & 0.992 & 0.022 & 0.861 & $-(0.000) 1$ & 1.002 & $0.8+42$ \\
\hline & $(-1.455)$ & $(44.788)$ & $(5.29)$ & & $(-0.0)(1)$ & 43.755 & \\
\hline \multirow[t]{2}{*}{ P 15} & -0.00013 & 0.991 & 0.016 & 0.891 & 0.0009 & 0.9986 & 0.88 .50 \\
\hline & $(-0.321)$ & $(51.938)$ & $(4.481)$ & & $(0.872)$ & $(.51 .148)$ & \\
\hline \multirow[t]{2}{*}{ P 16} & -0.0005 & 0.992 & 0.011 & $0.9(09$ & 0.0003 & 0.9977 & 0.90 .57 \\
\hline & $(-0.589)$ & $(57.506)$ & $(3.445)$ & & $(0.329)$ & $(57.154)$ & \\
\hline \multirow[t]{2}{*}{ P 17} & -0.0003 & 0.9917 & 0.000 & 0.921 & $0.000)+$ & 0.9961 & 0.9188 \\
\hline & $(-0.367)$ & $(62.244)$ & $(3.044)$ & & $(0.44(9)$ & $(62.0 .31)$ & \\
\hline \multirow[t]{2}{*}{ PI8 } & $0 .(0)(0) 1$ & 0.9922 & 0.0304 & 0.940 & 0.0004 & 0.994 & 0.9 .394 \\
\hline & $(0.16 .3)$ & $(72.322)$ & $(1.567)$ & & $(0.598)$ & $(72.611)$ & \\
\hline \multirow[t]{2}{*}{$P 19$} & $-0.00(12$ & 0.9889 & 0.0018 & 0.95 .3 & $0.000)+$ & 0.99 .3 & $0.95(1.4$ \\
\hline & $(-(0.385)$ & $(81.737)$ & $(3.968)$ & & $(0.674)$ & $(80.707)$ & \\
\hline \multirow[t]{2}{*}{ P 20} & 0.0002 & 0.009 & -0.001 & 0.959 & 0.0002 & 0.998 & 0.9542 \\
\hline & $(0.455)$ & $(88.966)$ & $(-(0.485)$ & & $(0.339)$ & $(89.392)$ & \\
\hline
\end{tabular}

Note: t-statistics in parentheses. $a, b$, and $c$ are coefficients estimated with equation (5.4). $a^{\prime}$ and $b^{\prime}$ are coefficients estimated with equation (5.5). 


\section{CHAPTER SIX}

\section{CONCLUSION}

This empirical study is based on the jump-diffusion asset pricing model developed by Hsia (1992). Employing all valid trading stocks in the NYSE and AMEX during the Gulf War period, the specifications of the jump-diffusion model are tested. The comparison between the jump-diffusion model and the conventional CAPM is carried out from two perspectives: on the specification of the CAPM and on the comparison of risk measures of two models. Then the application of the jump-diffusion model on Jantaary effect studies is executed in the same degree of strict manner as in the specification testing section. Findings generally favor the jump-diffusion model, especially in the January effect study. However, it is noticed that the jump-diffusion model is not as general as it is theoretically proved. It works much better than the conventional CAPM in studying period that is more eventful or when jumps are more frequent. In the period when diffusion is dominant, the jump-diffusion model does not work as well as the CAPM which is a diffusion model. That the jump-diffusion model does not converge to the diffusion CAPM should be a subject of future studies.

The major contribution of this empirical study is that it undertakes the challenge to identily the jump process from the diffusion process. It employs an innovative method 
which combines the efficient maximum likelihood estimation and concept of stochastic switching. The graphical results show that this is a reliable, efficient and sensible method. It makes the future jump-diffusion study easier and enhances the possibility of applying the jump-diffusion asset pricing model to financial practices.

\subsection{POTENTIAL APPLICATIONS}

Despite its limitations, the jump-diffusion model is an improvement over current asset pricing tools. The concept of mixed jump-diffusion processes should be useful in fields other than finance, including any discipline in the social sciences concerning the adoption of technology or social change. In the world of investment, two betals should make more sense than one beta. Current rating services such as Moody's, Standard and Poors, publish one beta as a risk factor. It would be to the users' advantage if they could publish two betas instead. Every industry has a different kind of business. External factors, such as policy change, have different focuses. Therefore, different securities should have different jump risks, associated with external factors, and different diffusion risks, associated with normal demand and supply movement. For example, policy regulating high-tech industry would affect Sears much less than Microsoft. Defense industry stocks maly perform well during a wall period but not be exciting during pealce. Even a common factor like interest rate change would have a diferent impact on a highly leveraged industry than on one that is not highly leveraged. Stocks of industries that are sensitive to external influences would certininly have higher jump beta than other stocks. 
While diffusion beta measures the security's relative risk to the market during normal times, jump beta measures its relative risk to the market during extraordinary times. This fact should be of interest to portfolio managers and sophisticated investors.

\subsection{REMARKS ON FOLLOW-UP STUDIES}

The jump-diffusion model has the potential to directly utilize deterministic switching (Goldfeld and Quandt, 10). Rewrite the model as

$$
\bar{R}_{j}=R_{f}+(1-\phi)\left(\bar{R}_{w}-R_{f}\right) \beta_{j}+\phi\left(\bar{R}_{w}-R_{f}\right) \beta_{\Lambda j}
$$

This coincides with the combined two-structure switching regression equation. It combines the following two equations:

$$
\bar{R}_{j}=R_{t}+\left(\bar{R}_{w}-R_{f}\right) \beta_{j}+\mathrm{k}_{j} \quad j \in[\text { diffusion }]
$$

and

$$
\bar{R}_{\Lambda j}=R_{\bar{f}}+\left(\bar{R}_{\Lambda w}-R_{f}\right) \beta_{\Lambda j}+\mathrm{K}_{\Lambda j} \quad \Delta j \in[j u m p]
$$

Multiplying (6.2) with $(1-\phi)$ and (6.3) with $\phi$, we get the switching regression function

$$
\left.\bar{R}_{j}=R_{f}+(1-\phi)\right)\left(\bar{R}_{w}-R_{f}\right) \beta_{j}+\phi\left(\bar{R}_{w}-R_{t}\right) \beta_{\Lambda j}+(1-\phi) \mathrm{K}_{j}+\phi \mathrm{K}_{\Lambda j}
$$

in which same number of parameters must be estimated. 
According to equation (6.4), the expected return is the combination of the excessive return associated with the diffusion risk and that with the jump risk. Two structures (processes) are clearly defined in equation (6.4). The challenge is to approximate $\phi($ or $\lambda$ ) with a continuous function if adopting Goldfeld and Quandt's method.

The potential of equation (6.4) is great. Since all needed parameters, including $\phi$, $\beta_{\mathrm{j}}$, and $\beta_{\Delta \mathrm{j}}$ can be estimated with one equation, problems associated with error-in-variable caused by several steps of estimation are eliminated. Therefore, results are more reliable. Unfortunately, the theoretical work on this suggestion is beyond the scope of this dissertation. Thus, it is pointed out for the future research. Until then, the method suggested in this dissertation works the best with jump-diffusion processes. 


\section{REFERENCES}

1. Ball, C. A., and W. N. Torous, "A Simplified Jump Process for Common Stock Returns," Journal of Financial and Quantitative Analysis, 18(1), 1983, 53-65.

2. _ _ "On Jumps in Common Stock Prices And Their Impact on Call Option Pricing," The Journal of Finance, 40, 155-173.

3. Banz, R. W., "The Relationship between Return and Market Value of Common Stocks," Journal of Financial Economics, 9, 1981, 3-18.

4. $\quad$ Bates, David S., "The Crash of '87: Was It Expected? The Evidence from Option Markets," The Journal of Finance, 46(3), July 1991, 1009-1044.

5. Beckers, S. "A Note on Estimating The Parameters of The Diffusion-Jump Model of Stock Returns," Joumal of Financial and Quantitative Analysis, 16(1), March 1981, 127-140.

6. Bhardwaj, Ravinder K. and Leroy D. Brooks, "The January Anomaly: Effects of Low Share Price, Transaction Costs, And Bid-Ask Bias," The Journal of Finance, Vol. 47, June 1992, 553-575.

7. Black, Fischer, "Capital Market Equilibrium with Restricted Borrowing," Joumal of Business, 45, July 1972, 444-455.

8. _. Michael C. Jensen, and Myron Scholes, "The Capital Asset Pricing Model: Some Empirical Tests," in Michael C. Jensen, editor, Studies in the Theory of Capital Markets, New York: Praeger, 1972

9. __ and M. Scholes, "The Pricing of Options and Corporate Liabilities," Joumil of Political Economy, May-June 1973, 637-659.

10. __ and Irwin Friend, "A New Look at The Capital Asset Pricing Model," The Journal of Finance, 28, March 1973, 19-33.

11. Bower, Dorothy H., Richard S. Bower, and Dennis E. Logue, " Arbitrage Pricing Theory and Utility Stock Returns," The Jourmal of Finance, 39, september 1984. $1041-1054$.

12. Brennan, Michael J., "Taxes, Market Valuation and Corporation Financial 
Policy," National Tax Joumal, December 1970, 417-427.

13. __ and Eduardo S. Schwartz, "Finite Difference Methods and Jump Processes Arising in the Pricing of Contingent Claims: A Synthesis," Journal of Financial and Quantitative Analysis, 13, September 1978, 461-474.

15. Brown, Stephen, and Mark Weinstein, "A New Approach to Testing Asset Pricing Theories: The Billinear Paradigm," The Journal of Finance, 38, June 1983, 711743.

16. Chen, Nai-fu, "Some Empirical Tests of the Theory of Arbitrage Pricing," The Journal of Finance, 38, December 1983, 1393-1414.

17. Clark, P., "A Subordinated Stochastic Process with Finite Variance for Speculative Prices," Econometrica, 41, 1973, 135-155.

18. Copeland, Thomas E., and J. F. Weston, Financial Theory and Corporate Policy. 3rd Edition, Mass.: Addison-Wesley, 1988.

19. Cox, J. C., and S. A. Ross, "The Valuation of Options for Alternative Stochastic Processes," Journal of Financial Economics, 3, 1976, 145-166.

20. Dybvig, Philip H., and Stephen A. Ross, "Yes, the APT Is Testable," The Journal of Finance, 40, September 1985, 1173-1188.

21. Fama, F. Eugene, "The Behavior of Stock Market Prices," Journal of Business, 38, January 1965, 34-105.

22. _. and Kenneth R. French, "The Cross-Section of Expected Stock Returns," Journal of Finance, 1992, Vol. 47, 427-465.

23. _ _ and ___ "Common Risk Factors in the Returns on Stocks and Bonds," Iournal of Financial Economics, 1993, Vol. 33, 3-56.

23. _, and Merton H. Miller, The Therry of Finance, 1972, New York: Holt.

24. _ and James D. MacBeth, "Risk, Return and Equilibrium: Empirical Test," Journal of Political Economy, May-June 1973, 607-636.

25. Fomby, Thomas B., R. Carter Hill, and Stanley R. Johnson, Advanced Econometrics Methods, 1984, Springer-Verlag New York Inc., 603-614.

26. Friend, Irwin and Marshall E. Blume, "Meatsurement of Portholio Performance 
under Uncertainty," American Economic Review, September 1970, 561-575.

27. __ Woram Landskroner, and Etienne Losq, "The Demand for Risky Assets Under Uncertain Inflation," The Journal of Finance, 31, December 1976, 1287 1298.

28. ___ Randolph Westerfield, and Michael Granito, "New Evidence on the Capital Asset Pricing Model," 33(3), The Journal of Finance, June 1978, 903-917.

29. Goldfeld, Stephen M and Richard E. Quandt, ed., Studies in Nonlinear Estimation, 1974, Ballinger Publishing Company, Cambridge, Mass.

30. Greene, William H., Econometric Analysis, 1990, Macmillan Publishing Company, New York.

31. Hoel, Port and Stone, Introduction to Statistical Theory, 1971, Houghton Mifflin, $172-174$

32. Hsia, Chi-Cheng, "Coherence of the Modern Theories of Finance," The Financial Review, 1981, 27-42.

33. __ "A Jump-Diffusion Asset Pricing Model," working paper, 1992, Portland State University.

34. Jensen, Michael C., "Capital Markets: Theory and Evidence," Bell Journal of Economics and Maniggement Science, Autumn 1972, 357-398.

35. Johnson, Gordon and Thomas Schneeweis, "Jump-Diffusion Processes in the Foreign Exchange Markets and the Release of Macroeconomic News," Computational Economics, 1994, Vol. 7, 309-329.

36. Jorion, Philippe, "On Jump Processes In The Foreign Exchange And Stock Markets," The Review of Financial Studies, 1988, VOL. 1, NO. 4, 427-445.

37. Keim, Donald B., "Size-Related Anomalies and Stock Return Seasonality: Further Empirical Evidence," Journal of Financial Economics, 12, 1983, 13-32.

38. _. "The CAPM and Equity Return Regularities," Financial Analysts Joumal, 42, Maly-June 1986, 19-34.

39. —, and Robert F. Stambaugh, "Predieting Returns in the Stock and Bond Markets," Iournal of Financial Economics, 17, December 1986, 357-390. 
40. Lakonishok, J., and S. Smidt, "Are Seasonal Anomalies Real? A Ninety-ycal" Perspective," Review of Financial Studies, 1, 403-425.

41. Lintner, John, "The Valuation of Risk Assets and the Selection of Risky Investments in Stock Portfolios and Capital Budgets," Review of Economics and Statistics, 47, February 1965, 13-37.

42. Litzenberger, Robert H., and Krishina Ramaswamy, "The Effect of Personal Taxes and Dividends on Capital Asset Prices," Journal of Financial Economics, 7, June 1979, 163-195.

43. Markowitz, Harry M., Portfolio Selection: Efficient Diversification of Investment. New York: John Wiley, 1959.

44. Mayers, David, "Non-Marketable Assets and the Capital Market Equilibrium under Uncertainty," in Jensen, ed., Studies in the Theory' of Capital Markets, New York: Praeger, 1972.

45. Melino, Angelo and Stuart M. Turnbull, "Pricing Foreign Currency Options with Stochastic Volatility," Journal of Econometrics, Vol 45, 1990, 239- 265.

46. Merton, R. C., "Option Pricing When Underlying Stock Returns Are Discontinuous," Journal of Financial Economics, 3, 1976, 125-144.

47. Miller, Merton H. and Myron Scholes, "Rates of Return in Relation to Risk: A Re-examination of Some Recent Finds," in Michael C. Jensen, editor, Studiess in the Theory of Capital Markets, New York: Praeger, 1972.

48. Modigliani, Franco, and Gerald A. Pogue, "An Introduction to Risk and Return," Financial Analysts Journal, 30, March-april 1974, 68-80, and Maly-June, 69-86.

49. Mullins, David W., Jr., "does the Capital Asset Pricing Model Work"?" Harvalrd Business Review, 60, January-February 1982, 105-114.

50. Naik, Vasanttilak and Moon Lee, "General Equilibrium Pricing of Options on The Market Portfolio with Discontinuous Returns," The Review of Financial Studies, 1990, Vol. 3, No. 4, 493-521.

51. Oldfield, G. S., R. J. Rogalski, and R. A. Jarrow, "An Autoregressive Jump Process for Common Stock Returns," Journal of Financial Economics, 5, 1977, $389-418$.

52. Omberg, Edward, "Efficient Discrete Time Jump Process Models in Option 
Pricing," Journal of Financial and Quantitative Analysis, 23, 1988, 161-174.

53. Praetz, P., "The Distribution of Share Price Changes," Journal of Business, Vol. 45, 1972, 49-55.

54. Press, J., "A Compound Events Model of Security Prices," Journal of Business, Vol. 40, 1967, 317-335

55. Reinganum, Marc R., "The Arbitrage Pricing Theory: Some Empirical Results," The Journal of Finance, 36, May 1981, 313-322.

56. Roll, R., "A Critique of the Asset Pricing Theory's Tests," Journal of Financial Economics, 4, March 1977, 129-176.

57. _. "Performance Evaluation and Benchmark Errors," Journal of Portfolio Management, 6, Summer 1980, 5-12.

58. _ _ and Stephen A. Ross, "An Empirical Investigation of the Arbitrage Pricing Theory," The Journal of Finance, 35, December 1980, 1073-1103.

59. _ _ "Vas Ist Das? The Turn of The Year Effect and The Return Premium of Small Firms," Journal of Portfolio Management, 9, Winter 1983, 18-28.

60. __, "Presidential Address: $R^{2}$," The Journal of Finance, 43(3), 1988, 541-566.

61. "The Capital Asset Pricing Model and the Market Model," Journal of Portfolio Management, 7, Winter 1981, 5-16.

62. Ross, Stephen A., "The Arbitrage Theory of Capital Asset Pricing," Journal of Economic Theory, 13, December 1976, 341-360.

63. Sharpe, William F., "Capital Asset Prices: A Theory of Market Equilibrium Under" Conditions of Risk," The Journal of Finance, 19, September 1964, 425-442.

64. Trzcinka, Charles, "On the Number of Factors in the Arbitrage Pricing Model," The Jourmal of Finance, 41, June 1986, 347-368.

65. F__ Financial Management and Policy, Sth Edition, Englewood Cliffs, New Jersey: Prentice Hall, 1989.

66. Wiggins, James B., "Option Values Under Stochastic Volatility," Ioumal of Financial Economics, Vol 19, 1987, 351-372. 


\section{APPENDIX A:}

DERIVATION OF THE MEAN-VARIANCE EFFICIENT FRONTIER

I. Objective Function

$$
\begin{gathered}
\text { Minimize } \sigma^{2}{ }_{\mathrm{p}}=\mathrm{X}^{\prime} \mathrm{VX} \\
\text { s.t. } \quad \mathrm{X}^{\prime} \mathrm{E}=\mathrm{E}_{\mathrm{p}} \\
\mathrm{X}^{\prime} \mathrm{L}=1 .
\end{gathered}
$$

II. The Lagrangian Function

$$
L=X^{\prime} V X-a l\left(X^{\prime} E-E p\right)-a 2\left(X^{\prime} L-1\right) .
$$

Let $\quad \partial \mathrm{L} / \partial \mathrm{X}=2 \mathrm{VX}-\mathrm{a} \mid \mathrm{E}-\mathrm{a} 2 \mathrm{~L}=0$,

we then get

$$
V X=\frac{1}{2}\left(\begin{array}{ll}
E & L
\end{array}\right)\left(\begin{array}{l}
a_{1} \\
a_{2}
\end{array}\right),
$$

which implies that

$$
X=\frac{1}{2} V^{-1}\left(\begin{array}{ll}
E & L
\end{array}\right)\left(\begin{array}{l}
a_{1} \\
a_{2}
\end{array}\right) .
$$

Pre-multiply (A.3) by (E L)', we obtain

$$
\left(\begin{array}{ll}
E & L
\end{array}\right)^{\prime} X=\frac{1}{2}\left(\begin{array}{ll}
E L & L
\end{array}\right)^{\prime} V^{-1}\left(\begin{array}{ll}
E & L
\end{array}\right)\left(\begin{array}{l}
a_{1} \\
a_{2}
\end{array}\right) .
$$

Let $\quad G=(E L)^{\prime} V^{-1}(E L)$,

then $\quad(E \quad L)^{\prime} X=\frac{1}{2} G\left(\begin{array}{l}a_{1} \\ a_{2}\end{array}\right)$. 
Therefore, substitute (AIa) and (AIb) to obtain

$$
\begin{aligned}
& \frac{1}{2}\left(\begin{array}{l}
a_{1} \\
a_{2}
\end{array}\right)=G^{-1}\left(\begin{array}{ll}
E & L
\end{array}\right)^{\prime} X \\
& =G^{-1}\left(\begin{array}{c}
E_{p} \\
1
\end{array}\right) \text {. }
\end{aligned}
$$

Now substitute (A5) to (A3), it yields

$$
X=V^{-1}\left(\begin{array}{ll}
E & L
\end{array}\right) G^{-1}\left(\begin{array}{c}
E_{p} \\
1
\end{array}\right) .
$$

Substitute (A6) to (A1), the objective function becomes

$$
\begin{aligned}
\sigma_{p}^{2}=X^{\prime} V X & =X^{\prime}\left(\begin{array}{ll}
E & L
\end{array}\right) G^{-1}\left(\begin{array}{c}
E_{p} \\
1 \\
E_{p} \\
1
\end{array}\right) . \\
& =X^{\prime}\left(\begin{array}{ll}
E & L
\end{array}\right) G^{-1} \\
& =\left(\begin{array}{ll}
E_{p} & 1
\end{array}\right) G^{-1}\left(\begin{array}{c}
E_{p} \\
1
\end{array}\right)
\end{aligned}
$$

III. The Value of $\mathrm{G}^{-1}$

Recall that

$$
\begin{aligned}
& G=\left(\begin{array}{ll}
E & L
\end{array}\right)^{\prime} V^{-1}\left(\begin{array}{ll}
E & L
\end{array}\right) \\
& =\left[\begin{array}{ll}
E^{\prime} V^{-1} E & L^{\prime} V^{-1} E \\
E^{\prime} V^{-1} L & L^{\prime} V^{-1} L
\end{array}\right] \\
& =\left[\begin{array}{ll}
B & A \\
A & C
\end{array}\right]
\end{aligned}
$$

Thus

where

$$
G^{1}=\frac{1}{D}\left|\begin{array}{cc}
C & -A \\
-A & B
\end{array}\right|
$$

$$
D=B C-A^{2}>0
$$


IV. The Parabolic Function of A Mean-Variance Efficient Frontier:

Substitute (A8) back to (A7), we can obtain

$$
\begin{aligned}
& \sigma_{p}^{2}=\left(\begin{array}{ll}
E_{p} & 1
\end{array}\right)\left(\frac{1}{D}\right)\left[\begin{array}{cc}
C & -A \\
-A & B
\end{array}\right]\left(\begin{array}{c}
E_{p} \\
1
\end{array}\right) \text {, } \\
& =\frac{1}{D}\left(C E_{p}^{2}-2 A E_{p}+B\right)
\end{aligned}
$$

the minimum variance frontier as a parabola in the $\left(E, \sigma^{2}\right)$ space.

V. The Global Minimum Variance Portfolio (GMVP):

It is easy to derive that GMVP is

$$
\begin{aligned}
& E_{0}=A / C \\
& \sigma_{0}^{2}=1 / C .
\end{aligned}
$$

VI. The Market Portfolio with the Existence of $\mathrm{R}_{\mathrm{r}}$ :

$$
\begin{gathered}
E_{m}=\frac{B-A R_{f}}{A-C R_{f}} \\
\sigma_{m}^{2}=\frac{E_{m}-R_{f}}{A \cdot C R_{f}}
\end{gathered}
$$

VII. The Composition of Efficient Portfolios

Substitute (A8) back to (A6), we get

$$
X=V^{-1}\left(\tau_{1} E+\tau_{2} L\right)
$$

where

$$
\tau_{1}=\left(C E_{p}-A\right) / D
$$




$$
\tau_{2}=\left(-A E_{p}+B\right) / D
$$


APPENDIX B:

DERIVATION OF THE JUMP-DIFFUSION TWO-BETA ASSET PRICING MODEL

In his Proposition A1, Bates (1991, p1039) shows that when asset prices follow jump-diffusion processes the equilibrium cum-dividend excess return is

$$
\mu-\mathrm{r}=\mathrm{R}(\mathrm{W}, \mathrm{t}) \mathrm{E}_{\mathrm{dq}=0}\left[(\mathrm{dS} / \mathrm{S})(\mathrm{dW} / \mathrm{W})-\lambda \mathrm{E}_{\mathrm{dq}=1}\left[\left(\Delta \mathrm{J}_{\mathrm{w}} / \mathrm{J}_{\mathrm{w}}\right)(\Delta \mathrm{S} / \mathrm{S})\right],\right.
$$

where

$$
d S / S=\left(\mu-\lambda K-d_{t}\right) d t+\sigma d z+K d q
$$

which is equation (4) of Bates (p1023), and

$$
d W / W=\left(\mu_{w}-\lambda K_{w}-C / W\right) d t+\sigma_{w} d z_{w}+K_{w} d q
$$

which is equation (8) of Bates (p1024), and

$$
\Delta \mathrm{J}_{\mathrm{w}} / \mathrm{J}_{\mathrm{w}}=\left(1+\mathrm{K}_{\mathrm{w}}\right)^{-\mathrm{R}}-1
$$

which appears in page 1039 of Bates, and

$\Delta \mathrm{S} / \mathrm{S}=\mathrm{K}=$ the percent discrete rate of return on the asset

when jump occurring.

The notations are defined as follow:

$\mu=$ instantaneous cum-dividend expected return on the asset, and $\mu_{\mathrm{w}}$ is similarly defined for optimally invested wealth

$r=\quad$ instantaneous riskless rate, a constant, which is endogenously derived from the model (p1039)

$E=\quad$ expectations operator

$S=\quad$ cum-dividend stock price

$\mathrm{W}=$ optimally invested wealth 


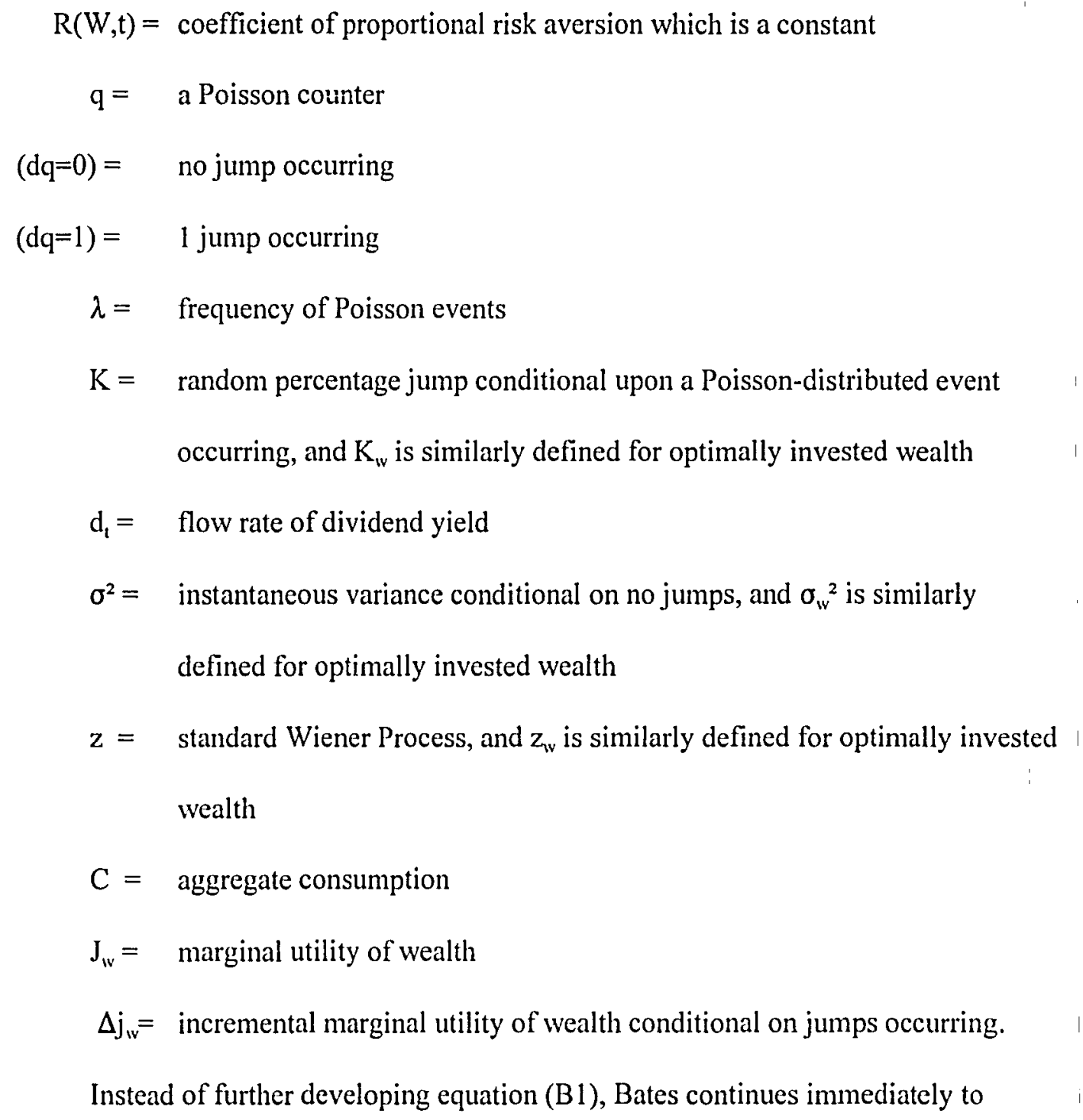

develop his option pricing model on financial futures. Equation (B1) is interesting and innovative, but it needs further development because it has unobservable parameters. This Appendix is devoted to continue the development of the jump-diffusion two-beta asset pricing model on the basis of Bates foundation.

Note that the left hand side (LHS) of equation (B1), $\mu-r$, is the excess return on a risky asset, while the right hand side (RHS) of (B1) is composed of two risk premiums, 
$\mathrm{RP}^{\mathrm{D}}$ and $\mathrm{RP}$, where

$$
R P^{D} \text { (premium for diffusion risk) }=\operatorname{Re}_{\mathrm{dq}=0}[(\mathrm{dS} / \mathrm{S})(\mathrm{dW} / \mathrm{W})]
$$

and $\quad R P^{J}$ (premium for jump risk) $=\lambda E_{\mathrm{dq}=1}\left[\left(\Delta J_{w} / J_{w}\right)(\Delta S / S)\right]$.

These two risk premiums are developed respectively in the following:

\section{A. Premium for Diffusion Risk}

Equation (B2a) looks familiar to finance readers. It can be written as

$$
R P^{D}=R \operatorname{Cov}\left(r_{w}, r_{s}\right)
$$

because $(d W / W)$ is a zero-mean increment in wealth, and $d W / W=r_{w}, d S / S=r_{s}$, respectively, where $r_{w}$ and $r_{5}$ are instantaneous returns on the optimally invested wealth and the asset, respectively, conditional on no jumps occurring. The $\operatorname{Cov}\left(r_{w}, r_{s}\right)$ is the instantaneous covariance per unit time between the asset and wealth returns conditional on no jumps. Not surprisingly, Bates also write $R P^{D}=R(W, t) \sigma_{s w}$ in his equation (5) on page 1039, which is same as Equation (B3) presented above.

\section{B. Premium for Jump Risk}

The premium for jump risk is more complicated because it involves an unobservable term, $\Delta \mathrm{J}_{\mathrm{w}} / \mathrm{J}_{\mathrm{w}}$. However, as a first step, equation (B2b) can also be written as a covariance,

$$
R P^{J}=\lambda \operatorname{Cov}\left(\Delta \mathrm{J}_{w} / J_{\mathrm{w}}, \Delta \mathrm{S} / \mathrm{S}\right)
$$

because $\Delta \mathrm{J}_{w} / \mathrm{J}_{\mathrm{w}}$ is also a zero-mean increment. Now we treat the term $\Delta \mathrm{J}_{\mathrm{w}} / \mathrm{J}_{\mathrm{w}}$. Using (BIc) to obtain $\left[1+\left(\Delta \mathrm{J}_{\mathrm{w}} / \mathrm{J}_{\mathrm{w}}\right)\right]=\left[\left(1+\mathrm{K}_{\mathrm{w}}\right)^{-\mathrm{R}}\right]$ which by taking logarithm on both sides is 


$$
\ln \left(1+\Delta \mathrm{J}_{\mathrm{w}} / \mathrm{J}_{\mathrm{w}}\right)=-\mathrm{R} \ln \left(1+\mathrm{K}_{\mathrm{w}}\right)
$$

Expanding the LHS and RHS of (B5) respectively, and collecting the second and higher order terms, and because $K_{w}=\Delta W / W$, we have

$$
\left(\Delta \mathrm{J}_{\mathrm{w}} / \mathrm{J}_{\mathrm{w}}\right)=-\mathrm{R}(\Delta \mathrm{W} / \mathrm{W})+\xi
$$

where

$$
\begin{aligned}
\xi=(1 / 2)\left[\left(\Delta \mathrm{J}_{\mathrm{w}} / \mathrm{J}_{\mathrm{w}}\right)^{2}+\mathrm{R}(\Delta \mathrm{W} / \mathrm{W})^{2}\right] \\
\quad-(1 / 3)\left[\left(\Delta \mathrm{J}_{\mathrm{w}} / \mathrm{J}_{\mathrm{w}}\right)^{3}+\mathrm{R}(\Delta \mathrm{W} / \mathrm{W})^{3}\right]+\ldots
\end{aligned}
$$

Substituting (B6) back to (B4) and since $\operatorname{Cov}(\xi, \Delta S / S)=0$, we have

$$
R P^{J}=-\lambda \operatorname{RCov}(\Delta W / W, \Delta S / S)
$$

Defining $\Delta r_{\mathrm{w}}=\Delta \mathrm{W} / \mathrm{W}$ and $\Delta \mathrm{r}_{\mathrm{s}}=\Delta \mathrm{S} / \mathrm{S}$ as the discrete rate of return on the optimally invested wealth and the asset, respectively, conditional on jumps occurring, (B7) is rewritten as

$$
R P^{J}=-\lambda R \operatorname{Cov}\left(\Delta r_{w}, \Delta r_{s}\right)
$$

\section{The Jump-Diffusion Asset Pricing Model}

Substituting (B3) and (B8) back to (B2a) and (B2b), respectively, which in turn are substituted back to (B1), we have

$$
\begin{aligned}
\mu-r= & R \operatorname{Cov}\left(r_{s}, r_{w}\right)+\lambda R \operatorname{Cov}\left(\Delta r_{s}, \Delta r_{w}\right) \\
= & R\left[\operatorname{Cov}\left(r_{s}, r_{w}\right)+\lambda \operatorname{Cov}\left(\Delta r_{s}, \Delta r_{w}\right)\right] .
\end{aligned}
$$

Since $\mu_{w}$, the instantaneous expected return on the optimally invested wealth, must also satisfy (B9), we have

$$
\mu_{w}-r=R\left[\sigma^{2}\left(r_{w}\right)+\lambda \sigma^{2}\left(\Delta r_{w}\right)\right]
$$


which implies

$$
R=\frac{\mu_{w}-r}{\sigma^{2}\left(r_{w}\right)+\sigma^{2}\left(\Delta r_{w}\right)} .
$$

Substitute (B10) in (B9), it yields

$$
\mu-r=\left(\mu_{w}-r\right) \frac{\operatorname{Cov}\left(r_{s}, r_{w}\right)+\lambda \operatorname{Cov}\left(\Delta r_{s}, \Delta r_{w}\right)}{\sigma^{2}\left(r_{w}\right)+\lambda \sigma 2\left(\Delta r_{w}\right)}
$$

and simplified to be

$$
\mu-r=\left(\mu_{w}-r\right)\left[(1-\phi) \beta_{s}+\phi \beta_{\Delta s}\right]
$$

where

$$
\begin{aligned}
& \beta_{s}=\frac{\operatorname{Cov}\left(r_{s}, r_{w}\right)}{\sigma^{2}\left(r_{w}\right)}=\operatorname{diffusion} \beta \\
& \beta_{\Delta s}=\frac{\operatorname{Cov}\left(\Delta r_{s}, \Delta r_{w}\right)}{\sigma^{2}\left(\Delta r_{w}\right)}=\text { jump } \beta \\
& \phi=\frac{\lambda \sigma^{2}\left(\Delta r_{w}\right)}{\sigma^{2}\left(r_{w}\right)+\lambda \sigma^{2}\left(\Delta r_{w}\right)}
\end{aligned}
$$

Equation (B12) is the jump-diffusion two-beta asset pricing model used in this research. It indicates that under the condition that asset returns are generated by a mixture of jump and diffusion processes, the systematic risk of a risky asset is a weighted average of diffusion beta and jump beta, where the weight factor, $\phi$, is a market parameter as defined by $(\mathrm{B} 12 \mathrm{c})$. 


\section{APPENDIX C: TABLES}

\section{Table 1}

Average Sizes of 30 Portfolios for 5 Years

(in thousand dollars)

\begin{tabular}{|lcrrrr|}
\hline P 1 & \multicolumn{1}{l}{1987} & \multicolumn{1}{l}{1988} & \multicolumn{1}{l}{1989} & \multicolumn{1}{l}{1990} & \multicolumn{1}{l}{1991} \\
P 2 & 9997 & 4010 & 4382 & 3578 & 2439 \\
P 3 & 14940 & 12107 & 13779 & 12722 & 5930 \\
P 4 & 19561 & 16528 & 19446 & 17866 & 14173 \\
P 5 & 26069 & 21651 & 24595 & 24759 & 19518 \\
P 6 & 34080 & 27672 & 31424 & 32357 & 25439 \\
P 7 & 42391 & 35266 & 40571 & 40845 & 32339 \\
P 8 & 51550 & 42999 & 49617 & 48938 & 40358 \\
P 9 & 61705 & 50755 & 59774 & 59863 & 50068 \\
P 10 & 72860 & 59906 & 70290 & 71475 & 59912 \\
P 11 & 85497 & 70305 & 81837 & 84206 & 71584 \\
P 12 & 101295 & 82144 & 94600 & 97533 & 86677 \\
P 13 & 121507 & 96238 & 110037 & 113447 & 103046 \\
P 14 & 144852 & 111469 & 130414 & 134673 & 123003 \\
P 15 & 169158 & 134819 & 154140 & 159766 & 148537 \\
P 16 & 199181 & 163286 & 187759 & 189856 & 175331 \\
P 17 & 238948 & 199254 & 225582 & 234123 & 205641 \\
P 18 & 292189 & 238423 & 276765 & 278961 & 254997 \\
P 19 & 363176 & 298495 & 352333 & 334014 & 320098 \\
P 20 & 459293 & 378882 & 438661 & 410887 & 410734 \\
P 21 & 572884 & 472088 & 539969 & 530661 & 505157 \\
P 22 & 709815 & 586045 & 650741 & 659334 & 628460 \\
P 23 & 895901 & 758901 & 830721 & 833974 & 792802 \\
P 24 & 1118397 & 968761 & 1069331 & 1053733 & 1017444 \\
P 25 & 1404878 & 1224342 & 1359764 & 1400342 & 1308129 \\
P 26 & 1815192 & 1646024 & 1850324 & 1894753 & 1819058 \\
P 27 & 2463188 & 2213584 & 2475313 & 2547907 & 2523307 \\
P 28 & 3426640 & 3208499 & 3606521 & 3763844 & 3917712 \\
P 29 & 5438555 & 5440840 & 5985875 & 6511852 & 6967539 \\
P 30 & 15174136 & 31900480 & 45152080 & 48041520 & 45885696 \\
\hline
\end{tabular}


Table 2

Statistics of Average Daily Returns

\begin{tabular}{|c|c|c|c|c|c|c|}
\hline NAME & $\underline{N}$ & MEAN & ST.DEV & VARIANCE & MINIMUM & MAXIMUM \\
\hline Rw & 506 & $4.68 \mathrm{E}-04$ & $8.57 \mathrm{E}-03$ & $7.35 \mathrm{E}-05$ & $-3.27 \mathrm{E}-02$ & $3.35 \mathrm{E}-02$ \\
\hline RI & 506 & $4.55 \mathrm{E}-03$ & $1.53 \mathrm{E}-02$ & $2.35 \mathrm{E}-04$ & $-4.29 \mathrm{E}-02$ & $6.49 \mathrm{E}-02$ \\
\hline R2 & 506 & $2.46 \mathrm{E}-03$ & $1.21 \mathrm{E}-02$ & $1.47 \mathrm{E}-04$ & $-4.66 \mathrm{E}-02$ & 7.1IE-02 \\
\hline R3 & 506 & $1.07 \mathrm{E}-03$ & $9.81 \mathrm{E}-03$ & $9.62 \mathrm{E}-05$ & $-3.21 \mathrm{E}-02$ & $3.52 \mathrm{E}-02$ \\
\hline R4 & 506 & $6.70 \mathrm{E}-04$ & $9.28 \mathrm{E}-03$ & 8.61E-05 & $-2.97 \mathrm{E}-02$ & $3.62 \mathrm{E}-02$ \\
\hline R5 & 506 & $5.22 \mathrm{E}-04$ & $8.36 \mathrm{E}-03$ & $7.00 \mathrm{E}-05$ & $-3.06 \mathrm{E}-02$ & $2.86 \mathrm{E}-02$ \\
\hline R6 & 506 & $3.12 \mathrm{E}-04$ & $9.03 \mathrm{E}-03$ & $8.16 \mathrm{E}-05$ & $-3.30 \mathrm{E}-02$ & $5.24 \mathrm{E}-02$ \\
\hline R7 & 506 & $7.03 \mathrm{E}-05$ & $8.73 \mathrm{E}-03$ & $7.62 \mathrm{E}-05$ & $-3.36 \mathrm{E}-02$ & $3.41 \mathrm{E}-02$ \\
\hline R8 & 506 & $1.83 \mathrm{E}-04$ & $7.63 \mathrm{E}-03$ & 5.82E-05 & -3.2 IE-02 & $3.56 \mathrm{E}-02$ \\
\hline R9 & 506 & $2.87 \mathrm{E}-04$ & $7.06 \mathrm{E}-03$ & $4.98 \mathrm{E}-05$ & $-3.24 \mathrm{E}-02$ & $3.44 \mathrm{E}-02$ \\
\hline R10 & 506 & $2.09 \mathrm{E}-04$ & $8.87 \mathrm{E}-03$ & $7.87 \mathrm{E}-05$ & $-4.55 \mathrm{E}-02$ & $4.30 \mathrm{E}-02$ \\
\hline RII & 506 & $2.30 \mathrm{E}-04$ & $6.76 \mathrm{E}-03$ & $4.56 \mathrm{E}-05$ & $-3.11 \mathrm{E}-02$ & $2.77 \mathrm{E}-02$ \\
\hline $\mathrm{R} 12$ & 506 & $5.98 \mathrm{E}-04$ & $7.13 \mathrm{E}-03$ & $5.08 \mathrm{E}-05$ & $-3.45 \mathrm{E}-02$ & $3.81 E-02$ \\
\hline $\mathrm{R} 13$ & 506 & $9.11 E-05$ & $7.31 \mathrm{E}-03$ & 5.35E-05 & $-3.44 \mathrm{E}-02$ & $2.88 \mathrm{E}-02$ \\
\hline $\mathrm{R} 14$ & 506 & $1.35 \mathrm{E}-04$ & $7.61 \mathrm{E}-03$ & $5.80 \mathrm{E}-05$ & $-3.26 \mathrm{E}-02$ & $3.28 \mathrm{E}-02$ \\
\hline R 15 & 506 & $4.30 \mathrm{E}-04$ & $7.86 \mathrm{E}-03$ & $6.18 E-05$ & $-4.12 \mathrm{E}-02$ & $3.73 \mathrm{E}-02$ \\
\hline R16 & 506 & $2.36 \mathrm{E}-04$ & $6.75 \mathrm{E}-03$ & $4.56 \mathrm{E}-05$ & $-2.98 \mathrm{E}-02$ & $1.97 \mathrm{E}-02$ \\
\hline $\mathrm{R} 17$ & 506 & $2.20 \mathrm{E}-04$ & 7.37E-03 & $5.44 \mathrm{E}-05$ & $-3.36 \mathrm{E}-02$ & $2.91 \mathrm{E}-02$ \\
\hline Ri8 & 506 & $3.46 \mathrm{E}-04$ & $7.21 \mathrm{E}-03$ & $5.20 \mathrm{E}-05$ & $-3.59 \mathrm{E}-02$ & $3.04 \mathrm{E}-02$ \\
\hline $\mathrm{R} 19$ & 506 & $4.01 \mathrm{E}-04$ & $7.87 \mathrm{E}-03$ & $6.19 \mathrm{E}-05$ & $-3.78 \mathrm{E}-02$ & $2.87 \mathrm{E}-02$ \\
\hline R20 & 506 & $3.38 \mathrm{E}-04$ & 7.49E-03 & 5.61E-05 & $-3.16 \mathrm{E}-02$ & $3.00 \mathrm{E}-02$ \\
\hline R21 & 506 & $2.78 \mathrm{E}-04$ & $6.80 \mathrm{E}-03$ & $4.62 \mathrm{E}-05$ & $-3.42 \mathrm{E}-02$ & $2.42 \mathrm{E}-02$ \\
\hline R22 & 506 & $3.87 \mathrm{E}-04$ & $7.48 \mathrm{E}-03$ & $5.59 \mathrm{E}-05$ & $-3.42 E-02$ & $2.90 \mathrm{E}-02$ \\
\hline R23 & 506 & $3.01 \mathrm{E}-04$ & $7.40 \mathrm{E}-03$ & $5.48 \mathrm{E}-05$ & $-3.64 \mathrm{E}-02$ & $2.79 \mathrm{E}-02$ \\
\hline R24 & 506 & $4.61 \mathrm{E}-04$ & $8.32 \mathrm{E}-03$ & $6.92 \mathrm{E}-05$ & $-3.14 \mathrm{E}-02$ & $3.44 \mathrm{E}-02$ \\
\hline R25 & 506 & $5.87 \mathrm{E}-04$ & $7.78 \mathrm{E}-03$ & $6.05 \mathrm{E}-05$ & $-2.85 \mathrm{E}-02$ & 3.22E-02 \\
\hline R26 & 506 & $3.73 \mathrm{E}-04$ & $8.69 \mathrm{E}-03$ & 7.55E-05 & $-2.98 \mathrm{E}-02$ & $3.18 \mathrm{E}-02$ \\
\hline R27 & 506 & $4.19 \mathrm{E}-04$ & $8.70 \mathrm{E}-03$ & $7.56 \mathrm{E}-05$ & $-3.04 E-02$ & $3.26 \mathrm{E}-02$ \\
\hline R28 & 506 & $4.35 \mathrm{E}-04$ & $8.84 E-03$ & 7.82E-05 & $-3.25 E-02$ & $3.49 \mathrm{E}-02$ \\
\hline R29 & 506 & 4.17E-04 & $8.90 \mathrm{E}-03$ & $7.92 \mathrm{E}-05$ & $-3.21 \mathrm{E}-02$ & $3.49 \mathrm{E}-02$ \\
\hline R30 & 506 & $4.87 \mathrm{E}-04$ & $8.78 \mathrm{E}-03$ & $7.71 \mathrm{E}-05$ & $-3.22 \mathrm{E}-02$ & $4.16 \mathrm{E}-02$ \\
\hline
\end{tabular}


Table 3

\section{Covariance/Variance Matrix}

\begin{tabular}{|c|c|c|c|c|c|c|c|c|}
\hline & $R w$ & R1 & R2 & R3 & R4 & R5 & $\mathrm{R} 6$ & R7 \\
\hline $\mathrm{Rw}$ & $7.35 E-05$ & & & & & & & \\
\hline R.1 & $2.59 E-05$ & $2.35 E-04$ & & & & & & \\
\hline$R .2$ & $3.19 E-05$ & $5.60 E-05$ & $1.47 E-04$ & & & & & \\
\hline R3 & $3.25 E-05$ & $4.91 E-05$ & $4.40 E-05$ & $9.62 \mathrm{E}-05$ & & & & \\
\hline R4 & $4.22 E-05$ & $5.34 E-05$ & $4.93 E-05$ & $4.77 E-05$ & $8.61 E-05$ & & & \\
\hline R5 & $3.77 \mathrm{E}-05$ & $4.62 \mathrm{E}-05$ & $3.99 \mathrm{E}-05$ & $4.03 E-05$ & $4.84 \mathrm{E}-05$ & $7.00 E-05$ & & \\
\hline R6 & $3.92 E-05$ & $3.65 E-05$ & $4.11 \mathrm{E}-05$ & $4.07 E-05$ & $4.56 E-05$ & $4.01 E-05$ & $8.16 E-05$ & \\
\hline R7 & $4.32 E-05$ & $3.89 E-05$ & $4.92 E-05$ & $4.20 E-05$ & $5.00 \mathrm{E}-05$ & $4.14 E-05$ & $4.18 E-05$ & $7.62 \mathrm{E}-05$ \\
\hline $\mathrm{RB}$ & $4.13 E-05$ & $3.64 E-05$ & $4.22 E-05$ & $3.76 \mathrm{E}-05$ & $4.24 \mathrm{E}-05$ & $3.95 \mathrm{E}-05$ & $4.10 E-05$ & $4.55 E-05$ \\
\hline$R 9$ & $4.12 \mathrm{E}-05$ & $2.86 E-05$ & $3.54 \mathrm{E}-05$ & $3.48 E-05$ & $4.00 \mathrm{E}-05$ & $3.50 E-05$ & $3.91 E-05$ & $4.25 \mathrm{E}-05$ \\
\hline RIO & $5.24 E-05$ & $4.12 \mathrm{E}-05$ & $4.84 E-05$ & $4.20 E-05$ & $4.94 \mathrm{E}-05$ & $4.68 \mathrm{E}-05$ & $4.81 E-05$ & $5.75 \mathrm{E}-05$ \\
\hline RII & $3.99 E-05$ & $3.22 E-05$ & $3.35 \mathrm{E}-05$ & $3.25 \mathrm{E}-05$ & $3.75 E-05$ & $3.40 E-05$ & $3.61 E-05$ & $4.14 \mathrm{E}-05$ \\
\hline $\mathrm{R} 12$ & $4.48 E-05$ & $3.02 E-05$ & $3.58 E-05$ & $3.46 \mathrm{E}-05$ & $4.15 E-05$ & $3.63 E-05$ & $3.91 E-05$ & $4.43 E-05$ \\
\hline R13 & $4.54 \mathrm{E}-05$ & $3.60 \mathrm{E}-05$ & $3.72 E-05$ & $3.62 \mathrm{E}-05$ & $4.25 E-05$ & $3.78 \mathrm{E}-05$ & $3.97 E-05$ & $4.47 E-05$ \\
\hline$R 14$ & $4.81 E-05$ & $3.33 E-05$ & $3.98 \mathrm{E}-05$ & $3.69 \mathrm{E}-05$ & $4.25 E-05$ & $3.95 E-05$ & $4.24 \mathrm{E}-05$ & $4.84 \mathrm{E}-05$ \\
\hline R15 & $5.32 \mathrm{E}-05$ & $3.51 E-05$ & $4.18 E-05$ & $4.06 E-05$ & $4.81 E-05$ & $4.27 E-05$ & $4.44 \mathrm{E}-05$ & $4.96 \mathrm{E}-05$ \\
\hline R26 & $4.35 E-05$ & $2.74 E-05$ & $3.40 \mathrm{E}-05$ & $3.11 E-05$ & $3.76 E-05$ & $3.32 E-05$ & $3.61 \mathrm{E}-05$ & $4.12 E-05$ \\
\hline R17 & $4.89 E-05$ & $3.23 E-05$ & $3.62 E-05$ & $3.26 \mathrm{E}-05$ & $4.09 E-05$ & $3.81 E-05$ & $3.97 E-05$ & $4.48 \mathrm{E}-05$ \\
\hline RIE & $4.79 E-05$ & $3.07 E-05$ & $3.34 \mathrm{E}-05$ & $3.24 E-05$ & $3.90 E-05$ & $3.50 E-05$ & $3.93 E-05$ & $4.08 \mathrm{E}-05$ \\
\hline$R 19$ & $5.57 E-05$ & $3.09 E-05$ & $3.84 \mathrm{E}-05$ & $3.70 E-05$ & $4.41 E-05$ & $4.06 \mathrm{E}-05$ & $4.22 \mathrm{E}-05$ & $4.69 \mathrm{E}-05$ \\
\hline 820 & $5.28 \mathrm{E}-05$ & $3.43 E-05$ & $3.58 E-05$ & $3.47 E-05$ & $4.07 E-05$ & $3.76 \mathrm{E}-05$ & $3.98 E-05$ & $4.38 E-05$ \\
\hline R.21 & $5.04 E-05$ & $2.79 E-05$ & $3.11 E-05$ & $3.12 \mathrm{E}-05$ & $3.76 E-05$ & $3.49 E-05$ & $3.64 \mathrm{E}-05$ & $4.01 E-05$ \\
\hline$R 22$ & $5.70 E-05$ & $2.57 E-05$ & $3.41 E-05$ & $3.49 E-05$ & $4.08 E-05$ & $3.70 E-05$ & $3.99 E-05$ & $4.26 \mathrm{E}-05$ \\
\hline $\mathrm{R} 23$ & $5.77 E-05$ & $2.84 E-05$ & $3.29 E-05$ & $3.34 E-05$ & $3.88 \mathrm{E}-05$ & $3.71 \mathrm{E}-05$ & $3.72 E-05$ & $4.14 E-05$ \\
\hline
\end{tabular}




\begin{tabular}{|c|c|c|c|c|c|c|c|c|}
\hline R24 & $6.59 \mathrm{E}-05$ & $3.22 E-05$ & $3.81 E-05$ & $3.65 E-05$ & $4.44 E-05$ & $4.15 E-05$ & $4.24 E-05$ & $4.65 \mathrm{E}-05$ \\
\hline R25 & $6.26 E-05$ & $2.63 E-05$ & $3.19 E-05$ & $3.32 E-05$ & $4.07 E-05$ & $3.70 E-05$ & $3.91 \mathrm{E}-05$ & $4.27 E-05$ \\
\hline$R 26$ & $6.95 E-05$ & $2.88 E-05$ & $3.43 \mathrm{E}-05$ & $3.57 E-05$ & $4.32 E-05$ & $4.04 E-05$ & $4.21 E-05$ & $4.60 E-05$ \\
\hline R27 & $7.14 E-05$ & $2.99 E-05$ & $3.25 E-05$ & $3.53 E-05$ & $4.41 E-05$ & $3.94 \mathrm{E}-05$ & $4.11 E-05$ & $4.51 E-05$ \\
\hline$R 28$ & $7.33 E-05$ & $2.80 E-05$ & $3.11 E-05$ & $3.44 \mathrm{E}-05$ & $4.39 E-05$ & $3.85 E-05$ & $4.10 E-05$ & $4.55 \mathrm{E}-05$ \\
\hline R29 & $7.47 E-05$ & $2.64 \mathrm{E}-05$ & $3.19 E-05$ & $3.30 \mathrm{E}-05$ & $4.18 E-05$ & $3.75 E-05$ & $3.89 E-05$ & $4.32 E-05$ \\
\hline$R 30$ & $7.06 \mathrm{E}-05$ & $2.37 \mathrm{E}-05$ & $3.11 E-05$ & $3.16 \mathrm{E}-05$ & $4.11 E-05$ & $3.61 E-05$ & $3.72 \mathrm{E}-05$ & $4.24 E-05$ \\
\hline & $\mathrm{R} 8$ & R9 & R10 & RII & $\mathrm{R} 12$ & R13 & $\mathrm{R} 14$ & R.15 \\
\hline R8 & $5.82 E-05$ & & & & & & & \\
\hline RS & $3.88 E-05$ & $4.98 \mathrm{E}-05$ & & & & & & \\
\hline R10 & $5.00 E-05$ & $4.74 E-05$ & $7.87 \mathrm{E}-05$ & & & & & \\
\hline RII & $3.83 E-05$ & $3.54 \mathrm{E}-05$ & $4.77 E-05$ & $4.56 E-05$ & & & & \\
\hline R12 & $3.86 E-05$ & $3.95 E-05$ & $4.97 E-05$ & $3.78 E-05$ & $5.08 E-05$ & & & \\
\hline$R 13$ & $4.18 E-05$ & $3.91 E-05$ & $5.22 E-05$ & $4.05 E-05$ & $4.13 E-05$ & $5.35 E-05$ & & \\
\hline 214 & $4.20 E-05$ & $4.14 E-05$ & $5.31 E-05$ & $4.06 \mathrm{E}-05$ & $4.39 E-05$ & $4.49 E-05$ & $5.80 E-05$ & \\
\hline R15 & $4.46 E-05$ & $4.39 E-05$ & $5.76 E-05$ & $4.27 E-05$ & $4.63 E-05$ & $4.79 E-05$ & $5.06 \mathrm{E}-05$ & $6.18 E-05$ \\
\hline R16 & $3.62 \Xi-05$ & $3.56 \mathrm{E}-05$ & $4.64 \mathrm{E}-05$ & $3.57 E-05$ & $3.80 E-05$ & $3.91 E-05$ & $4.16 \mathrm{E}-05$ & $4.35 \mathrm{E}-05$ \\
\hline$R 17$ & $4.13 E-05$ & $3.88 E-05$ & $5.13 E-05$ & $3.96 \mathrm{E}-05$ & $4.17 E-05$ & $4.32 \mathrm{E}-05$ & $4.56 E-05$ & $4.87 \mathrm{E}-05$ \\
\hline R.18 & $3.87 E-05$ & $3.82 E-05$ & $4.85 E-05$ & $3.81 E-05$ & $4.09 E-05$ & $4.19 E-05$ & $4.39 E-05$ & $4.69 E-05$ \\
\hline R19 & $4.39 E-05$ & $4.17 E-05$ & $5.28 \mathrm{E}-05$ & $4.14 E-05$ & $4.50 E-05$ & $4.60 E-05$ & $4.83 E-05$ & $5.15 E-05$ \\
\hline R20 & $4.12 E-05$ & $3.98 E-05$ & $5.21 E-05$ & $3.94 E-05$ & $4.16 E-05$ & $4.37 E-05$ & $4.57 E-05$ & $4.94 E-05$ \\
\hline R21 & $3.73 E-05$ & $3.63 \mathrm{E}-05$ & $4.67 E-05$ & $3.59 E-05$ & $3.88 E-05$ & $4.03 E-05$ & $4.20 \mathrm{E}-05$ & $4.57 E-05$ \\
\hline R.22 & $3.99 E-05$ & $3.94 \mathrm{E}-05$ & $5.03 E-05$ & $3.82 E-05$ & $4.28 E-05$ & $4.28 E-05$ & $4.62 \mathrm{E}-05$ & $4.95 E-05$ \\
\hline R.23 & $3.90 E-05$ & $3.94 E-05$ & $5.03 E-05$ & $3.76 E-05$ & $4.16 E-05$ & $4.31 E-05$ & $4.50 E-05$ & $4.91 E-05$ \\
\hline P.24 & $4.40 E-05$ & $4.30 E-05$ & $5.62 E-05$ & $4.25 E-05$ & $4.66 E-05$ & $4.74 E-05$ & $4.98 E-05$ & $5.50 E-05$ \\
\hline$R 25$ & $4.14 E-05$ & $3.94 \mathrm{E}-05$ & $5.08 E-05$ & $3.88 E-05$ & $4.24 E-05$ & $4.38 E-05$ & $4.56 \mathrm{E}-05$ & $5.03 E-05$ \\
\hline R26 & $4.29 E-05$ & $4.30 \mathrm{E}-05$ & $5.49 E-05$ & $4.17 E-05$ & $4.61 E-05$ & $4.78 \mathrm{E}-05$ & $4.93 E-05$ & $5.51 E-05$ \\
\hline$R 27$ & $4.21 E-05$ & $4.28 E-05$ & $5.46 E-05$ & $4.11 E-05$ & $4.67 E-05$ & $4.73 E-05$ & $5.00 E-05$ & $5.49 E-05$ \\
\hline R28 & $4.24 E-05$ & $4.27 E-05$ & $5.30 \mathrm{E}-05$ & $4.11 E-05$ & $4.55 \mathrm{E}-05$ & $4.65 \mathrm{E}-05$ & $4.97 E-05$ & $5.52 \mathrm{E}-05$ \\
\hline
\end{tabular}




\begin{tabular}{|c|c|c|c|c|c|c|c|c|}
\hline R29 & $4.13 E-05$ & $4.11 E-05$ & $5.22 \mathrm{E}-05$ & $4.01 \mathrm{E}-05$ & $4.49 \mathrm{E}-05$ & $4.58 E-05$ & $4.80 E-05$ & $5.30 E-05$ \\
\hline R30 & $3.97 E-05$ & $3.95 E-05$ & $5.04 E-05$ & $3.85 E-05$ & $4.39 \mathrm{E}-05$ & $4.33 E-05$ & $4.58 E-05$ & $5.15 E-05$ \\
\hline & RI6 & RI7 & $R 18$ & R19 & $\mathrm{R} 20$ & R21 & $\mathrm{R} 22$ & $\mathrm{R} 23$ \\
\hline R.15 & $4.56 \mathrm{E}-05$ & & & & & & & \\
\hline$R 17$ & $4.02 E-05$ & $5.44 \mathrm{E}-05$ & & & & & & \\
\hline PI8 & $3.92 \mathrm{E}-05$ & $4.38 E-05$ & $5.20 E-05$ & & & & & \\
\hline R19 & $4.27 E-05$ & $4.88 E-05$ & $4.73 E-05$ & $6.19 E-05$ & & & & \\
\hline$R 20$ & $4.06 E-05$ & $4.66 E-05$ & $4.46 E-05$ & $5.14 E-05$ & $5.61 E-05$ & & & \\
\hline R22 & $3.76 E-05$ & $4.31 E-05$ & $4.09 E-05$ & $4.72 E-05$ & $4.45 E-05$ & $4.62 E-05$ & & \\
\hline R22 & $4.10 E-05$ & $4.67 E-05$ & $4.52 \mathrm{E}-05$ & $5.16 \mathrm{E}-05$ & $4.89 E-05$ & $4.56 \mathrm{E}-05$ & $5.59 E-05$ & \\
\hline R23 & $4.02 E-05$ & $4.57 E-05$ & $4.43 E-05$ & $5.06 E-05$ & $4.83 E-05$ & $4.57 E-05$ & $5.07 E-05$ & $5.48 E-05$ \\
\hline R.24 & $4.51 E-05$ & $5.13 E-05$ & $4.92 \mathrm{E}-05$ & $5.72 E-05$ & $5.37 E-05$ & $5.09 E-05$ & $5.64 \mathrm{E}-05$ & $5.72 E-05$ \\
\hline R25 & $4.12 E-05$ & $4.69 E-05$ & $4.55 E-05$ & $5.27 E-05$ & $5.00 E-05$ & $4.76 E-05$ & $5.31 E-05$ & $5.30 E-05$ \\
\hline$R 26$ & $4.55 E-05$ & $5.08 \mathrm{E}-05$ & $4.97 E-05$ & $5.73 E-05$ & $5.52 \mathrm{E}-0.05$ & $5.18 E-05$ & $5.69 E-05$ & $5.84 E-05$ \\
\hline$R 27$ & $4.50 E-05$ & $5.09 \mathrm{E}-05$ & $5.02 \mathrm{E}-05$ & $5.70 E-05$ & $5.56 \mathrm{E}-05$ & $5.22 \mathrm{E}-05$ & $5.81 E-05$ & $5.93 E-05$ \\
\hline R28 & $4.52 E-05$ & $5.10 E-05$ & $4.92 \mathrm{E}-05$ & $5.79 E-05$ & $5.55 \mathrm{E}-05$ & $5.25 E-05$ & $5.87 E-05$ & $5.98 E-05$ \\
\hline$R 29$ & $4.31 E-05$ & $4.97 E-05$ & $4.84 \mathrm{E}-05$ & $5.68 E-05$ & $5.42 \mathrm{E}-0.5$ & $5.12 E-05$ & $5.82 E-05$ & $5.88 E-05$ \\
\hline R30 & $4.23 E-05$ & $4.70 E-05$ & $4.62 \mathrm{E}-05$ & $5.37 E-05$ & $5.09 E-05$ & $4.81 E-05$ & $5.38 E-05$ & $5.47 E-05$ \\
\hline & R.24 & R25 & $\mathrm{R} 26$ & R27 & $\mathrm{R} 28$ & R29 & R30 & \\
\hline P.24 & $6.92 E-05$ & & & & & & & \\
\hline R25 & $6.00 \mathrm{E}-05$ & $6.05 E-05$ & & & & & & \\
\hline$R 26$ & $6.64 E-05$ & $6.31 E-05$ & $7.55 E-05$ & & & & & \\
\hline 827 & $6.73 E-05$ & $6.36 \mathrm{E}-05$ & $7.08 \mathrm{E}-05$ & $7.56 \mathrm{E}-05$ & & & & \\
\hline$R 28$ & $6.78 E-05$ & $6.43 E-05$ & $7.21 E-05$ & $7.33 E-05$ & $7.82 E-05$ & & & \\
\hline R29 & $6.72 \mathrm{E}-05$ & $6.39 E-05$ & $7.11 E-05$ & $7.30 E-05$ & $7.52 E-05$ & $7.92 \mathrm{E}-05$ & & \\
\hline R30 & $6.27 \mathrm{E}-05$ & $5.92 \mathrm{E}-05$ & $6.49 E-05$ & $6.72 E-05$ & $6.94 \mathrm{E}-05$ & $7.18 \mathrm{E}-05$ & $7.71 E-05$ & \\
\hline
\end{tabular}


Table 7

Portfolio Estimates with Gulf War Period Samples

\begin{tabular}{|c|c|c|c|c|c|c|}
\hline & $\mathrm{N}$ & $R_{j}$ & $\sigma\left(R_{f}\right)$ & $\beta_{j}^{\prime}$ & $\beta_{\Delta y}$ & $\beta_{j}$ \\
\hline & ---- & $\ldots$ & $-\cdots----\cdot$ & $\ldots-\ldots$ & $-\ldots$ & $-\ldots$ \\
\hline $\mathrm{R}_{1}$ & 506 & 0.0045478 & 0.0153432 & 0.35181 & 0.41734 & 0.01722 \\
\hline$R_{2}$ & 506 & 0.0024577 & 0.0121144 & 0.43339 & 0.48651 & 0.13181 \\
\hline $\mathrm{R}_{3}$ & 506 & 0.0010740 & 0.0098104 & 0.44171 & 0.48668 & 0.21047 \\
\hline $\mathrm{R}_{4}$ & 506 & 0.000669660 & 0.0092781 & 0.57374 & 0.58094 & 0.53808 \\
\hline$R_{s}$ & 506 & 0.000522056 & 0.0083636 & 0.51321 & 0.53479 & 0.35937 \\
\hline$R_{6}$ & 506 & 0.000312450 & 0.0090312 & 0.53320 & 0.55808 & 0.33898 \\
\hline $\mathrm{R}_{7}$ & 506 & 0.000070261 & 0.0087287 & 0.58835 & 0.62875 & 0.34041 \\
\hline $\mathrm{R}_{8}$ & 506 & 0.000183328 & 0.0076302 & 0.56197 & 0.59348 & 0.37755 \\
\hline$R_{9}$ & 506 & 0.000286576 & 0.0070592 & 0.56112 & 0.58607 & 0.38756 \\
\hline$R_{10}$ & 506 & 0.000208624 & 0.0088739 & 0.71361 & 0.75627 & 0.44743 \\
\hline$R_{11}$ & 506 & 0.000230119 & 0.0067559 & 0.54265 & 0.57240 & 0.35348 \\
\hline$R_{12}$ & 506 & 0.000597908 & 0.0071259 & 0.60922 & 0.62588 & 0.46481 \\
\hline$R_{13}$ & 506 & 0.000091132 & 0.0073121 & 0.61825 & 0.64331 & 0.43807 \\
\hline$R_{14}$ & 506 & 0.000135447 & 0.0076130 & 0.65409 & 0.68384 & 0.45133 \\
\hline$R_{15}$ & 506 & 0.000429806 & 0.0078598 & 0.72373 & 0.75454 & 0.53517 \\
\hline $\mathrm{R}_{16}$ & 506 & 0.000235631 & 0.0067521 & 0.59139 & 0.60296 & 0.47121 \\
\hline$R_{17}$ & 506 & 0.000220159 & 0.0073746 & 0.66475 & 0.69345 & 0.47238 \\
\hline$R_{18}$ & 506 & 0.000346241 & 0.0072133 & 0.65225 & 0.67472 & 0.49437 \\
\hline$R_{19}$ & 506 & 0.000400690 & 0.0078681 & 0.75727 & 0.78013 & 0.57842 \\
\hline$R_{20}$ & 506 & 0.000337710 & 0.0074895 & 0.71818 & 0.73842 & 0.59182 \\
\hline$R_{21}$ & 506 & 0.000278132 & 0.0068006 & 0.68531 & 0.70558 & 0.54647 \\
\hline$R_{22}$ & 506 & 0.000386554 & 0.0074753 & 0.77577 & 0.78405 & 0.69995 \\
\hline $\mathrm{R}_{23}$ & 506 & 0.000301 .208 & 0.0074028 & 0.78515 & 0.80306 & 0.66387 \\
\hline$R_{24}$ & 506 & 0.000460598 & 0.0083211 & 0.89674 & 0.91554 & 0.77445 \\
\hline$R_{25}$ & 506 & 0.000586969 & 0.0077808 & 0.85234 & 0.85866 & 0.81205 \\
\hline $\mathrm{R}_{26}$ & 506 & 0.000372755 & 0.0086903 & 0.94606 & 0.94207 & 0.95335 \\
\hline$R_{27}$ & 506 & 0.000419243 & 0.0086963 & 0.97148 & 0.97997 & 0.93097 \\
\hline $\mathrm{R}_{2 \mathrm{~B}}$ & 506 & 0.000434601 & 0.0088419 & 0.99798 & 1.00081 & 1.00224 \\
\hline$R_{29}$ & 506 & 0.000417271 & 0.0089001 & 1.01645 & 1.01406 & 1.03373 \\
\hline$R_{30}$ & 506 & 0.000487035 & 0.0087817 & 0.96005 & 0.97452 & 0.88214 \\
\hline
\end{tabular}

Panel A: $\quad$ For the whole period 


\begin{tabular}{|c|c|c|c|c|c|c|}
\hline & $\mathbf{N}$ & $R_{1}$ & $\sigma\left(R_{j}\right)$ & $\beta_{j}^{\prime}$ & $\beta_{\Delta y}$ & $\beta_{j}$ \\
\hline & --- & $\ldots \ldots$ & $-\ldots$ & $\ldots$ & $\ldots$ & . \\
\hline$R_{1}$ & 145 & 0.0031251 & 0.0130067 & 0.42227 & 0.67882 & -0.00953 \\
\hline $\mathrm{R}_{2}$ & 145 & 0.000888382 & 0.0085315 & 0.47643 & 0.40659 & 0.69379 \\
\hline$R_{3}$ & 145 & 0.000129495 & 0.0070481 & 0.33045 & 0.35935 & 0.27725 \\
\hline$R_{4}$ & 145 & 0.000236594 & 0.0068465 & 0.42178 & 0.47802 & 0.37785 \\
\hline$R_{5}$ & 145 & -0.000303728 & 0.0062561 & 0.37799 & 0.39465 & 0.36414 \\
\hline $\mathrm{R}_{6}$ & 145 & -0.000703143 & 0.0075596 & 0.57016 & 0.62702 & 0.45890 \\
\hline $\mathrm{R}_{7}$ & 145 & -0.000498368 & 0.0057149 & 0.42417 & 0.42995 & 0.37476 \\
\hline $\mathrm{R}_{\mathrm{g}}$ & 145 & -0.000087907 & 0.0050464 & 0.41290 & 0.48503 & 0.22436 \\
\hline$R_{9}$ & 145 & -0.000259828 & 0.0060657 & 0.50926 & 0.53047 & 0.42263 \\
\hline$R_{10}$ & 145 & -0.000418257 & 0.0066893 & 0.56126 & 0.59615 & 0.48338 \\
\hline$R_{11}$ & 145 & -0.000232966 & 0.0045915 & 0.39209 & 0.41189 & 0.34544 \\
\hline$R_{12}$ & 145 & 0.000276755 & 0.0052494 & 0.49773 & 0.49314 & 0.45226 \\
\hline$R_{13}$ & 145 & -0.000581247 & 0.0051357 & 0.47644 & 0.49417 & 0.3925 \\
\hline $\mathrm{R}_{14}$ & 145 & -0.000450624 & 0.0057756 & 0.52083 & 0.51318 & 0.49436 \\
\hline$R_{25}$ & 145 & -0.000152318 & 0.0061462 & 0.63842 & 0.67276 & 0.54709 \\
\hline$R_{16}$ & 145 & $7.55658 \mathrm{E}-6$ & 0.0051090 & 0.53580 & 0.52697 & 0.51163 \\
\hline$R_{17}$ & 145 & -0.000069809 & 0.0050034 & 0.52731 & 0.50783 & 0.54527 \\
\hline$R_{1 B}$ & 145 & -0.000052294 & 0.0057743 & 0.62067 & 0.62844 & 0.59568 \\
\hline$R_{19}$ & 145 & -0.000022921 & 0.0058378 & 0.61036 & 0.59978 & 0.58599 \\
\hline $\mathrm{R}_{20}$ & 145 & -0.000236234 & 0.0053704 & 0.56997 & 0.55355 & 0.58745 \\
\hline$R_{22}$ & 145 & -0.000424400 & 0.0051319 & 0.58950 & 0.59296 & 0.57588 \\
\hline$R_{22}$ & 145 & -0.000146408 & 0.0057312 & 0.68094 & 0.66700 & 0.68336 \\
\hline$R_{23}$ & 145 & -0.000207912 & 0.0063156 & 0.76740 & 0.78702 & 0.70919 \\
\hline$R_{24}$ & 145 & -0.000026812 & 0.0063849 & 0.79461 & 0.81128 & 0.71481 \\
\hline$R_{25}$ & 145 & -0.000053024 & 0.0062413 & 0.80191 & 0.82856 & 0.72779 \\
\hline $\mathrm{R}_{26}$ & 145 & -0.000242032 & 0.0070528 & 0.88583 & 0.89085 & 0.87526 \\
\hline$R_{27}$ & 145 & -0.000172465 & 0.0072453 & 0.95860 & 0.96685 & 0.93492 \\
\hline $\mathrm{R}_{\mathbf{2} \mathrm{a}}$ & 145 & 0.000055298 & 0.0070521 & 0.93320 & 0.95743 & 0.87846 \\
\hline $\mathrm{R}_{29}$ & 145 & $-1.420412 \mathrm{E}-6$ & 0.0074502 & 1.00012 & 0.99159 & 1.00693 \\
\hline$R_{30}$ & 145 & 0.000433793 & 0.0075754 & 0.97192 & 0.96860 & 0.99183 \\
\hline
\end{tabular}

Panel B: $\quad$ For Pre-Invasion Period 


\begin{tabular}{|c|c|c|c|c|c|c|}
\hline & $\mathrm{N}$ & $R_{y}$ & $\sigma\left(R_{j}\right)$ & $\beta_{j}^{\prime}$ & $\beta_{\Delta y}$ & $\beta_{j}$ \\
\hline & $\cdots$ & $--\cdots----$ & ------- & $\ldots \ldots$ & $\cdots-\cdots$ & $\cdots$ \\
\hline $\mathrm{R}_{1}$ & 150 & 0.0054097 & 0.0178690 & 0.35399 & 0.37487 & 0.07575 \\
\hline $\mathrm{R}_{2}$ & 150 & 0.0040496 & 0.0163955 & 0.36541 & 0.45254 & -0.62921 \\
\hline$R_{3}$ & 150 & 0.0016458 & 0.0125292 & 0.54662 & 0.59881 & 0.02483 \\
\hline $\mathrm{R}_{4}$ & 150 & 0.0008065 & 0.0120802 & 0.63246 & 0.62786 & 0.67583 \\
\hline $\mathrm{R}_{5}$ & 150 & 0.0006182 & 0.0111331 & 0.58477 & 0.61546 & 0.16948 \\
\hline$R_{6}$ & 150 & 0.0001420 & 0.0115426 & 0.53668 & 0.56302 & 0.09549 \\
\hline $\mathrm{R}_{7}$ & 150 & $6.18067 e-05$ & 0.0124038 & 0.72959 & 0.78377 & 0.20247 \\
\hline$R_{8}$ & 150 & 0.0002787 & 0.0097641 & 0.56408 & 0.60463 & 0.11122 \\
\hline $\mathrm{R}_{\mathrm{g}}$ & 150 & -0.0001172 & 0.0095632 & 0.65365 & 0.69135 & 0.25967 \\
\hline$R_{10}$ & 150 & $9.13665 e-05$ & 0.0125275 & 0.89238 & 0.94421 & 0.30013 \\
\hline $\mathrm{R}_{11}$ & 150 & 0.0003681 & 0.0090461 & 0.64467 & 0.68288 & 0.23100 \\
\hline $\mathrm{R}_{12}$ & 150 & 0.0009514 & 0.0098977 & 0.72796 & 0.74107 & 0.54131 \\
\hline$R_{13}$ & 150 & $4.26089 e-05$ & 0.0097802 & 0.70822 & 0.73796 & 0.33683 \\
\hline$R_{14}$ & 150 & $-3.24566 e-05$ & 0.0105034 & 0.73738 & 0.77084 & 0.30804 \\
\hline$R_{15}$ & 150 & 0.0003241 & 0.0110217 & 0.84667 & 0.88202 & 0.45133 \\
\hline$R_{16}$ & 150 & 0.0001612 & 0.0088424 & 0.64136 & 0.66267 & 0.28145 \\
\hline $\mathrm{R}_{17}$ & 150 & $4.69865 e-05$ & 0.0099769 & 0.74577 & 0.78538 & 0.29186 \\
\hline $\mathrm{R}_{1 \mathrm{a}}$ & 150 & 0.0003428 & 0.0098698 & 0.72938 & 0.75251 & 0.42610 \\
\hline $\mathrm{R}_{19}$ & 150 & 0.0001579 & 0.0108641 & 0.83818 & 0.87511 & 0.34951 \\
\hline$R_{20}$ & 150 & $4.87588 e-05$ & 0.0102602 & 0.79581 & 0.81938 & 0.53659 \\
\hline $\mathrm{R}_{22}$ & 150 & 0.0002665 & 0.0090915 & 0.74769 & 0.77489 & 0.40665 \\
\hline $\mathrm{R}_{22}$ & 150 & 0.0005681 & 0.0098212 & 0.81261 & 0.83363 & 0.52989 \\
\hline $\mathrm{R}_{23}$ & 150 & 0.0003458 & 0.0099579 & 0.85890 & 0.88348 & 0.54445 \\
\hline$R_{24}$ & 150 & 0.0006691 & 0.0111455 & 0.96460 & 0.99307 & 0.63485 \\
\hline $\mathrm{R}_{2 \mathrm{~S}}$ & 150 & 0.0007332 & 0.0097697 & 0.85481 & 0.86678 & 0.72256 \\
\hline $\mathrm{R}_{26}$ & 150 & 0.0001999 & 0.0112779 & 0.97874 & 0.97011 & 1.03996 \\
\hline$R_{27}$ & 150 & 0.0005911 & 0.0113237 & 1.00558 & 1.02386 & 0.84044 \\
\hline $\mathrm{R}_{20}$ & 150 & 0.0004630 & 0.0114894 & 1.02897 & 1.03268 & 1.01628 \\
\hline $\mathrm{R}_{29}$ & 150 & 0.0005877 & 0.0111636 & 1.00733 & 1.00749 & 1.02263 \\
\hline $\mathrm{R}_{30}$ & 150 & 0.0004647 & 0.0112979 & 0.99044 & 1.00930 & 0.81144 \\
\hline
\end{tabular}

Panel C: For Invasion Period 


\begin{tabular}{|c|c|c|c|c|c|c|}
\hline & $N$ & $R_{j}$ & $\sigma\left(R_{j}\right)$ & $\beta_{j}^{\prime}$ & $\beta_{\Delta j}$ & $\beta_{j}$ \\
\hline & --- & $\ldots \ldots$ & $\ldots$ & $\ldots$ & $\ldots$ & - \\
\hline $\mathrm{R}_{1}$ & 211 & 0.0049126 & 0.0148828 & 0.29471 & 0.36265 & -0.00297 \\
\hline $\mathrm{R}_{2}$ & 211 & 0.0024044 & 0.0104291 & 0.50052 & 0.57721 & 0.18011 \\
\hline$R_{3}$ & 211 & 0.0013166 & 0.0092244 & 0.35296 & 0.37018 & 0.28100 \\
\hline$R_{4}$ & 211 & 0.0008700 & 0.0084346 & 0.58396 & 0.58182 & 0.57606 \\
\hline$R_{5}$ & 211 & 0.0010212 & 0.0072599 & 0.48981 & 0.48728 & 0.48496 \\
\hline$R_{6}$ & 211 & 0.0011316 & 0.0078111 & 0.49680 & 0.51303 & 0.41389 \\
\hline $\mathrm{R}_{7}$ & 211 & 0.0004670 & 0.0071610 & 0.48157 & 0.49032 & 0.42047 \\
\hline $\mathrm{R}_{\mathrm{g}}$ & 211 & 0.0003020 & 0.0074046 & 0.65620 & 0.64959 & 0.67333 \\
\hline$R_{9}$ & 211 & 0.0009490 & 0.0053808 & 0.45270 & 0.44455 & 0.46582 \\
\hline $\mathrm{R}_{10}$ & 211 & 0.0007228 & 0.0068399 & 0.54250 & 0.54304 & 0.52373 \\
\hline$R_{11}$ & 211 & 0.0004502 & 0.0060852 & 0.48682 & 0.49142 & 0.44613 \\
\hline $\mathrm{R}_{12}$ & 211 & 0.0005673 & 0.0057916 & 0.50479 & 0.51913 & 0.41697 \\
\hline$R_{13}$ & 211 & 0.0005877 & 0.0064854 & 0.57271 & 0.57459 & 0.54665 \\
\hline$R_{14}$ & 211 & 0.0006576 & 0.0061396 & 0.61341 & 0.63501 & 0.51526 \\
\hline$R_{15}$ & 211 & 0.0009050 & 0.0059995 & 0.59277 & 0.59181 & 0.58742 \\
\hline $\mathrm{R}_{16}$ & 211 & 0.0004452 & 0.0060146 & 0.55275 & 0.54949 & 0.55658 \\
\hline$R_{17}$ & 211 & 0.0005425 & 0.0065427 & 0.63260 & 0.65144 & 0.54012 \\
\hline$R_{18}$ & 211 & 0.0006226 & 0.0057407 & 0.55627 & 0.57616 & 0.46027 \\
\hline$R_{19}$ & 211 & 0.0008644 & 0.0064324 & 0.73049 & 0.78350 & 0.72586 \\
\hline $\mathrm{R}_{20}$ & 211 & 0.0009375 & 0.0063064 & 0.69569 & 0.70731 & 0.64249 \\
\hline$R_{22}$ & 211 & 0.0007692 & 0.0058246 & 0.65108 & 0.65593 & 0.62078 \\
\hline $\mathrm{R}_{22}$ & 211 & 0.0006238 & 0.0065681 & 0.78135 & 0.76958 & 0.82156 \\
\hline$R_{23}$ & 211 & 0.0006194 & 0.0058134 & 0.68485 & 0.67882 & 0.70514 \\
\hline$R_{24}$ & 211 & 0.0006473 & 0.0070840 & 0.86147 & 0.84848 & 0.90861 \\
\hline$R_{25}$ & 211 & 0.0009228 & 0.0071233 & 0.87958 & 0.86379 & 0.93980 \\
\hline $\mathrm{R}_{26}$ & 211 & 0.0009181 & 0.0075283 & 0.93403 & 0.92560 & 0.96310 \\
\hline $\mathrm{R}_{27}$ & 211 & 0.0007037 & 0.0073852 & 0.92766 & 0.91247 & 0.99023 \\
\hline$R_{28}$ & 211 & 0.0006750 & 0.0077511 & 0.99412 & 0.97313 & 1.08851 \\
\hline$R_{29}$ & 211 & 0.0005838 & 0.0079893 & 1.04108 & 1.03661 & 1.06010 \\
\hline $\mathrm{R}_{30}$ & 211 & 0.0005395 & 0.0074519 & 0.90931 & 0.92486 & 0.84241 \\
\hline
\end{tabular}

Panel D: For Post-Invasion Period 
Table 14

\section{Portfolio Estimates with Turn-of-the-Year Sample}

\begin{tabular}{|c|c|c|c|c|c|}
\hline & $R_{j}$ & $\sigma\left(R_{j}\right)$ & $\beta_{j}^{\prime}$ & $\beta_{\Delta y}$ & $\beta_{j}$ \\
\hline & $-\cdots-\cdots$ & $---\ldots$ & $-\cdots-\cdots$ & $\ldots \ldots$ & $\ldots \ldots$ \\
\hline $\mathrm{R}_{1}$ & 0.0224082 & 0.0189570 & 1.012122 & 0.9978 & -0.2981 \\
\hline $\mathrm{R}_{2}$ & 0.0185801 & 0.0179088 & 1.058303 & 1.02669 & 0.62322 \\
\hline $\mathrm{R}_{3}$ & 0.0153708 & 0.0146008 & 1.006402 & 1.01639 & -0.1723 \\
\hline $\mathrm{R}_{4}$ & 0.0144954 & 0.0129956 & 0.930818 & 0.9038 & 1.27434 \\
\hline$R_{5}$ & 0.0138876 & 0.0144181 & 1.065084 & 1.05818 & 0.94643 \\
\hline$R_{6}$ & 0.0129085 & 0.0139093 & 1.098238 & 1.08941 & 0.88958 \\
\hline $\mathrm{R}_{7}$ & 0.0120597 & 0.0143230 & 1.111219 & 1.09318 & 0.91875 \\
\hline$R_{g}$ & 0.0115253 & 0.0137148 & 1.141785 & 1.12329 & 0.98419 \\
\hline$R_{9}$ & 0.0107713 & 0.0137029 & 1.174707 & 1.15149 & 1.29907 \\
\hline $\mathrm{R}_{10}$ & 0.0105937 & 0.0130334 & 1.138424 & 1.13354 & 0.75325 \\
\hline$R_{11}$ & 0.0097603 & 0.0136043 & 1.10133 & 1.10104 & 0.64932 \\
\hline $\mathrm{R}_{12}$ & 0.0088547 & 0.0121757 & 1.052405 & 1.04662 & 0.78382 \\
\hline$R_{13}$ & 0.0092436 & 0.0139359 & 1.245749 & 1.23874 & 1.19228 \\
\hline$R_{14}$ & 0.00814 & 0.0120518 & 1.043669 & 1.0377 & 0.96678 \\
\hline$R_{15}$ & 0.0081496 & 0.0123757 & 1.119904 & 1.11372 & 1.2585 \\
\hline $\mathrm{R}_{16}$ & 0.0076694 & 0.0114132 & 1.057456 & 1.05192 & 0.96944 \\
\hline$R_{17}$ & 0.0067321 & 0.0114158 & 1.045925 & 1.04138 & 1.18771 \\
\hline$R_{18}$ & 0.0065637 & 0.0106772 & 0.9832133 & 0.98786 & 0.71551 \\
\hline$R_{19}$ & 0.0066445 & 0.0107311 & 0.9969362 & 0.99359 & 0.99662 \\
\hline$R_{20}$ & 0.0064564 & 0.0109896 & 1.027927 & 1.01848 & 0.91243 \\
\hline$R_{21}$ & 0.0057077 & 0.0103320 & 0.9807668 & 0.96968 & 1.13092 \\
\hline $\mathrm{R}_{22}$ & 0.005188 & 0.0106267 & 1.014363 & 1.00218 & 1.35165 \\
\hline$R_{23}$ & 0.004622 & 0.0102475 & 1.012212 & 1.02007 & 0.89479 \\
\hline$R_{24}$ & 0.0048745 & 0.0103861 & 1.027704 & 1.03836 & 0.79764 \\
\hline$R_{25}$ & 0.0043455 & 0.0094244 & 0.95825 & 0.96347 & 0.57834 \\
\hline $\mathrm{R}_{26}$ & 0.0043657 & 0.0095300 & 0.9690998 & 0.97321 & 0.8104 \\
\hline $\mathrm{R}_{27}$ & 0.0040211 & 0.0097021 & 1.001781 & 1.00208 & 0.90163 \\
\hline $\mathrm{R}_{28}$ & 0.0037508 & 0.0097376 & 1.015797 & 1.00881 & 1.20026 \\
\hline $\mathrm{R}_{29}$ & 0.0028753 & 0.0096244 & 1.007809 & 1.00787 & 1.24703 \\
\hline$R_{30}$ & 0.0019264 & 0.0094893 & 0.995836 & 0.99651 & 0.97606 \\
\hline
\end{tabular}




\section{APPENDIX D: GAUSS@ PROGRAM AND SAMPLE OUTPUTS}

*************************PROGRAM

use nlopt;

output file=vwest 2 .out reset;

$\mathrm{n}=342$;

load data[n,5]=c:Istoreltapelmkt.mth; @var: caldt, date, ew, vw, s\&p $500 @$ $\mathrm{x}=$ data[1:n,4]; @use VW@

clear data;

print meanc $(\mathrm{x}) \sim \operatorname{stdc}(\mathrm{x}) \sim \operatorname{stdc}(\mathrm{x})^{\wedge} 2$

$\mathrm{z}=\ln (\mathrm{x}+1) ; @ \mathrm{x}=(\mathrm{P}-\mathrm{P}(-1) / \mathrm{P}(-1) ; \mathrm{z}=\ln (\mathrm{P} / \mathrm{P}(-1)) @$

wait;

@ estimating the structure of $\mathrm{z} @$

@ (ln) z poisson mixture of normals @

method $=5$;

@use quadratic hill climbing method@

- iter $=2000$;

step $=2$;

conv $=2$;

let $c=0.30 .0003-0.00080 .000050 .0001$;

$\{\mathrm{c}, \mathrm{vc}\}=\operatorname{maxlik}(\& l l f \mathrm{f}, \mathrm{z}, \mathrm{c})$;

wait;

$1=\operatorname{prob}(z, c)$;

(a) probability of a jump process occuring (a)

(a) numerically the number of jumps can be estimated too (a)

lambda=meanc $(1 .>0.25)$;

(a) calculate $\lambda$ by guessing@

@separate samples into jump and diffusion sets@

$x \mathrm{j}=\operatorname{selif}(x, 1 .>0.25)$;

$\mathrm{x} 0=\operatorname{delif}(\mathrm{x}, 1 .>0.25)$;

$\operatorname{var} x j=\operatorname{stdc}(x j)^{\wedge} 2$;

varx $0=\operatorname{stdc}(x 0)^{\wedge} 2$; 
$\mathrm{xi}=1 .>0.25$

print $\mathrm{x} \sim 1 \sim \mathrm{xi}$;

print meanc $(\mathrm{x}) \sim \operatorname{meanc}(\mathrm{xj}) \sim$ meanc $(\mathrm{x} 0)$;

print $\operatorname{stdc}(x)^{\wedge} 2 \sim \operatorname{varxj} \sim \operatorname{var} 0$;

phi=lambda./(varx0./varxj+lambda);

print lambda;

print phi;

end;

proc pdfp $(1, x)$;

(a) poisson probability distribution (a)

(a) I=mean rate of an event's occurance @

(a) $\mathrm{x}=$ number of event=0,1,2,... @

$\operatorname{retp}\left(\exp (-1)^{*}\left(1^{\wedge} x\right) \cdot /(x !)\right)$

endp;

proc llfp $(x, b)$;

(a) log-likelihood function of poisson mixture of normals @

@ b= [lamda,mu,theta,sigma2,delta2]' @

local $\mathrm{p}, \mathrm{j}, \mathrm{z}, \mathrm{s}, \mathrm{f}$;

$\mathrm{p}=1 ; \mathrm{f}=0 ; \mathrm{j}=0$;

do until $\mathrm{p}<$ tol;

$\mathrm{s}=\operatorname{maxc}\left(\operatorname{real}\left(\operatorname{sqrt}\left(\mathrm{b}[4]+\mathrm{b}[5]^{*} \mathrm{j}\right)\right) \mid 1.0 \mathrm{e}-13\right)$;

$\mathrm{z}=(\mathrm{x}-\mathrm{b}[2]-\mathrm{b}[3] * \mathrm{j}) \cdot / \mathrm{s}$;

$\mathrm{p}=\operatorname{pdfp}(\mathrm{b}[1], \mathrm{j}) \cdot{ }^{*} \operatorname{pdfn}(\mathrm{z}) . / \mathrm{s}$;

$\mathrm{f}=\mathrm{f}+\mathrm{p}$;

$\mathrm{j}=\mathrm{j}+\mathrm{l}$;

endo;

$\operatorname{retp}(\operatorname{sumc}(\ln (\mathrm{f})))$;

endp;

$\operatorname{proc} \operatorname{prob}(x, b)$;

(a) sample separation information (probability) (a) 


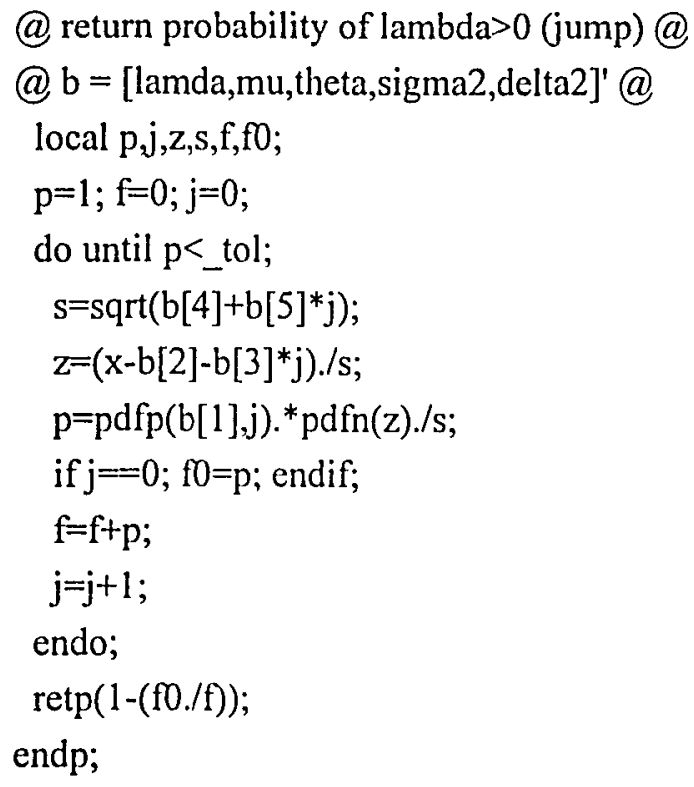

$\begin{array}{lll}\operatorname{mean}(v w) & \sigma(v w) & \sigma^{2}(v w) \\ 0.0095733 & 0.044938 & 0.0020194\end{array}$

NLOPT/GAUSS Version 3.1C: Applied Data Associates.(1996/01/16/08:05:57)

Maximum Likelihood Estimation

Model: Total Log-Likelihood Function

Number of Parameters $=5$

Maximum Number of Iterations $=5000$

Step Size Search Method $=2$

Convergence Criterion $=2$

Tolerance $=0.001$

Initial Result:

Log Likelihood $=\quad-681.30$

Parameters $=$

$\begin{array}{lllll}0.30000 & 0.00030000 & -0.00080000 & 5.0000 \mathrm{e}-05 & 0.00010000\end{array}$ 
Using Quadratic Hill-Climbing Algorithm

Iteration $=1$ Step Size $=1.2000$ Log Likelihood $=154.21$

Parameters $=\begin{array}{lllll}0.29992 & 0.0019863 & -0.0019549 & 0.00038185 & 3.9674 \mathrm{e}-05\end{array}$

Iteration $=2$ Step Size $=2.5859$ Log Likelihood $=391.44$

Parameters $=\quad \begin{array}{llllll}0.29992 & 0.0019907 & -0.0019478 & 0.00016001 & 0.00085953\end{array}$

Iteration $=3$ Step Size $=2.9869$ Log Likelihood $=577.14$

Parameters $=\begin{array}{llllll}0.30058 & 0.013119 & -0.0041669 & 0.00082172 & 0.0015546\end{array}$

Iteration $=4$ Step Size $=1.9248$ Log Likelihood $=587.91$

Parameters $=\quad \begin{array}{llllll}0.30147 & 0.010747 & -0.0081215 & 0.0012237 & 0.0023090\end{array}$

Iteration $=5$ Step Size $=0.9578$ Log Likelihood $=588.49$

Parameters $=\begin{array}{llllll}0.30198 & 0.012300 & -0.011931 & 0.0010857 & 0.0027571\end{array}$

Iteration $=6$ Step Size $=1.0515$ Log Likelihood $=\quad 588.51$

Parameters $=\begin{array}{lllll}0.30256 & 0.012414 & -0.012820 & 0.0011057 & 0.0027630\end{array}$

Iteration $=7$ Step Size $=2.2555$ Log Likelihood $=588.53$

Parameters $=\begin{array}{llllll}0.34185 & 0.012703 & -0.012154 & 0.0010650 & 0.0025272\end{array}$

Iteration $=8$ Step Size $=1.0229$ Log Likelihood $=588.53$

Parameters $=\begin{array}{llllll}0.34227 & 0.012684 & -0.012146 & 0.0010677 & 0.0025476\end{array}$

Iteration $=9$ Step Size $=0.9771$ Log Likelihood $=588.53$

Parameters $=\begin{array}{llllll}0.35057 & 0.012737 & -0.012009 & 0.0010601 & 0.0025069\end{array}$

Iteration $=10$ Step Size $=0.9979$ Log Likelihood $=588.53$

Parameters $=\begin{array}{lllll}0.35064 & 0.012737 & -0.012011 & 0.0010601 & 0.0025075\end{array}$

Iteration $=11$ Step Size $=0.7972$ Log Likelihood $=588.53$

Parameters $=\begin{array}{llllll}0.35064 & 0.012737 & -0.012010 & 0.0010601 & 0.0025075\end{array}$

Iteration $=12$ Step Size $=0.0032$ Log Likelihood $=588.53$

Parameters $=\quad \begin{array}{lllll}0.35064 & 0.012737 & -0.012010 & 0.0010601 & 0.0025075\end{array}$

Final Result:

Log Likelihood $=\quad 588.53$

Gradient of Log Likelihood $=$ $\begin{array}{llllll}0.00012969 & -0.0062481 & -0.0037863 & -0.0022737 & 0.0045475\end{array}$

Asymptotic

$\begin{array}{ccc}\text { Parameter } & \text { Std. Error } & \text { t-ratio } \\ 0.35064 & 0.27989 & 1.2528 \\ 0.012737 & 0.0034507 & 3.6910 \\ -0.012010 & 0.0093349 & -1.2866\end{array}$




$\begin{array}{lll}0.0010601 & 0.00028679 & 3.6965 \\ 0.0025075 & 0.0014575 & 1.7203\end{array}$

$\begin{array}{ccc}-0.0016906 & 0.19468 & 0.0000 \\ 0.052682 & 0.23730 & 0.0000 \\ -0.011931 & 0.22316 & 0.0000 \\ 0.027738 & 0.17975 & 0.0000 \\ -0.0055536 & 0.20367 & 0.0000 \\ 0.021740 & 0.17591 & 0.0000 \\ 0.025793 & 0.17812 & 0.0000 \\ 0.017190 & 0.17527 & 0.0000 \\ 0.017681 & 0.17524 & 0.0000 \\ 0.0045900 & 0.18399 & 0.0000 \\ 0.017415 & 0.17525 & 0.0000 \\ 0.015097 & 0.17563 & 0.0000 \\ 0.020132 & 0.17546 & 0.0000 \\ -0.011283 & 0.22089 & 0.0000 \\ 0.030477 & 0.18266 & 0.0000 \\ 0.0088496 & 0.17925 & 0.0000 \\ 0.0030871 & 0.18613 & 0.0000 \\ 0.0037412 & 0.18517 & 0.0000 \\ 0.038696 & 0.19604 & 0.0000 \\ 0.0069412 & 0.18113 & 0.0000 \\ -0.0097050 & 0.21566 & 0.0000 \\ 0.033636 & 0.18696 & 0.0000 \\ -0.0044042 & 0.20079 & 0.0000 \\ -0.051854 & 0.54211 & 1.0000 \\ 0.016743 & 0.17531 & 0.0000 \\ 0.030898 & 0.18317 & 0.0000 \\ 0.031955 & 0.18454 & 0.0000 \\ 0.029308 & 0.18133 & 0.0000 \\ 0.0030976 & 0.18611 & 0.0000 \\ 0.013539 & 0.17617 & 0.0000 \\ 0.012131 & 0.17687 & 0.0000 \\ -0.0086405 & 0.21234 & 0.0000\end{array}$




$\begin{array}{ccc}-0.020897 & 0.26220 & 1.0000 \\ 0.024831 & 0.17746 & 0.0000 \\ -0.052508 & 0.55045 & 1.0000 \\ -0.010300 & 0.21759 & 0.0000 \\ -0.012869 & 0.22657 & 0.0000 \\ -0.075355 & 0.83291 & 1.0000 \\ -0.0069725 & 0.20749 & 0.0000 \\ 0.042359 & 0.20442 & 0.0000 \\ 0.017490 & 0.17525 & 0.0000 \\ 0.0062021 & 0.18197 & 0.0000 \\ 0.085504 & 0.46344 & 1.0000 \\ 0.010937 & 0.17761 & 0.0000 \\ 0.043419 & 0.20715 & 0.0000 \\ 0.041599 & 0.20255 & 0.0000 \\ -0.039347 & 0.39948 & 1.0000 \\ 0.026871 & 0.17898 & 0.0000 \\ 0.049173 & 0.22447 & 0.0000 \\ -0.0062388 & 0.20548 & 0.0000 \\ 0.034287 & 0.18797 & 0.0000 \\ -0.027401 & 0.30089 & 1.0000 \\ 0.0079032 & 0.18013 & 0.0000 \\ 0.033697 & 0.18705 & 0.0000 \\ -0.036356 & 0.37121 & 1.0000 \\ -0.033621 & 0.34749 & 1.0000 \\ 0.0050746 & 0.18335 & 0.0000 \\ 0.094102 & 0.55491 & 1.0000 \\ 0.027025 & 0.17911 & 0.0000 \\ 0.011526 & 0.17722 & 0.0000 \\ -0.022046 & 0.26835 & 1.0000 \\ 0.018047 & 0.17524 & 0.0000 \\ 0.044444 & 0.20991 & 0.0000 \\ 0.0090438 & 0.17907 & 0.0000 \\ 0.058523 & 0.26286 & 1.0000 \\ -0.033886 & 0.34970 & 1.0000 \\ -0.0067120 & 0.20676 & 0.0000 \\ -0.053628 & 0.56486 & 1.0000\end{array}$




$\begin{array}{ccc}0.030493 & 0.18268 & 0.0000 \\ 0.020560 & 0.17555 & 0.0000 \\ 0.0050643 & 0.18336 & 0.0000 \\ -0.067296 & 0.74257 & 1.0000 \\ -0.065078 & 0.71482 & 1.0000 \\ 0.051498 & 0.23277 & 0.0000 \\ -0.022584 & 0.27133 & 1.0000 \\ 0.055630 & 0.24951 & 0.0000 \\ -0.032164 & 0.33568 & 1.0000 \\ -0.019671 & 0.25596 & 1.0000 \\ -0.073256 & 0.81127 & 1.0000 \\ 0.056722 & 0.25438 & 1.0000 \\ -0.0047206 & 0.20156 & 0.0000 \\ -0.10532 & 0.98486 & 1.0000 \\ -0.064342 & 0.70541 & 1.0000 \\ -0.051130 & 0.53295 & 1.0000 \\ 0.074206 & 0.36194 & 1.0000 \\ 0.050049 & 0.22750 & 0.0000 \\ 0.047477 & 0.21890 & 0.0000 \\ -0.018171 & 0.24872 & 0.0000 \\ 0.050456 & 0.22895 & 0.0000 \\ 0.060708 & 0.27389 & 1.0000 \\ 0.052021 & 0.23474 & 0.0000 \\ 0.016886 & 0.17529 & 0.0000 \\ 0.044794 & 0.21089 & 0.0000 \\ 0.033328 & 0.18649 & 0.0000 \\ -0.036399 & 0.37160 & 1.0000 \\ 0.0031291 & 0.18607 & 0.0000 \\ -0.040284 & 0.40883 & 1.0000 \\ 0.042502 & 0.20478 & 0.0000 \\ -0.0049980 & 0.20226 & 0.0000 \\ -0.040683 & 0.41289 & 1.0000 \\ -0.0012738 & 0.19382 & 0.0000 \\ 0.091262 & 0.52370 & 1.0000 \\ 0.028371 & 0.18036 & 0.0000 \\ 0.031343 & 0.18374 & 0.0000\end{array}$




$\begin{array}{ccc}0.0087325 & 0.17935 & 0.0000 \\ 0.0055040 & 0.18281 & 0.0000 \\ 0.016392 & 0.17536 & 0.0000 \\ -0.020886 & 0.26215 & 1.0000 \\ -0.0042341 & 0.20038 & 0.0000 \\ 0.035971 & 0.19080 & 0.0000 \\ -0.0076669 & 0.20946 & 0.0000 \\ 0.0086963 & 0.17938 & 0.0000 \\ 0.049759 & 0.22649 & 0.0000 \\ 0.011251 & 0.17740 & 0.0000 \\ -0.026063 & 0.29213 & 1.0000 \\ -0.042561 & 0.43254 & 1.0000 \\ -0.0059295 & 0.20466 & 0.0000 \\ -0.047988 & 0.49428 & 1.0000 \\ -0.021875 & 0.26742 & 1.0000 \\ -0.0078117 & 0.20988 & 0.0000 \\ 0.054505 & 0.24468 & 0.0000 \\ -0.029263 & 0.31380 & 1.0000 \\ 0.052593 & 0.23694 & 0.0000 \\ 0.00038243 & 0.19063 & 0.0000 \\ -0.11768 & 0.99594 & 1.0000 \\ 0.013041 & 0.17640 & 0.0000 \\ 0.0023336 & 0.18730 & 0.0000 \\ 0.0030473 & 0.18619 & 0.0000 \\ -0.023460 & 0.27631 & 1.0000 \\ -0.044431 & 0.45302 & 1.0000 \\ -0.038375 & 0.39003 & 1.0000 \\ -0.019667 & 0.25593 & 1.0000 \\ -0.069971 & 0.77460 & 1.0000 \\ -0.086125 & 0.91907 & 1.0000 \\ -0.11008 & 0.99069 & 1.0000 \\ 0.16529 & 0.99129 & 1.0000 \\ -0.042136 & 0.42801 & 1.0000 \\ -0.025095 & 0.28607 & 1.0000 \\ 0.13904 & 0.94114 & 1.0000 \\ 0.059596 & 0.26817 & 1.0000\end{array}$




$\begin{array}{ccc}0.029170 & 0.18118 & 0.0000 \\ 0.047217 & 0.21809 & 0.0000 \\ 0.054795 & 0.24591 & 0.0000 \\ 0.051563 & 0.23301 & 0.0000 \\ -0.062394 & 0.68018 & 1.0000 \\ -0.021314 & 0.26441 & 1.0000 \\ -0.036241 & 0.37018 & 1.0000 \\ 0.057922 & 0.25997 & 1.0000 \\ 0.031560 & 0.18402 & 0.0000 \\ -0.010970 & 0.21982 & 0.0000 \\ 0.12649 & 0.87596 & 1.0000 \\ 0.0038041 & 0.18508 & 0.0000 \\ 0.028857 & 0.18085 & 0.0000 \\ -0.011133 & 0.22038 & 0.0000 \\ -0.0084282 & 0.21170 & 0.0000 \\ 0.046136 & 0.21478 & 0.0000 \\ -0.0077509 & 0.20970 & 0.0000 \\ -6.5705 \mathrm{e}-05 & 0.19146 & 0.0000 \\ 0.025078 & 0.17762 & 0.0000 \\ -0.021601 & 0.26594 & 1.0000 \\ 0.0049878 & 0.18346 & 0.0000 \\ 0.060064 & 0.27055 & 1.0000 \\ -0.037577 & 0.38246 & 1.0000 \\ -0.016619 & 0.24170 & 0.0000 \\ -0.010034 & 0.21671 & 0.0000 \\ 0.0039078 & 0.18493 & 0.0000 \\ -0.012089 & 0.22372 & 0.0000 \\ 0.051975 & 0.23456 & 0.0000 \\ -0.014932 & 0.23458 & 0.0000 \\ -0.014541 & 0.23301 & 0.0000 \\ 0.00074087 & 0.18999 & 0.0000 \\ -0.039898 & 0.40495 & 1.0000 \\ 0.044009 & 0.20872 & 0.0000 \\ 0.0069223 & 0.18115 & 0.0000 \\ -0.056906 & 0.60777 & 1.0000 \\ -0.011249 & 0.22078 & 0.0000\end{array}$




$\begin{array}{ccc}0.032550 & 0.18536 & 0.0000 \\ 0.082639 & 0.43542 & 1.0000 \\ 0.020782 & 0.17561 & 0.0000 \\ -0.012362 & 0.22471 & 0.0000 \\ 0.057407 & 0.25754 & 1.0000 \\ 0.039294 & 0.19730 & 0.0000 \\ -0.0062716 & 0.20557 & 0.0000 \\ -0.10598 & 0.98582 & 1.0000 \\ 0.033642 & 0.18697 & 0.0000 \\ 0.016464 & 0.17534 & 0.0000 \\ 0.047681 & 0.21955 & 0.0000 \\ -0.027344 & 0.30050 & 1.0000 \\ 0.064427 & 0.29463 & 1.0000 \\ 0.0076520 & 0.18039 & 0.0000 \\ -0.013629 & 0.22943 & 0.0000 \\ 0.046058 & 0.21455 & 0.0000 \\ 0.014022 & 0.17598 & 0.0000 \\ 0.064449 & 0.29476 & 1.0000 \\ 0.0014634 & 0.18873 & 0.0000 \\ -0.070612 & 0.78201 & 1.0000 \\ 0.063238 & 0.28772 & 1.0000 \\ 0.025886 & 0.17819 & 0.0000 \\ 0.065065 & 0.29845 & 1.0000 \\ 0.0028800 & 0.18644 & 0.0000 \\ -0.11590 & 0.99503 & 1.0000 \\ 0.050618 & 0.22953 & 0.0000 \\ 0.058668 & 0.26357 & 1.0000 \\ 0.036352 & 0.19149 & 0.0000 \\ 0.068284 & 0.31891 & 1.0000 \\ 0.020279 & 0.17549 & 0.0000 \\ 0.028183 & 0.18017 & 0.0000 \\ 0.018838 & 0.17527 & 0.0000 \\ 0.10676 & 0.69702 & 1.0000 \\ -0.034962 & 0.35887 & 1.0000 \\ -0.041809 & 0.42456 & 1.0000 \\ 0.016790 & 0.17530 & 0.0000\end{array}$




$\begin{array}{ccc}0.044252 & 0.20939 & 0.0000 \\ -0.016009 & 0.23907 & 0.0000 \\ 0.011227 & 0.17742 & 0.0000 \\ -0.0075994 & 0.20926 & 0.0000 \\ -0.0012174 & 0.19371 & 0.0000 \\ -0.054560 & 0.57697 & 1.0000 \\ -0.062157 & 0.67708 & 1.0000 \\ 0.057514 & 0.25804 & 1.0000 \\ 0.047199 & 0.21803 & 0.0000 \\ -0.028416 & 0.30782 & 1.0000 \\ -0.025116 & 0.28620 & 1.0000 \\ -0.051847 & 0.54201 & 1.0000 \\ -0.0092095 & 0.21409 & 0.0000 \\ 0.041859 & 0.20318 & 0.0000 \\ -0.027713 & 0.30300 & 1.0000 \\ -0.022523 & 0.27099 & 1.0000 \\ -0.020430 & 0.25979 & 1.0000 \\ 0.12488 & 0.86479 & 1.0000 \\ 0.012465 & 0.17668 & 0.0000 \\ 0.11644 & 0.79547 & 1.0000 \\ 0.047228 & 0.21812 & 0.0000 \\ 0.016041 & 0.17541 & 0.0000 \\ 0.037785 & 0.19420 & 0.0000 \\ 0.028295 & 0.18028 & 0.0000 \\ 0.033857 & 0.18730 & 0.0000 \\ 0.073272 & 0.35467 & 1.0000 \\ 0.0072308 & 0.18082 & 0.0000 \\ 0.038807 & 0.19627 & 0.0000 \\ -0.029900 & 0.31842 & 1.0000 \\ 0.010027 & 0.17827 & 0.0000 \\ 0.016642 & 0.17532 & 0.0000 \\ -0.021287 & 0.26426 & 1.0000 \\ 0.027500 & 0.17953 & 0.0000 \\ -0.0084041 & 0.21163 & 0.0000 \\ -0.0097499 & 0.21580 & 0.0000 \\ -0.036575 & 0.37320 & 1.0000\end{array}$




$\begin{array}{ccc}0.016060 & 0.17541 & 0.0000 \\ 0.0048567 & 0.18363 & 0.0000 \\ -0.051607 & 0.53897 & 1.0000 \\ 0.022433 & 0.17617 & 0.0000 \\ -0.017583 & 0.24601 & 0.0000 \\ 0.11294 & 0.76184 & 1.0000 \\ 0.0019398 & 0.18794 & 0.0000 \\ 0.0015736 & 0.18854 & 0.0000 \\ -0.0097702 & 0.21586 & 0.0000 \\ 0.024085 & 0.17700 & 0.0000 \\ 0.080241 & 0.41310 & 1.0000 \\ 0.016429 & 0.17535 & 0.0000 \\ -2.1396 \mathrm{e}-05 & 0.19138 & 0.0000 \\ -0.0031064 & 0.19775 & 0.0000 \\ 0.058617 & 0.26332 & 1.0000 \\ 0.016518 & 0.17534 & 0.0000 \\ -0.0028723 & 0.19722 & 0.0000 \\ -0.0041815 & 0.20025 & 0.0000 \\ -0.037493 & 0.38167 & 1.0000 \\ 0.043837 & 0.20826 & 0.0000 \\ 0.068453 & 0.32004 & 1.0000 \\ 0.044123 & 0.20903 & 0.0000 \\ 0.0067063 & 0.18139 & 0.0000 \\ 0.072760 & 0.35077 & 1.0000 \\ 0.055339 & 0.24824 & 0.0000 \\ -0.013001 & 0.22705 & 0.0000 \\ 0.051472 & 0.23267 & 0.0000 \\ 0.014599 & 0.17578 & 0.0000 \\ -0.055750 & 0.59254 & 1.0000 \\ 0.072166 & 0.34631 & 1.0000 \\ -0.078446 & 0.86196 & 1.0000 \\ 0.052619 & 0.23705 & 0.0000 \\ 0.017931 & 0.17524 & 0.0000 \\ -0.025964 & 0.29151 & 1.0000 \\ 0.12921 & 0.89331 & 1.0000 \\ & 0.20366 & 0.0000\end{array}$




$\begin{array}{ccc}0.025168 & 0.17768 & 0.0000 \\ -0.015286 & 0.23603 & 0.0000 \\ 0.0063313 & 0.18182 & 0.0000 \\ 0.047538 & 0.21910 & 0.0000 \\ 0.047111 & 0.21775 & 0.0000 \\ 0.035773 & 0.19045 & 0.0000 \\ -0.020571 & 0.26052 & 1.0000 \\ -0.21831 & 1.0000 & 1.0000 \\ -0.075037 & 0.82972 & 1.0000 \\ 0.068655 & 0.32140 & 1.0000 \\ 0.045279 & 0.21227 & 0.0000 \\ 0.049550 & 0.22576 & 0.0000 \\ -0.022262 & 0.26954 & 1.0000 \\ 0.010731 & 0.17775 & 0.0000 \\ 0.0039104 & 0.18493 & 0.0000 \\ 0.049115 & 0.22427 & 0.0000 \\ -0.0061476 & 0.20523 & 0.0000 \\ -0.028290 & 0.30695 & 1.0000 \\ 0.037945 & 0.19451 & 0.0000 \\ 0.022076 & 0.17603 & 0.0000 \\ -0.014738 & 0.23380 & 0.0000 \\ 0.019847 & 0.17540 & 0.0000 \\ 0.067336 & 0.31267 & 1.0000 \\ -0.018369 & 0.24965 & 0.0000 \\ 0.021545 & 0.17584 & 0.0000 \\ 0.047607 & 0.21932 & 0.0000 \\ 0.038711 & 0.19607 & 0.0000 \\ -0.0024426 & 0.19627 & 0.0000 \\ 0.081874 & 0.42818 & 1.0000 \\ 0.020120 & 0.17545 & 0.0000 \\ -0.0029204 & 0.19733 & 0.0000 \\ -0.028477 & 0.30825 & 1.0000 \\ 0.019596 & 0.17536 & 0.0000 \\ 0.020869 & 0.17563 & 0.0000 \\ -0.067993 & 0.75108 & 1.0000 \\ 0.013916 & 0.17602 & 0.0000\end{array}$




$\begin{array}{ccc}0.023314 & 0.17658 & 0.0000 \\ -0.027354 & 0.30057 & 1.0000 \\ 0.088221 & 0.49130 & 1.0000 \\ -0.0060161 & 0.20488 & 0.0000 \\ -0.0043154 & 0.20057 & 0.0000 \\ -0.087449 & 0.92680 & 1.0000 \\ -0.049022 & 0.50680 & 1.0000 \\ -0.010038 & 0.21673 & 0.0000 \\ 0.063086 & 0.28685 & 1.0000 \\ 0.028050 & 0.18004 & 0.0000 \\ 0.042509 & 0.20480 & 0.0000 \\ 0.073558 & 0.35688 & 1.0000 \\ 0.024494 & 0.17724 & 0.0000 \\ 0.0030969 & 0.18611 & 0.0000 \\ 0.039945 & 0.19872 & 0.0000 \\ -0.041997 & 0.42655 & 1.0000 \\ 0.045304 & 0.21234 & 0.0000 \\ 0.024251 & 0.17710 & 0.0000 \\ -0.013320 & 0.22826 & 0.0000 \\ 0.015612 & 0.17550 & 0.0000 \\ -0.038268 & 0.38900 & 1.0000 \\ 0.10476 & 0.67492 & 1.0000 \\ 0.0095733 & -0.0046981 & 0.017288 \\ 0.0020194 & 0.0046552 & 0.00043895 \\ 0.35088 & & \\ 0.78819 & & \\ & & \end{array}$

